\title{
Gallische und germanische Stämme und Kulturen im Ober- und Mittel-Rheingebiet zur späteren La-Tènezeit
}

\author{
Von K. Schumacher
}

Das gegenseitige Verhältnis der gallischen und germanischen:Grenzstämme im Rheingebiet während der letzten Jahrhunderte vor Christus bildet eines der interessantesten Kapitel unserer Altertumsforschung, da es sowohl nach der geschichtlichen wie der kulturellen Seite wichtige Anfschlüsse eröffnet. Es berülhrt aber zugleich auch eine der schwierigsten Fragen unserer jungen Wissenschaft, da die Scheidung und Unschreibung des gallischen und des germanischen Kultureigentums in diesem Grenzgebiet noch wenig klargestellt ist. Im Vergleich mit anderen Perioden unserer Frühgeschichte bieten zwar die antiken Schriftsteller und die erhaltenen Bodenaltertümer verhältnismässig zahlreiche Anhaltspunkte, indessen ist die Deutung dieser wie jener nicht selten zweifelhaft und umstritten.

Wenn wir eine sichere Grundlage gewinnen wollen, bedürfen wir m. E. einer viel umfassenderen Sammlung und einer weit schärferen Sichtung. der vorhandenen archäologischen Funde, als sie bisher geschehen ist. Für ein solches Unternehmen Amregung und Fingerzeige zu geben, ist der Hauptzweck der folgenden Zeilen.

Auf die Entstehung und das Wesen der keltischen und germanischen Kultur in dieser Periode näher einzugehen, liegt im Hinblick auf mehrere zusammenfassende neuere Arbeiten keine Veranlassung vor. Deswegen mögen einige wenige Bemerkungen namentlich zu J. Déchelettes grossartiger Leistung [Manuel d'archéologie préhistorique celtique et galloromaine II. 3 (1914)] g'en̈̈g'en, ein Werk, das uns erst die Möglichkeit zu eindringendem Vergleich der Forschungsergebnisse auf germanischem und gallischem Boden geschaffen hat. Leider ist der Verfasser mit so vielen anderen Opfern des letzten Krieges der Wissenschaft für éwig entrissen, so dass wir auf die in Aussicht gestellte Verknüpfung der spätgallischen und frührömischen Kultur in Band III wohl werden verzichten müssen.

Der Meinung Déchelettes, dass die Früh-La-Tènekultur nicht im rückständigen ligurischen Hinterlande von Massilia entstanden sein kann, neige auch ich immer melır zu. Viel wahrscheinlicher ist ihre Heimat in Ostfrankreich und in der Umgebung des Ober- und Mittelrheingebiets zu suchen, wo die rührige Hallstatt-Bevölkerung bereits lebhafte Handelsbeziehungen mit dem vorgeschritteneren Süden pflegte. Wohl von hier aus sind in der Früh-La-Tènestufe die Kelten in die Ebene der Marne herabgestiegen, von hier aus über die Alpen nach Oberitalien und in östlicher Richtung donauabwärts gezogen, genau wie es die alte Wandersage der: Gallier bei Livius und Justin erkennen lässt (vgl. Mainzer Ztschr. II (1907) S. 16). Wenn die Münzgeschichte deï mittleren und späteren Lat-Tènezeit 
Massilia als das grösste Haudelszentrum des Westens dartut, so dürfen diese Verhältnisse nicht ohme weiteres in gleichem Unfange für die Frühstufe gallischer Kultur vorausgeset\%t werden.

Schon am Ende der Früh-La-Tènezeit hat das keltische Volk seine grösste geographische Ausdehnung erreicht, weun man von einigen späteren Einzelunternehmungen, wie den Galaterzügen, absieht: es herrschte von Spanien bis Ungarn, von Oberitalien bis Mitteldeutschland. In der Mittel- und Spät-La-Tèneperiode drang dann seine Kultur noch weit über jene Grenzen vor, im Norden bis Südskandinavien, im Osten bis nach Russland.

Innerhalb des eigentlichen Keltengebietes entwickelte sich eine merkwürdige Gleichartigkeit der Kultur, yom mittelfranzösischen Bergland bis zum Böhmerwald und vom Apennin bis zum deutschen Mittelgebirge, getragen vielfach von. den gleichen, weit zersplitterten Stämmen und beberrscht von denselben Handelszentren. So hatte die gallische Zivilisation hereits das einheitliche Gepräge einer Weltkultur, die ihrer Nachfolgerin, der römischen, überall den Borlen bereitete.

Von dieser Gleichartigkeit heben sich aber auch mannigfache Sondererscheinungen $a b$, bei dem einen Stanm mehr, dem anderen weniger ausjesprochen, teils auf Naturaulagen, teils auf Kultureinflüssen und nachbarlichen Einwirkungen beruhend. Schon Cäsar sagt von den drei Stämmen Galliens (Belgen, Aquitanier, Kelten-Gallier): hi omnes lingua, institutis. legibus inter se differunt. Gerade diese Einzelzüge sind bis jetzt weniger betont worden und sollen im folgenden besondere Beachtung finden, da sie wichtige Aufschlüsse über das innere Vesen mancher Volks- und KulturGruppe versprechen.

\section{Die helvetische Gruppe}

1. Den Kernpunkt der Frage nach der historischen und kulturellen Stellung des helvetischen Stammes bildet die richtige Beurteilung der weltberühmten $\mathrm{S}$ t a t i on $\mathrm{L}$ a - T èn e. ${ }^{1}$ )

Die schmale, nur wenig über den Seespiegel sich erhebende Landsenke zwischen Neuenburger und Bieler See stellt den natürlichen Ubergang von len Ostabhängen des Jura- und Doubs-Gebietes in das weite Aartal dar, also aus dem rauhen Sequanerland in den fruclitbarsten Teil Helvetiens, und ist gewissermassen eine grosse Brücke, die sicherlich zu allen Zeiten,

1) Wichtigere Literatur über La-Tíne: F. Keller, 6. Pfahlbaubericht 1 SC6 S. 293-307. - E. Vouga, Les Helvètes à La-Tène 1885. - J. Undsel, Über die Station La-Tène, Christiania 1885. - V. Gross, La-Tène, un oppidum Helvète 1886. R. Forrer, Antiqua 1886 S. 17, Reallexikon (1907) S. 447, 632. - J. Heierli, Urgeschichte der Schweiz 1201 S. 341-352. - D. Viollier, Anz. 1. Schweiz. Altk. IX (1907) S. $284 \mathrm{f}$. (pl. XV, Fibeln); Festgabe für Hugo Blümner 1914 S. 260-266 (Les Celtes sur lo lihin). - W. Wavre et P. Vouga, La-Tène, reprise des fouilles, rapport I-V (1908-1914), Neuchûtel. Vgl auch VI. Jahresber. d. Schweiz. Ges. f. Urg. 1913/14 S. 104f. und Les dirnières fouilles à La-Tíne 1014. - J. Déchelette, La collection Millon (1913) S. 155 f.. Manuel d'Archéologie 11.3 (1914) S. 935 f. - A. Naef, Le cimetière gallo-helvète de Vevey, Anz. 1. Schweiz. Altk. III (1901) S. 14 I., 105 f., IV (19n2!(03) S. 18 f., 200 f. 
wo hüben und drüben verschiedenartige Interessen obwalteten, durch einen Grenz- und Zollposten besetzt war: Diese militärische und kommerzielie Bedeutung kommt in erster Linie der Station bei La-Tène zu. Schon ibre luage unmittelbar am Ausfluss der Zihl (Thièle) aus dem Neuenburger See

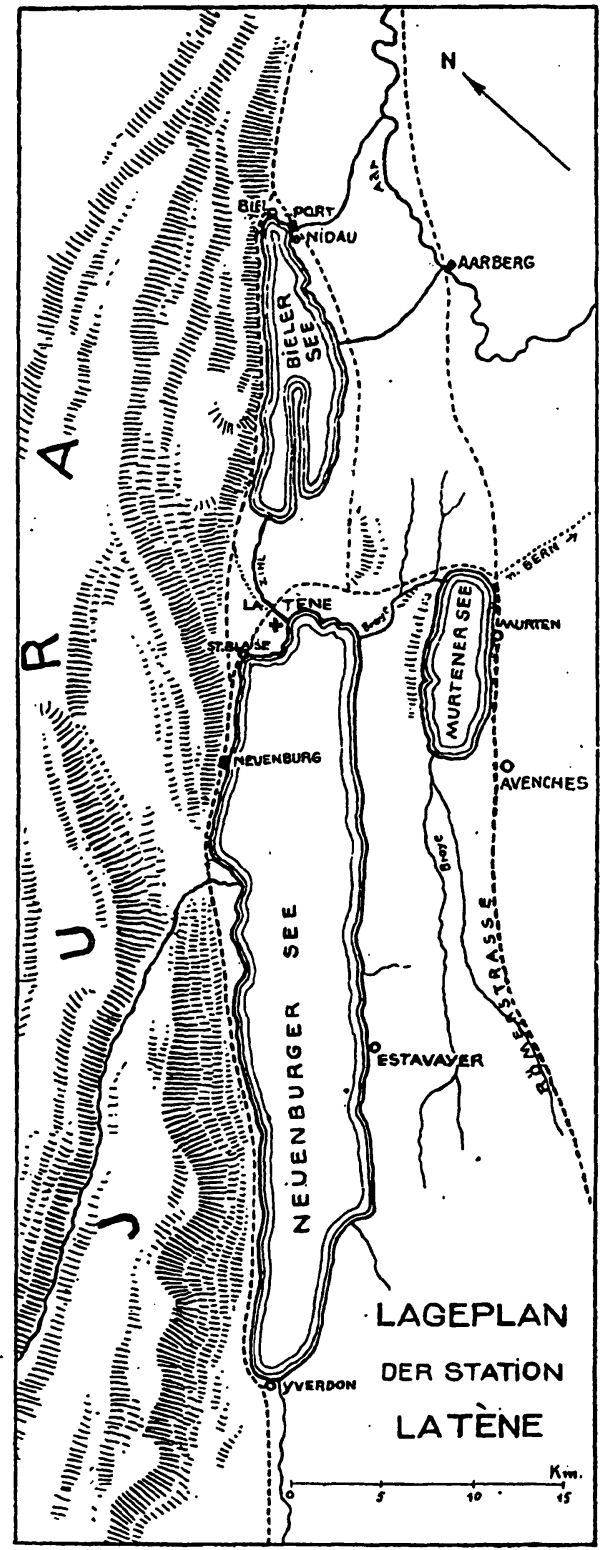

Abb. 1. ani tiefsten Punkte der morastigen Niederung, während unmittelbar daneben sich bei Epagnier ein günstiger Landrücken bis zum See vorschiebt, zeigt, dass die Station einen besonderen $\mathrm{Z}$ weck verfolgt haben muss. Dies haben auch die Ausgrabungen der letzten Jahre klar bewiesen. Die schon von Desor und E. Vouga festgestellten und neuerdings bestätigten zwei. langen Holzbrücken über die Zihl und durch die Niederung, ebenso wie die Neuauffindung grosser Massen ungebrauchter Waffen und Geräte bei den Brücken in den Überresten verschiedenartiger Holzbauten verraten deutlich den militärisch bervachten Stapelplatz, der auch durch das fast vollständige Fehlen allen Frauenschmuckes angedeutet ist. Auch die Anzeichen von Werkstätten und Schmieden sprechen nicht dagegen, die sich auch bei den römischen Kastellen finden und bei einem solchen Waffenlager leicht erklärlich sind. Die Zerstörung der älteren Brücke durch Brand, die unversehrten Waffendepots, mehrere Menschenschädel mit Schwerthieben, ungebogene Lanzenspitzen, schartige Schwerter und anderes verraten heftige Kämpfe, während andere Stellen freiwillig geräumt zu sein scheinen.

Eine Anknüpfung an bestimmte historische Vorgänge ist leider noch nicht sicher möglich. Zwar gehört ein grosser Teil der Funde dem Ende der Mittel-La-Tèneperiode, also dem 2./1. Jahrhundert, der Zeit kurz vor und zwischen Cimbern- bzw. AriovistZug und der Auswanderung der Helvetier im Jahre 58, während richtige Spät-La-Tènesachen (wie Fibeln des Nauheimer Typus) sehr selten sind. Da Bibracte, wo die Helvetier von Cäsar zurückgeschlagen wurden, genau dieselben Schwerter und Fibeln wie La-Tène selbst geliefert hat, wird die Zerstörung der Station bei La-Tène von manchen Forschern unbedenklich 
mit dem Auszug der Helvetier im Jahre 58 und der überlieferten Verbrennung aller ihrer oppida (12) und vici (400) zusammengebracht.

La-Tène ist nicht die einzige Fundstelle dieser Art. Am nördlichen Ende des Bieler Sees, am Ausfluss der Zihl bei Nida u-Port, wurde namentlich durch Oberst F. Schırab von Biel eine ähnliche Station bei einer alten Brücke entdeckt, deren Funde jetzt im wesentlichen im Landesmuseum in Zürich und im historischen Museum zu Bern vereint sind (nur weniges in Biel). ${ }^{1)}$ Auch sie liegt an einem Strassenknotenpunkt als Brückenkopf, bei dem noch in römischer Zeit wichtigen Hafenplatz Port (= portus), wo - kaum nur zufällig - auch eim römischer Legionshelm gefuuden wurde. Aber die laselbst ausgegrabenen zahlreichen Schwerter, Lanzen, Fibeln usN. gehören fast ausschliesslich der Spät-La-Tènezeit an. Aus diesem Gruncle haben bereits mehrere Gelehrte die Vermutung ausgesprochen, dass die Helretier nach der Schlacht bei Bibracte nicht mehr nach La-Tène, wo die Spät-La-Tènestufe fast fehlt, zurückkehrten, sondern sich in NidauPort niederliessen.

Ein dritter, ähnlicher Punkt ist etwas unterhalb von Bern bei Tie fen a u auf der Engehalbinsel, der das ganze obere Aartal sperrt. Auch hier sind bei einem Strașsenbau Unmassen von Waffen, Gürtelhaken, Fibeln usw. zum Torschein gekommen (auch schwertförmige Barren bzw. Halbfabrikate wie bei Port), sowohl aus der Mittel- wie der Spät-La-Tèveperiode. ${ }^{2}$ ) Dieser letztere Umstand lehrt, dass diese Station die bei La-Tène lange überdauert hat, und warnt uns, das frühere Aufhören der letzteren ohne weiteres mit dem Auszuge des. Jahres 58 in Zusammenhang zu bringen.

Nach der Lage und den Funden sind also an allen drei Flussübergängen zweifelsohne militärische Posten mit Waffenniederlagen und Werkstätten snzunehmen. Ihr besonderer Zweck im Einzelfall ist allerdings nicht mit voller Sicherheit für jeden zu bestimmen. In La-Tène sieht J. Déchelette (Coll. Millon S. 159, Manuel II. 3 (1914) S. 938 f.), wie sclıon früher J. Undset und R. Forrer, einen militärisch besetzten Zoll- und Handelsposten, ähnlich wie Châlons-sur-Saône (Cabillonum), das ganz ähnliche Funde ergab, und das nach Caesar und Strabo eine Zollstation zwischen Aeduern und Sequanern und in römischer Zeit der Sitz des praefectus classis Araricae war. In den zahlreichen ungebranchten Waffen und Werkzeugen vermutet Déchelette Handelsware, die dort unter Zollaufsicht lag und nicht selten gegen feindljche Angriffe heschützt werden musste, wie ja anch der Krieg zwischen

1) F. Keller, 2. Pfahlbaubericht 1858 S. 114, j (1863) S. 176 (48). - J. Heierli, 9. Pfahlbaubericht S. 67, Lirgeschichte der Schweiz 1901 S. 336 f. - R. Forrer, Reallexikon (1907) s. 631 f. (..Helvetische Zollstation“).

$\because$ Jetzt im Mus. zu Bern. Vgl. v. Bonstetten, Notice sur les armes etc. Lausanne 1852 , supplément au recueil d'antiquités Suisses, Lausanne 1860, F. Keller, 6. Pfahlbaubericht 1866 S. 303 u. a. die die Fundstelle als ein Schlachtfeld betrachten. S. Müller, Nord. Altertumskunde II (1898) S. 145/146 sieht in den Funden von Tiefenau und La-Tène OpferNiederlagen wie die der schleswig-holsteinischen Moore. Déchelette, Manuel 11.3 (1914) S. 973 Anm. 2 betrachtet es mit Recht als ein oppidum im Flussknie, wie Vesontio (Bosangron), eben-o (J. Tschumi, Jahresber. d. hist. Mus. in Bern 1913 S. 19. 
den Aeduern und Sequanern wegen Zollstreitigkeiten auf der Sâne ent standen ist.

Fiir die Richtigkeit der Auffassung als Zoll- und Handelsstation spricht auch folgender Umstand. Von der grossen Römerstrasse Augusta Praetoria (Mosta) - Octorlurum (Martiginy)-Minnodunum (Moudon)-Aventicum (Avenches) - Petinisca - Salodurum (Solothurn) - Augusta Rauricorun (Augst-Bascl) lösen sich zwei Äste ab, der eine über Avenches, Murten, Joressant, Gampelen nach der Zilhlbrücke, der andere von Port bei Nidau über Mörigen, Hagneck, Ins ebenfalls nach der Zihlbrücke, die offenbar unterhalb (weiter nördlich) von der La-T'ènebrücke lag. Sie münden daun in die Strasse ein, die von Salodurum am Westufer des Bieler und Neuenburger Sees entlang nach Eburodunum (Yverdon) führte. Alle diese W'ege lestanden aber schon in der vorrömischen Zeit, wie sich aus vielen Funden erschliessen lässt, und wurden in der römischen nur so weit als möglich geradlinig und mit festem Steinkörper ausgebaut. $\left.{ }^{1}\right)$ Es ergibt sich daraus, dass die schmale Landbrïcke zmischen Neuenburger und Bieler See den Durchgangsverkehr zwischen Jura- und Aargebiet vermittelte und in militärischer wie kommerzieller Beziehung nicht ohne Wichtigkeit war. Der Hauptweg von Vesontio, der Sequaner-Hauptstadt, führte allerdings über den Jura (Pontarlier) nach dein Südende des Neuenburger Sees nach Ebu(o)rodunum, das direkte Verbindungen nach Aventicum, Minnodunum und an den-Genfer See hatte, aber die Verbindung Eburodunum-Salodurm westlich vom Neuenburger und Bieler See und wahrscheinlich auch manche Saumpfade, die von diesen beiden Seen unmittelbar über das Gebirge nach Gallien führten, machten eine Station bei La-Tène notwendig: $\left.{ }^{*}\right)$

Betrachten wir die ganze Reibe ron Stationen Geneva (Genf), Noviodunum (später colonia Julia Equestris, Nyon) am Südende des Genfer Sees, Lousonna und Viviscus am Nordende, Eburodunum am Süi-, La-Tène am Nordende des Neuenburger, Portus-Nidau am Nordende des Bieler Sees, ferner Salodurum (Solothurn) und ein dem Namen nach umbekauntes oppidum bei Olten, so ist der Gedanke an eine geschlossene Kette gegen den Jura gerichteter Militär- und Zollposten schou in der La-Tènezeit schwerlich abzuweisen. Der Jura aber bildete bekanntlich die Grenze zwischen dem Heivetier- und Sequanerland (Caesar bell. gall. I. 8: "fines Sequanorum ab Helvetiis dividit"). Es soll damit nicht gesagt sein, dass liese Kette von festen Punkten, bezeichnenderweise mehrfach nach den Namen yallischer Häuptlinge genannt (-dunum), schon von Hause aus gewissermassen als Limes angelegt wurde, sondern die Vermutung liegt nur nalie, dass sie diese Bedeutung allmählich erhielt; es mag dabei gerade das gallische Häuptlingswesen mitgespielt haben, las wir: aus Caesars Berichten und den Münzanfschriften kennen. Wenn dor Helretier Orcitirix (=Orgetorix) etwa 10000 . Mannen und Klienten anf-

1) Vgl. z. B. VI. Jahresber. d. Schweiz. Ges. f. Urg. 1913/14 S. 98.

2) Was die militärische Bewachung eines solchen Punktes bedeutet, beweist aın besten die Brücke bei Geneva, über welche die Helvetier vergeblich auszuwanderı ver'suchten (Caesar bell. Gall. I. 6, 7). 
brachte, um sich dem Rechtsspruch des Volkes zu entziehen (bell. gall. I. 4), muss er auch wohlausgerüstete Waffenplätze an wichtigen Punkten gehabt haben, ebenso wie es rou dem Aeduer Dumnorix, dem Generalpächter der Zölle (complures annos portoria reliquaque omnia Aeduorum vectigalia parvo pretio redempta habere) heisst: „magnum numerum equitatus suo sumptu semper alere et circum se habere" (bell. gall. I. 18). In dieser gallischen Periode bestanden offenbar ganz ähnliche Verhältnisse wie in der mittelalterlichen Feudalzeit mit ihren Burgen, Strassen- und Flusssperren.

Vielleicht hat schon in der Hallstattzeit eine ähnliche, wenn auch anders geartete Kette von Wehranlagen bestanden. Längs des rechten Aarufers finden sich auf den Vorhöhen vielfach in der Nähe von Hallstatt-Grabhügelgruppen Ringwälle und Erdwerke, von denen aber leicler noch kein einziges näber untersucht ist (vgl. z. B. die archäologische Karte des Kantons Solothurn von Heierli). F. Keller, Jahn, v. Bonstetten erklärten sie für vorrömische Befestigungen, neuerdings sieht E. Tatarinoff (Beiträge zur solothurnischen ditertumskunde $1913 \mathrm{Nr} .10$ ) in ihneu eine Art alamannischen Limes gegen die vou Nordwesten kommenden Burgunder und Franken. Ohne gründliche Grabungen, die dringend wünschenswert sind, lässt sich natürlich keine Entscheidung gewinnen. Leicht möglich wäre, dass die clurch die buntbemalten Gefäisse charakterisierte Hallstattbevölkerung, die in der mittleren Hallstattzeit das fruchtbare Aartal besetzte, sich gegen die einem anderen Volke angehörigen Pfahlbautensiedler des Neuenburger und Bieler Sees erustlich zu wehren hatte. Auch beruht es wohl schwerlich nur auf Zufall, dass die Pfahlbausiedlungen nach der ersten Hallstattstufe (einschiiesslich der Gündlinger) aufhören, also gleichzeitig mit der Einwanderung des neuen Stammes, wie es vielleicht ebenso kein Zufall ist, dass in gewissen Gebieten (z. B. Kanton Solothurn) Früh-La-Tènefunde fast ganz fehlen, dagegen die Hallstattgrabhügel, wie die von Subingen, zeitlich sehr weit herabreichen. Natürlich können und werden an den gleichen Stellen auch im frühen Mittelalter Erdwerke („Burstel“ usw.) angelegt worden sein.

2. Die zeitliche und völkische Stellung der Station La-Tène ergibt sich etwas klarer aus den $\mathrm{g} l$ e i c h z e i t i g e $\mathrm{n} \mathrm{Gr}$ a b f u n d e n der. Schweiz, lie vom Genfer See bis zum Rhein bei Basel, im ganzen Aar- und Thurgebiet his zum Bodensee bereits in namhafter Anzahl vorhanden sind. Am wichtigsten erscheinen die etwas grösseren Gräberfelder von Vevey am Genfer Sr(e., Saint-Sulpice (Kanton Waadt), $\left.{ }^{2}\right)$ Münsingen (Kanton Bern), ${ }^{3}$ )

1) Anz. f. Schweiz. Alterk. III (1901) S. 14 f., 105 f., IV (1902) S. 18 1., 260 f. (A. Naef).

2) Anz. XVI (1914) S. 257 f. (J. Gruaz). Dieses noch nicht völlig aufgedeckte grosse Gräberfeld (bereits über 80 Gräber) kann bei der genau zu verfolgenden allmählichen Entsteliung des Friedhols lür chronologische Schlüsse noch sehr wichtig werden. Bis jetzt ist crst ein einziges gesichertes Mittel-La-Tènegrab geöflnet (Nr. 77), das im äussersten Osten des Friedhofs liegt. Waffenbeigaben sind im Verhältnis selten, werden sich aber wohl mit der żunehmenden Zahl der Mittel-La-Tènegräber mehren.

3) J. Wiedmer-Slern, Das gallische Gräberfeld bei Münsingen 1908 (Arch. d. hist. Ver. d. Kantons Bern XVIII H. 3).

Praehistoriache Zeitschrift VI Heft $3: 41914$ 16 
Gempenach (Kanton Freiburg), ${ }^{1}$ ) Andelfingen (Kanton Zürich), ${ }^{2}$ ) die ähnlich wie La-Tène selbst mit der Früh-La-Tènezeit beginnen und in einem späteren Abschnitt der Mittel-La-Tèneperiode endigen und alle gleichen völkischen Charakters sein dürften. Wenn in Andelfingen Waffenbeigaben fast fehlen, in Vevey häufiger, in Münsingen sehr zahlreich sind, so bängt dies z. T. wohl mit dem Umstande zusammen, dass in Andelfingen nur ganz wenige Gräber der späten Mittel-La-Tènestufe vertreten sind (Grab 21, 27), welche Stufe auch in anderen Gräbergruppen der Schweiz stark kriegerischen Charakter verrät, wie in Gräbern bei Arni und Basadingen im Thurgau, Mandach (Aargau), Wangen (Zürich), Zürich selbst usw. Wichtig ist nư, dass die in diesen Männergräbern der Mittel-La-Tènezeit gefundenen Waffen (Schwerter, Lanzen, Schildbuckel), Gürtelhaken und Fibeln völlig mit denen von La-Tène selbst übereinstimmen, und dass alle diese Gräber in derselben Zeit wie La-Tène aufhören und keinen einzigen Gegenstand der Spät-La-Tènezeit aufweisen, Männer- wie Frauengräber, welche-letztere fast noch zahlreicher gefunden sind als die ersteren. Diese Tatsache kann in Anbetracht der grossen Anzahl von gleichen Gräbern aus den verschiedensten Gegenden der West- und Nordschweiz nicht dem Zufall zugeschrieben werden, sondern sie hängt sicherlich mit gewissen historischen Ereignissen zusammen, wenn auch im einzelnen, sogar für La-Tène selbst, dem Zufall ein gewisser Spielraum zugestanden werden muss.

Für die zeitliche Bestimmung dieser Gräber liegen mannigfache Anhaltspunkte vor. Vor allem sind es Nachahmungen macedonischer und massaliotischer Münzen und keltischer Prägungen, die picht selten dem Toten mitgegeben sind (Frauenfeld, Horgen, Wiedikon, Vevey usw.), zum Teil dieselben, die in La-Tène und Tiefenau zum Vorschein kamen; leider aber können sie noch nicht ganz genau datiert werden. Jedenfalls ist es in den entscheidenden Einzelfällen kaum möglich, mit Bestimmtheit anzugeben, ob die betreffende Münze vor oder nach ca. 100 (Cimbern-TigurinerZug) bzw. 58 v. Chr. (Auswanderung der Helvetier) anzusetzen ist. ${ }^{3}$ ) Und ebenso misslich steht es nach unserem augenblicklichen Wissen mit der Datierung der anderen Beigaben, der Fibeln, goldenen und silbernen Fingerringe (zum Teil mit Gemmen), ${ }^{4}$ ) den Glasringen, den Geräten und Gefässen aus Bronze und Eisen. Wenn wir auch von einzelnen Gegenständen, namentlich gewissen Münzen, sagen können, dass sie wahrscheinlicher noch dem zweiten als dem ersten Jahrhundert angehören, so wissen wir doch nicht, wie lange sie sich gehalten haben, sei es in allgemeinerem Gebrauch, sei es in zufälliger Einzelaufbewahrung. Auch von den Münzen des ersten Jahr-

1) Anz. 1897 S. 126 f. (J. Heierli).

2) Anz. XIV (1912) S. 16 f. (D. Viollier).

3) Vgl. z. B. J. Heierli, Urgesch. der Schweiz 1901 S. 394 f., Anz. f. Schweiz. Altk. 1902 S. 34 f. (Naef), Rev. arch. 1902 I S. 276 f. (J. Déchelette), R. Forrer, Kelt. Numismatik der Rhein- und Donaulande 1208 S. 218 f., 225, 304 f. u. s.

4) Vgl. F. Henkel, Die röm. Fingerringe der Rheinlande 1913 S. 6 Nr. 27 (Horgen), S. 212 f. u. s., Déchelette, Man. II. 3 S. 1268 f. 
hunderts ist der Anfangstermin vielfach noch unbekannt. ${ }^{1}$ ) Selbst die Tongrefässe, sonst die besten Zeitmesser, lassen uns ziemlich im Stich, da sie sowohl in den Gräbern wie in der Station La-Tène selten sind. Einige der wichtigsten Formen sind auf Abb. 2-4 wiedergegeben. Abb. 2 und 3, die den Herren Direktoren Dr. Viollier in Zürich und Dr. Wegeli in Bern zu verdanken sind, enthalten Grabfunde im Züricher und Berner Museum,) Abb. 4 zeigt Funde aus La-Tène (nach dem IV. Bericht von P. Vouga [1912]
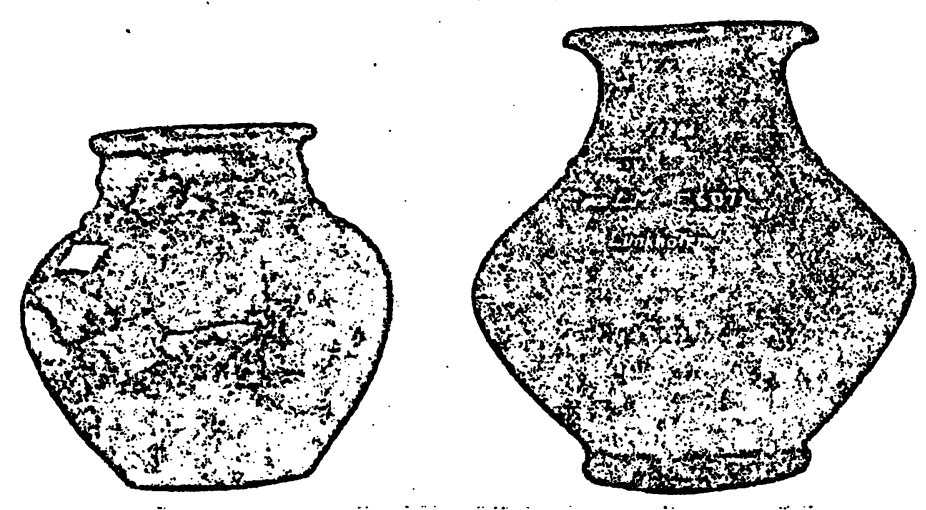

Abb. 2. Tongefässe von Wetzikon und Lunkhofen.
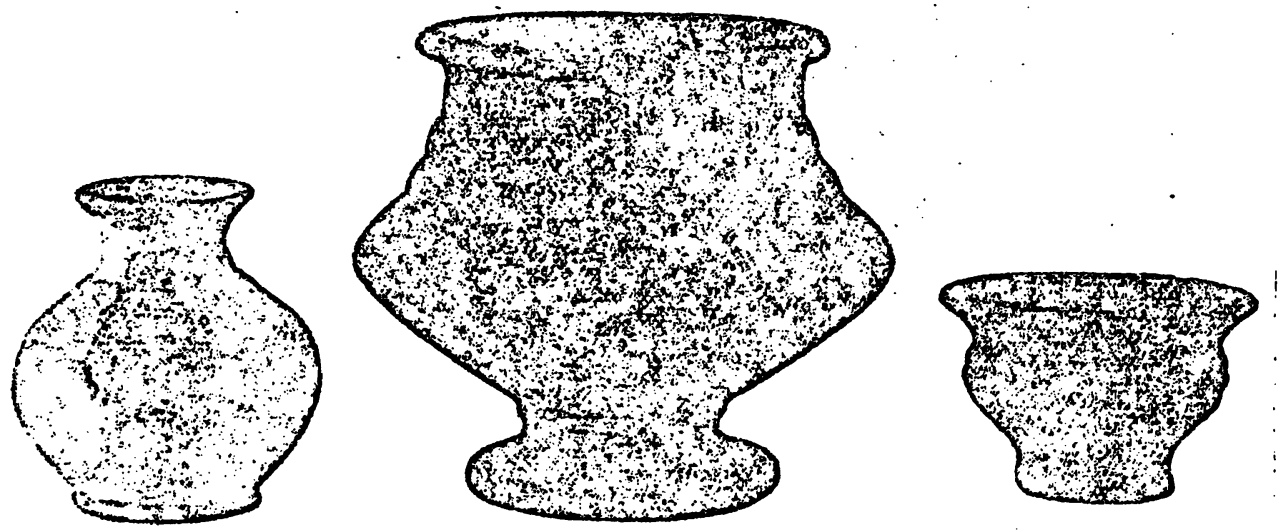

Abb. 3. Tongefässe ron Aaregg.

nud anderen rom Zentralmuseum ergänzten lixemplaren des Museums in Neur(hâtel). Ihr seltenes Torkommen in Gräbsen könnte auf rituelle Griande z.urückzuführen sein, in La-T'ene, wo aurl/ verliältnismässig wenige Scherben orhotıen sind, ist os auffallend. Weitans die meisten Gefaisse von Jál'ène

1) Cber den langrn Trmlaw manchre gallischen Münzæn gerade dieser Periode vgl. K. Forrer. Kelt. Numismatik 19 (y) S. 117 u. s.

2) Ahb. 2 von Junkhofen und Wrtzikon, Abb. 3 von Aaregg, wo (wie bei der Fing(.) ain Giäberifld zu dem oppidum Tiefenau. 
sind Kumpen, Schüsseln, Teller, offenbar Essgeschirre der Soldaten, wie sie auch in vielen römischen Kastellen vorherrschen. Nach den erfreulichen Ergebnissen der letzten Kampagne waren daneben in grosser Menge Holzgefässe in Benutzung, die sich natürlich nur unter besonders günstigen Umständen im Boden erhalten haben. Es sind namentlich hohe, fast halbkugelige Schüsseln, zum Teil mit verdicktem Horizontalrand (mit Löchern zum Aufhängen), grosse flache Teller, die auf der Unterseite durch Rillen und Wülste schön. profiliert sind, kleinere Schalen gleicher Art, eine sehr gefällige Schale ähnlich der aus Ton von Basel (Abb.7, 5) und Flörsheim (Abb. 11, 9), die höchstwahrscheinlich auf jene Holzform zurückgehen, grosse ovale Platten, die den bekannten metallenen namentlich aus römischer Zeit gleichen, kleine Ürnchen oder Dosen wie die Tonform Abb. 7, 3 u. a. mehr. Herr Prof. Dr. P. Vouga, der Leiter der letztjährigen Ausgrabungen in LaTène, hat auf meine Anregung die ganze Serie für das Mainzer ZentralMuseum in Holz nachbilden lassen, wo sie eine Zierde der La-Tène-Abtei-

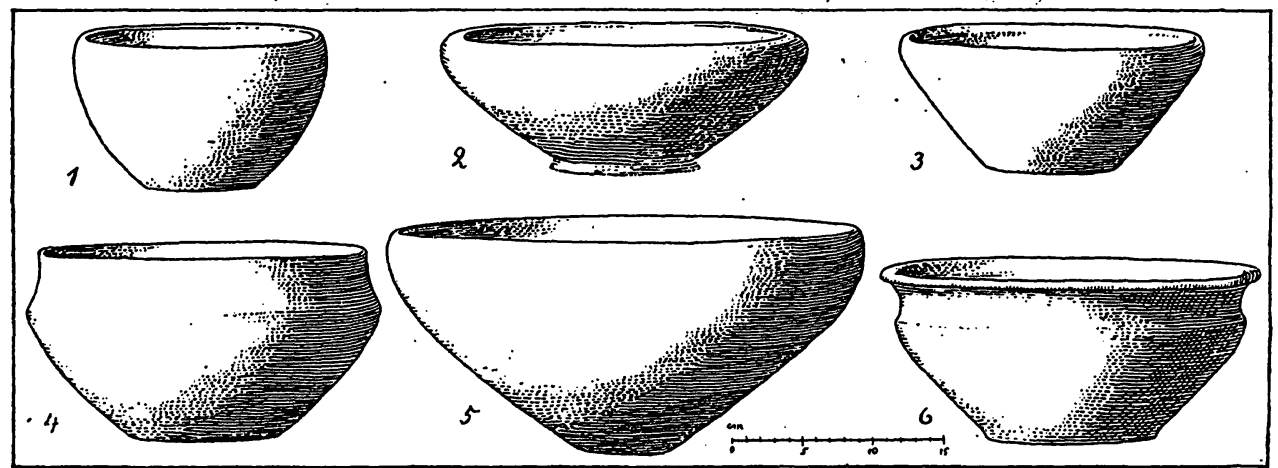

Abb. 4. Tongefässe von La-Tène.

lung darstellen. Ein Blick auf dieselben lässt manche Eigentümlichkeiten der gleichzeitigen Tongefässe verstehen, vor allem die eigenartig wulstigen Reifverzierungen, die Verdickung des Mündungsrandes, die auffallende Form Abb. 7, 5. Es kann kaum ein Zweifel obwalten, dass jene so fein gedrehten Holzgefässe einen Einfluss auf die gleichzeitigen Töpferscheibearbeiten ausübten. Auch der so auffallende Mangel an Tongeschirr in den Gräbern erklärt sich vielleicht durch die Mitgabe von (jetzt vergangenen) Holzgefässen, wie sie ähnlich auch in alamannischen Gräbernn (Oberflacht, Leihgestern usw.) beobachtet wurde. - Die Tongefässe bestehen meist aus grauem, gutgeschlämmtem Ton und sind öfters durch Schmauchung usw. g'eschwärzt. Die feineren sind wie die Holzgefässe auf der Drehscheibe (oder mit Schablonen) hergestellt und unterscheiden sich wesentlich von der Spät-La-Tèneware (vgl. z. B. den bekannten Krug von Port im Züricher Miuseum).

Die Formen der Tongefässe, wie der Krug (Abb. 2 und 3), der Kessel die Schüsseln und Schalen (Abb. 4), sind unmittelbar aus denen der späteren Früh-La-Tènezeit entstanden und haḅen in dẹ Spät-La-Tèneperiode ihre 
wiederum leicht abgeänderten Weiterbildungen, denen vor allem die scharfen Riefelungen des mittleren Abschnitts fehlen.

Fasst man alle durch diese Gräbergruppe gegebenen chronologischen Hinweise ins Auge, so darf man immerhin mit einiger Sicherheit sagen, dass sie nicht allzu tief in das 2. Jahrhundert v. Chr. hineinragt und im wesentlichen dem Beginn des 1. Jahrhunderts v. Chr. angehört, also den eigentlichen Helvetiern zwischen Cimbernkrieg und der Auswanderung im Jahre 58 v. Chr. Daraus ergibt sich auch für die Station La-Tène die Wahrscheinlichkeit ihrer - wenn auch nicht gänzlichen - Aufgabe im Jahre 58 v. Chr., nachdem sie schon früher mehrere Male durch feindliche Einfälle usw. stark mitgenoumen worden war, an ärgsten offenbar beim Übergang aus dem Besitz der Sequaner in den der Helvetier um das Jahr 100 v. Chr.

Wieweit die Einzelfunde in La-Tène noch der sequanischen, wierreit der helvetischen Periode angehören, bedarf noch eingehender Untersuchung, wofür die nenen Ausgrabungen auch stratigraphische Anhaltspunkte liefern dürften, namentlich mit Rücksicht auf die Lage zu den beiden Holzbrïcken. Viele, auch manche der schönverzierten Schwertscheiden, gehören nach meinem Dafürhalten noch dem Ende der vorhelvetischen Periode an, ${ }^{1}$ ) wie der Charakter der Ornamente, analoge Funde in Frankreich und Ungarn²) und der Vergleich mit den (jüngeren) Funden vom Mont Beuvray, Alesia, Stradonitz usw. lehren ${ }^{3}$ ).

3. DieRa uriker. Burckhardt-Biedermann ${ }^{4}$ ) hat die sich widersprechenden Angaben der antiken Scliriftsteller über die Ausdelnumg der Rauriker und Sequaner in der Weise zu lösen versucht, dass er die Sequaner ursprünglich nur in der Franche-Comté wohnen und erst nach dem Cimberneinfall die Rauriker aus dem Oberelsass an die nördlichen Ablänge des Jura verdrängen lässt. Gleichlautende Fluss- und Bergnamen im Basler Jura, im Sch marzwald und in den Vogesen würden andeuten, dass die Rauriker auch anf dem rechten Rheinufer sassen. Wie verhalten sich nun zu dieser Aufstellung die Bodenfunde? Natürlich kann nur auf einige der wichtigsten

1) Vgl. auch Mainzer Festschrift 1902 S. 101 Anm. 53 (P. Reinecke).

2) Vgl. Déchelette, Manuel II. 3 S. 1119 Abb. 463. Ihren Entstelıungsort sucht Déchelette (S. 1118) in der Nähe des Oberrheins oder der oberen Donau. Vielleicht war eine Hauptwerkstätte in der Schweiz selbst, wo der Berner Jura das Roheisen bot und viele Schwertbarren und die meisten verzierten Exemplare gefunden sind; eine andere lag wohl in den Ostalpen, die die schönen Schwerter Slawoniens und Ungarns lieferte. Vgl. auch die Literatur bei M. Jahn, Die Bewafinung der Germanen, Diss. 1914 S. $2 i$.

3) Die älteren, zum Teil noch in die Früh-La-Tèneperiode hineinreichenden Schwerter sind mit Mittelgrat versehen und haben eine zugespitzte Griffangel, die bei den jüngeren mehr scharkkantig viereckig ist.

4) Th. Burckhardt-Biedermann, Die Wohnsitze der Rauriker und die Gründung ihrer Kolonie. Zeitschrift f. Geschichte d. Oberrheins N. F. 24 (1909). - Derselbe: Die Kolonie Augusta Raurica, ihre Verfassung und ihr Territorium. Basel 1910. Vgl. auch die Literatur bei K. Stehlin: „Bibliographie von Augusta Raurica und Basilia“ (Basler Ztschr. I. Gesch. u. Altertumskunde X S. 38-180). Vgl. auch O. Bremer, Ethnographie der germanischen Stämme (1899) S. 58/59 und F. Kaufimann, Deutsche Altertumskunde 1914 S. 216 
eingegangen werden, in erster Linie auf die neu entdeckte Spät-LaTène-Ansiedlung bei der Gasfabrik in Basel, 1) wo bereits mehr als ein halbes Hundert Hüttenstellen und um den Kern derselben eine kastellartige Palissadenumgrabung ermittelt sind. E. Major kommt bei seiner sorgfältigen Beschreibung der Kleinfunde zum Ergebnis, dass „die Bewohner kurz. vor dem Eindringen der Römer unter Mitnalme des noch benutzbaren Hausrates ihre Niederlassung im Stich liessen, dass sie also möglicherweise jenen helvetischen Stämmen sich anschlossen, die im Jahre 58 v. Chr. nach Gallien einzudringen versuchten". Die Zeitbestimmung hängt namentlich von der Datierung dreier Bronzefibeln des Nauheimer Typus und der keramischen Überreste ab. Die Fibeln (Anz. 1914 S. 3) begegnen auch in Bibracte (Builliot, Fouilles du Mont Beuvray 1899 pl. L. 17, Déchelette, Les fouilles du Mont Beuvray 1904 pl. XIV. 1-4, L'oppidum de Bibracte S. 55 fig. 14 a und die Zusammenstellung Manuel d'Arch. II. 3 [1914] S. 971 u. 1257) wie in Port und Tiefenau und gehören ohne Zweifel der Zeit zwischen Cäsar und Augustus an (vgl. unten S. 254). Die sehr zahlreiche bemalte Keramik vom Typus-der von Bibracte, die Déchelette (Les fouilles S. 161 f., Manuel II. 3 S. 1493) mit Recht im wesentlichen in die zweite Hälfte des letzten vorchristlichen Jahrhunderts ansetzt, weist auf dieselbe Zeit hin. Diese bemalte gallische Ware mit geometrischen und pflanzlichen Ornamenten ist zwar durch die ganze West- und Nordostschweiz vertreten, ${ }^{2}$ ) aber nur in den einfacheren Formen und Verzierungsweisen, nicht in dem Reichtum wie bei Basel und auf dem Mont Beuvray. Dieser Umstand wie die Feinheit des Materials lässt für die feinere Ware auf Import aus dem Aeduer-Arverner Gebiet schliessen, wie für die Weinamphoren, wenn diese auch ursprünglich italischer Herkunft und über Marseille eingeführt sein mögen (Déchelette, Maṇuel II. 3 S. 954, fig. 397, S. 968 Anm. 2).

Die Lage unmittelbar an dem grossen Rheinknie gegenüber dem Einfluss der Wiese und in nächster Nähe eines auch zur römischen Zeit wichtigen Strassenknotenpunktes, wo die von der burgundischen Pforte, dem Jura und aus dem Innern Helvetiens kommenden Strassen in die Rheinstrasse einmünden, ${ }^{3}$ ) könnte ebenso wie die festgestellte Palissadenanlage auf einen militärischen Posten hinweisen. Dem widerspricht das völlige Fehlen von Waffen und der grosse Reichtum an feinem Geschirr, Weinamphoren

1) Anz. f. Schweiz. Altk. 1913 S. 1-17 (K. Stehlin), 1914 S. 1-11 (H. G. Stehlin, P. Revilliod, E. Major).

2) Ausser der von Déchelette, Fouilles S. 165 und Manuel II. 3 S. 1491 erwähnten noch in Vindonissa (auch aus dem zwischen Tiberius bis Trajan entstandenen Schutthügel), Solothurn usw., nicht im Tessin, wo eine etwas andersartige Bemalung (vgl. auch Déchelette, Manuel II. S. 1492 Anm. 3). Dass die mit einfachen roten und weissen Zonen verzierten Gefässe weit in die römische Zeit hineinragen, zeigen auch zahlreiche Beispiele von Südbaden, so von Hüfingen-Donaueschingen, Messkirch usw. Über im Elsass gefundene vgl. Forrer, Zur Ur- und Frühgeschichte des Elsass S. 29 Anm. 3 (von Achenheim und Stützheim).

3) Deshalb erscheint es mir nicht ausgeschlossen, dass es das in den Itinerarien erwähnte Arialbin(n)um ist. Mit Recht bemerkt Zangemeister C. I. L. XIII S. 59: „intervallum leugarum VII inter Cambete et Arialbinum indicatum Basileam ducit", vgl. auch Elsässische Monatsschr. 1911 S. 393 (F. Stolle) 
usw., während landwirtschaftliche Geräte ganz zurücktreten. $\mathrm{Da}$ in der Nähe auch der mittelalterliche Hafen Basels war, dürfte die Siedlung ein Handelsemporium darstellen, welches namentlich die aus dem Sequanerund Aeduerlande durch die burgundische Pforte kommenden Waren, besonders Wein, weiter rheinabwärts vermittelte. Dabei ist nicht ausgeschlossen, ja sogar wahrscheinlich, dass eine militärische Anlage den wichtigen Punkt schützte. ${ }^{\mathbf{1}}$ )

Eine ähnliche, kaum kleinere Siedlung lag unmittelbar am rechten Rheinhochgestade bei $\mathrm{H}$ ochstetten (bei Altbreisach), wo der von Freiburg über Gündlingen kommende uralte Verkehrsweg in die Rheinuferstrasse mündet. Beim Abgraben einer Kiesgrube 1896/97 wurden mehrere Wohngruben (und Gräber?) angeschnitten, deren Inhalt K. Gutmann zum Teil noch gerettet hat (Präh. Bl. XI (1899) S. 68 f., E. Wagner, Fundstätten

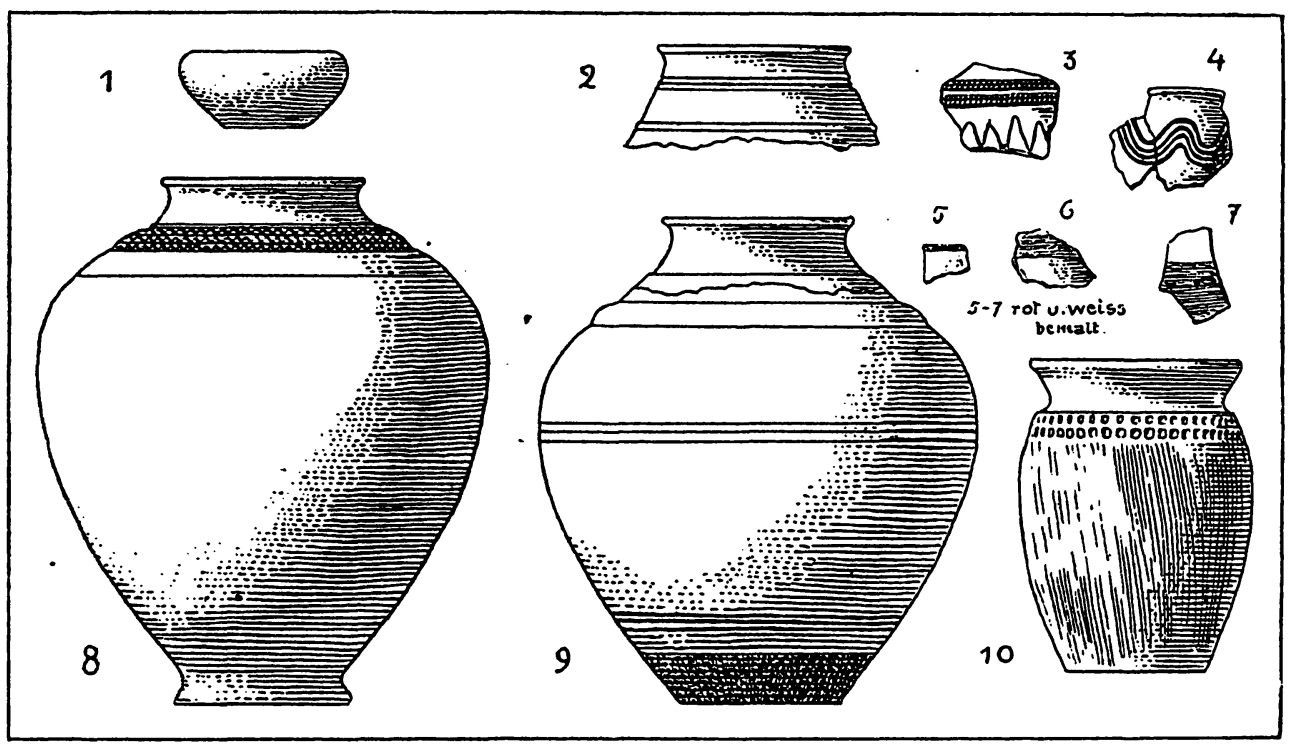

Abb. 5. Tongefässe von Hochstetten.

1 (i908) S. 185 f.). Auch irn Jahre 1900 sah ich dort eine neu angeschnittene Wohngrube. Dass die Fundstelle wit den vielen Spät-La-Tènegefässen eiu Grab gewesen sei, wie Gutmann meint, ist mir wegen der Form der Grube, ler vielen Gefässfragmente und Tierknochen unwahrscheinlich. Allerdings wurden in der Nähe verschiedene Skclettgräber gefunden. die zuin T'eil zu dieser gállischen Siedlung gehört haben könnten. Neuerdings (Herbst 1914) rurrlen in der Nähe der Kieskaute mehrere Wohngruben und eine Herdstelle angeschnitteu, wie mir K. Gutmann mitteilt. Nach dessen Beobachtungeu latte die Siedlung eine sehr grosse Ausdehnung und ausserdem eine Nachbarin anf der Höbe von Altbreisach, wie er bei Anlage der Wasser-

1) Wie mir Herr Dr. E. Wajor mitteilt, wurde neuerdings auch auf der rechten Seite des Rheins im alten Wenkenhof bei Rjehen, das noch zum Kanlon Basel gehrrt, Spät-LaTinekeramik. bis jetzt allerdings nur grobe Ware, gefunden. 
leitung 1914/15 feststellen konnte. Die Tongefässe und Scherben (zum Teil abgebildet bei Wagner, Abb. $124 \mathrm{a}-\mathrm{e}$ ), darunter auch solche mit den rotaufgemalten Zonen, stimmen vollständig mit denen von Basel überein und lassen keineñ' Zweifel, dass sie von Galliern der Spät-La-Tènezeit herrühren, nicht von Germanen..$^{1}$ ) Bei Gefäss 9 der Abb. 5 ist die Zugehörigkeit des Halsstückes nicht ganz sicher, aber sehr wahrscheinlich.

Wichtiger noch ist die grosse Fest $\mathrm{u}$ ng be i Z a r te n im Dreisantal, deren Gleichstellung mit dem ptolemäischen Tarodunum kaum zu bezweifeln ist. ${ }^{2}$ ) Die 1901 von E. Fabricius und F. Leonhard vorgenommenen Ausgrabungen baben die grosse Bedeutung der Anlage erwiesen (die von Wall ungebene Fläche bildet ein Areal von $190 \mathrm{ha}$ ) und den Charakter des murus gallicus (,alternis trabibus ac saxis“) durch Auffinden der Holzeinlagen (und eisernen Nägel am Haupttor) dargetan. Die im $12 m$ breiten und $4 m$ tiefen Graben gefundenen Scherben sind zwar nicht sehr zahlreich, aber immerhin charakteristisch genug, um die völlige Gleichartigkeit mit den Funden von Basel erkennen zu lassen (jetzt im Museum zu Freiburg). Es begegnen nicht nur dieselben Randprofile, sondern auch dieselben Ornamente: Gittermuster, schwarz auf rotem Grund aufgemalt, mehrfache Wellenlinienbänder, Stempeleindrücke, sogar barbotineartig aufgesetzte Pünktchen (wie Déchelette, Mont Beuvray pl. IX, 22, XXXIII). Diese keramischen Zeugen verraten genau dieselbe Kultur und Zeitstufe wie die von Hochstetten und Basel und bekunden, dass Tarodunum als ein Hauptoppidum der Gallier und speziell wohl der Rauriker auf dem rechten Rheinufer bis zu Cäsars Zeit dem Germanenandrang widerstand und eine Sammelstätte für die zerstreuten Siedlungen der Rheinebene bildete.

Diese Funde von Hochstetten und Zarten bestätigen also die Ansicht Burckhardt-Biedermanns, dass die Rauriker oder ein ihnen nahe verwandter Stamm $^{3}$ ) auch auf dem rechten Rheinufer sassen, und zwar bis zum Kaiserstuhl. Cäsar kann deshalb mit Recht schreiben (bell. Gall. 6, 24), dass die Hercynia silva „oritur ab Helvetiorum et Nemetum et $R$ a u r i c o r u m finibus", wobei. er Schwarzwald, Schwäbischen Jura und Böhmerwald als einheitlichen Gebirgszug zusammenfasst. ${ }^{4}$ ) - Auf dem linken Rheinufer, wo die stolze Römerstadt Augusta Rauricorum bei Basel-Augst ihr Gedächtnis festhielt, reichten ihre Sitze nach den literarischen Nachrichten in der Zeit bis zum Eindringen der wohl aus der Schweiz durch die Helvetier vertriebenen Sequaner, also zwischen 107-80 v. Chr., wahrscheinlich bis zur gleichen Linie in der Gegend von Colmar (Ztschr. f. Gesch. d. Oberrh.

1) Korresp.-Bl. f. Anthr. 1907 S. 59 werden sie von Kossinna den Nemetern an der Hercynia silva (also vor 71) zugeschrieben.

2) Krrbl. d. Ges. Ver. 1901 S. 162-164, F. Haug. - E. Fabricius, Die Besitzergreifung Badens durch die Römer (1905) S. $13 \mathrm{f}$. - Derselbe, Verh. der 46. Vers. deutscher Philologen 1901 S. 109 f. - E. Wagner, Fundstätten I (1908) S. 221-223, Abb. 146. Kat. 5 d. röm.-germ. Zentr.-Mus. (1913) S. 162 Nr. 266.

3) Man könnte ev. auch an die. Tulingi denken, welche mit den Helvetiern und Raurikern auszogen (vgl. z. B. P. Huber, Die Glaubwürdigkeit Caesars in seinem Bericht über den gallischen Krieg, Bamberg 1913, S. 30 Anm. 4).

4) Vgl. auch L. Schmidt, Gesch. d. deutschen Stämme II. 2 (1913) S. 143 Anm. 6. 
XXIV S. 403). Die Bodenfunde des südlichen Elsass sind allerdings für diese Periode bis jetzt zu spärlich bzw. zu wenig gesammelt, um dies mit gleicher Sicherheit wie für das rechte Rheinufer erweisen zu können, und ausserdem dürfte eine Unterscheidung der Hinterlassenschaft der Sequaner und Rauriker in dieser Periode und Gegend sehr schwierig sein. Ausgrabungen in ihren Hauptorten wären dringend wïnschenswert. Argentovaria (Horburg?), Arialbinnum, Urunci(ae?), Cambes(ete?) und Stabula liegen in ihrem Gebiet, sind aber noch nicht alle genau ermittelt, wenn auch mit ziemlicher Sicherheit zu erschliessen, namentlich auf Grund der Leugenangaben (Zangemeister a. o. S. 59 und F. Stolle a. o. S. 399 f.) und der von K. Gutmann, G. Werner u. a. betriebenen Strassenutersuchung (vgl. VII. Ber. d. röm.-germ. Kommission 1915 S. 16 f.). Das allerding's etwas zweifelhafte Helretum köunte die helvetische Grenzstation bezeichnen.

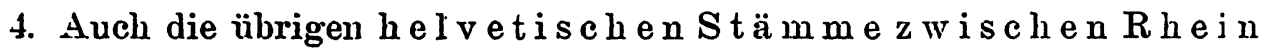
u n d M a i n, die durch die Schriftstellernachrichten über den Cimbernzug, ferner durch Tacitus Germania 28 (inter Hercyniam silvam Rhenumque et Noenum amnes Helvetii, ulteriora Boii, Gallica utraque gens tennere) und

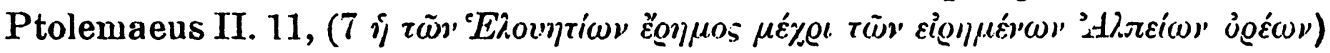
mindestens für das 2. Jahrh. v. Chr. literarisch sicher bezeugt sind, haben im Boden Spuren hinterlassen, nach denen auch olne jene Berichte zum mindesten auf nahe Verwandtschaft mit den Helvetiern zu schliesseu wäre. An erster Stelle stehen die Funde von Lopodunum (Ladenburg), gleichfalls einer Brückenfestung, an dem Punkt, wo die vorrömische Rheintalstrasse den Neckar überschritt, ${ }^{1}$ ) und das sehr reiche Frauengrab ron Dühren (Alt. h. Vorz. VT. 15), welches ebenfalls bei einer leider noch nicht genauer untersuchten Verschanzung lag. Sie stimmen so vollständig mit der oben beschriebenen helvetischen Gräbergruppe der Mittel-La-Tènezeit überein, dass sie trotz der in Dührener Grabe gefundenen Volcae-Münze sclıwerlich von ihnen zu trennen sind. Dem Grabe von Dühren am nächsten stehen in der Schweiz die Gräber von Horgen (Silberfibel, Gold- und Gagatring, blaue Glasringe. Münze), Mettmenstetten (Bronzefibeln, gelbe Glasringe usw.), Frauenfeld, Mötschwil (5. Jahresber. d. schweiz. Ges. f. Urgeschichte 1912/13 S. 151. f.), Aaregg (Fibeln, grosse und kleine Glasringe usw.), doch ist das Diihrener Grab weitaus das reichste von allen, dessen griechiscber. Spiegel auf Handelsbeziebungen mit halbgriechischen Kolonien binweist. ${ }^{2}$ ) Die sieben Fibeln von Dühren aus Silber, Bronze und Eisen und zum 'Teil reich ver\%iert (A. h. V. V Taf. 15 Nr. 248-253) stimmen in Typus völlig überein (abgeselen von der längeren Spirale von Nr. 253). Der Bügel ist zwar teilwcise ziemlich flachgestreckt und erinnert dadurch an manche spüteren Formen des Mittel- und Spät-La-Tène-Schemas,;) doch begegnet diese İrscheinumg.

1) Album der Berl präh. Ausstellg. 1880 Sekt. VII Taf. 8; E. Wagner, Fundstätten Il (1911) S. 3334 Abb. 273: Alt. heidn. Vor\%. V S. 80, 375 (K. Schumatcher). Der Name von Dühren (im cod. Lauresh. villa Durnina) weist vielleicht auch auf - durum.

2) Cber gallische Spiegel jetzt Déchelette, Manuel JJ. 3 S. $1286 \mathrm{f}$.

3) Vgl. die Zusammenstellung A. h. Vorz. V Taf. 20 (I'. Reinecke), Ztschr. 1. Ethı. 1911 S. 685 (R. Beltz) und Déchelette, Manuel II. 3 S. 1253, auch O. Almgren, Studien über nordeuropäische Fibelformen 1897 Taf. I. 3. 
auch schon bei späten Früh-La-Tènefibeln und in dem zweifelsohne noch frühen mittel-la-Tènezeitlichen Grabe von Horkheim. Auch in Ornavasso kommen ganz ähnliche Fibeln vor, etwas ältere mit Münzen der Jahre 219, 204 und 200 (E. Bianchetti, i sepolcreti di Ornavasso 1895 Taf. X. 3, Grab 88, 127, X. 12, Gr. 117); die einer Dührener sehr ähnliche, gestreckte Silberfibel 'Taf. X. 15 (Gr. 4) ist mit einer Münze des Jahres 144 gefunden; andere Taf. IX. 6 (Gr. 10) und IX. 2 mit Münzen des Jahres 129, 124, die jüngste 92. Auch die den filigranverzierten Dührener Silberfibeln sehr ähnlichen Taf. X. 4 und 5 (Gr. 18, 15) stammen aus einer Gräbergruppe vom Ende des 2. Jahrhunderts, da die Nebengräber Münzen aus den Jahren 129 (Gr. 10, 14), 112 und 110 (Gr. 17) entlıalten. Eine der Dührener sehr ähnliche Bronzepfanne lieferte Grab 6 mit Fibel wie Grab 4 (auch mit Bronzekrug) und Münzen des Jahres 149 und 144. Waren auch Münzen wie Fibeln manchmal in langem Gebrauch, so gibt doch eine so grosse Anzahl übereinstimmender Zeugnisse einen sicheren Anhaltspunkt zur Datierung des Dührener Grabes noch in die Zeit vor dem Cimbernkrieg und vor dem helvetischen Auszug aus Süddeutschland. Immerhin aber dürfte es, wie anch die Schweizer Parallelfunde nahelegen, schon der zweiten Hälfte des 2. Jahrhunderts angehören, und zwar wahrscheinlich von Helvetiern herrühren (vgl. A. h. V. V. S. 80 f.). Allerdings mag sich die Kultur der benachbarten Bojer und Volcae Tectosages, die Cäsar noch im hercynischen Walde erwälnnt, in dieser Periode nur wenig von der helvetischen unterschieden haben, so dass man auch an eine Wandergrup.pe dieses Volkes denken könnte (vgl. auch Déchelette, Manuel II. 3 S. 1345).

Dass Lopodunum ,; wohl immer ein vorgeschobener Posten der transrhenanischen Stämme“ war, wie A. Schliz, Fundber. aus Schwaben XIII (1905) S. 35, meint, dünkt mir (trotz der Station Loposagium im Sequanergebiet) wenig wahrscheinlich, schon weil die Rheinebene südlich des Neckars und der Odenwald helvetischer Besitz war und Lopodunum den Übergang der Rheintalstrasse über den Neckar sicherte, wie so viele - duna an Flussübergängen. Aụch in Frankfurt dürfte am alten Mainübergang beim Domhügel ein keltischer Posten anzunehmen sein, wofür schon einige Anhaltspunkte vorliegen. ${ }^{1}$ )

In Württemberg sei nur auf die Gräberfunde von Horkheim bei Heilbronn hingewiesen (Fundber. a. Schwaben X [1902] S. 24 f.), welche durch Schwert- und Fibelformen von scheinbarem Früh-La-Tènetypus, vergesellschaftet mit richtigen Mittel-La-Tènefibeln wie von Dühren, immerhin noch einen etwas älteren Abschnitt der Mittel-La-Tènezeit verraten, ähnlich wie die „Vasenkopf“- und Molnnkopffibeln usw. der Flacligräber von BerstadtWölfersheim bei Friedberg in der Wetterau, $\left.{ }^{2}\right)$ in Württemberg von Bop-

1) W. Ztschr. XXIV (1905) S. 354, G. Wolff, D. südl. Wetterau 1913 S. 108 f. Über ähnliche bewachte Flussübergänge dieser Periode am Neckar vgl. Schliz a. o. S. 35.

2) P. Helmke, Die Altertümersammlung des Friedberger Geschichtsvereins (1904) Taf. III; Westd. Ztschr. XIX (1900) S. 398 (Lindenschmit) und zugehörige Fundstücke des Frankfurter historischen Museums. Ähnliche Fibeln auch von mehreren Punkten in Baden und Rheinhessen. Vgl. auch Ztschr. ft Ethn. 1911 S. 719 f. (R. Beltz). 
fingen, Schelklingen, Kirchheim u. T. u. s.). Der Gesamtfund von Grafeneck (O.-A. Münsingen, Mus. Stuttgart): zusammengerolltes Schwert und Lanze, Flügelschildbuckel, Schildhandhabe, Schere, Messer, Scherben, kann an und für sich ebensowohl von einem boischen wie helvetischen Skelett(oder Brand-) grab herriihren; ${ }^{1}$ ) nach der geographischen Lage ist es wohl boischer Herkunft.

Nahe Verwandtschaft mit diesen Grabfunden von Ladenburg, Dühren, Horkheim usw. zeigt der Kulturniederschlag in den sog. Viereckschanzen zwischen Main, Neckar und Douau, wie von Gerichtstetten, Einsiedel usw., ${ }^{2}$ ) ausser den Glasringen vor allem dieselbe Keramik. Diese Anlagen sind, wie ich zuerst nachgewiesen habe, befestigte gallische Gutshöfe vom Ende der Mittel-La-Tène- und Beginn der Spät-La-Tèmeperiode und sind in Südwestleutschland zweifelsohne grösstenteils den Helvetiern zuzuschreiben, wenn sie auch bei Bojer’n und Vindelikern ähnlich begegnen (vgl. P. Reinecke, Die Heimat, Beilage der Nürnberger Ztg., 2. Jahrg. 1914 Nr. 3-5 und Mainzer Zischr. 1913/14 S. 114 Anm. 24). Wenn in einigen derselben römische Scherl,en gefunden sind, so verraten sie nur eine fortgesetzte oder neue Besiedlung derselben Stelle in rönischer Zeit. Ubrigens können manche der „römischen" Scherben von Einsiedel (im Museum Stuttgart) ebensowohl aus lem letzten Jahrhundert v. Chr. stammen, wie auch die Bruchstücke eines Henkels und Borlenstiickes einer Amphora rom Heidengraben bei Erkenbrechtweiler (O.-A. Nürtingen, Mus. Stuttgart) völlig mit solchen der Basler Spät-La-Tènestation und vom Mont Beuvray (vgl. Déchelette, Manuel II. 3 [1914] S. 954) übereinstinimen und als Weinfässer in der Spät-La-Tènezeit wohl auch ans Gallien eingeführt sind. Leider sind die Fundstücke aus diesen helretischen Gutshöfen Badens und Württembergs noch zu wenig zahlreich, als dass sie ein genügendes Vergleichsmaterial mit dem gleichzeitigen schweizerischen Grabinventar bilden könnten, wenn auch die bayerischen Ausgrabungen einige Ergänzung bieten.. ${ }^{3}$ ) Für die Gesamtfrage der.Zeitdauer des Aufenthalts helvetischer Stämme in Südwestdeutschland sind sie auch deshalb von geringerer Bedeutung, da für verschiedene Teile Sïdwestdeutschlands ein Zuriickbleiben und Nachrïcken gallischer Bevölkerung bis in römische Zeit hinein nachgewiesen ist, was gerade für einzelne Bauernfarmen Geltung haben dürfte. ${ }^{4}$ ) Jedenfalls beweist die Keramik und die Tatsache der Befestigung, dass sie bis zur germanischen Invasion Siirlwestdentschlands durch dic Cimbern und die Scharen des Ariovist herabreichen, zum Teil sogar noch weiter.

1) P. Gössler, Die vor- und frühgesch. Altert. d. Oberamts Urach 1909 S. 158/159, Abb. S, Oberamts Münsingen 1912 S. 231, Fundber. a. Schwaben X (1902) S. 18, XXI (1913) S. 24 2j u. s. Vgl. auch Mainzer Ztschr. 1913/1.4 S.113 (P. Reinecke).

2) Verölf. d. Karlsruher Sammlung II (1899) S. 75 f. (Gerichtstetten), Ber. d. röm.germ. Kommission 1909 S. 42 (Aufstetten), Fundber. a. Schwaben XIX (1911) S. $13 \mathrm{f}$. (Echterdingen. Einsiedel), vgl. auch die Literatur Katalog d. rörn.-germ. Zentral-Museums V (1913) S. 40 l., VIl. Ber. d. röm.-germ. Kommission 1915 S. 109 u. s.

3) Xamentlich in den Viereckschanzen von Amerdingen und Haunsheim (im NationalMuseum in München, vgl. P. Reinecke a. O. Nr. 5).

4) Vgl. die Literatur I. Ber. d. röm.-germ. Kommission (1905) S. 12. 
Durch Posidonius, Cüsar bzw. Strabo, Florus u. a. wissen wir, dass ein Teil der Helvetier in Südwestdeutschland (Tigurini und Tongeni = Toutoni?) sich dem Cimberneinbruch nach Gallien anschloss, hier aber grossenteils umkam, wenigstens der letztgenannte Stamm, während die Tig u r i n e r mit den Cimbern nach Oberitalien zogen und als Wächter der Alpenpässe der Niederlage auf dem raudischen Felde entgingen. Da nach Caesar (bell. gall. I. 12) und der Inschrift C. I. L. XIII 5076 (genio pagi Tigorini) die Tiguriner späterhin in der Gegend von Aventicum sassen, ${ }^{1}$ ) müssen sie wie die Bituriges Vivisci, die ursprünglich vielleicht am Main mit den Bituriges Cubi zusammenwohnten, ${ }^{2}$ ) nach dem Cimbernkrieg sich in der Südwestschweiz niedergelassen haben. Wie stimmen damit die Bodenfunde?

Vergleicht man die älteren La-Tènefunde Südwestdeutschlands mit denen der Nord- und Westschweiz, so fällt die grosse Ähnlichkeit sofort ins Auge, von der Früh- bis zum Ende der Mittel-La-Tènezeit. Das Schweizer Material ist jetzt namentlich in den Museen zu Zürich und Bern übersichtlich zusammengestellt. D. Viollier unterscheidet für das schweizerische Früh-La-Tène drei Entwicklungsstufen (vgl. Anz. f. Schw. Altk. XIV [1912] S. 546, Festgabe f. Hugo Blümner 1914 S. 265 f.):

I a (Bülach, Engstringen, Hildisriede, Mettmenstetten, Morges, Schlieren, Zürich usw.): Certosa-Fibeln und Fibeln mit kleinem Fussknopf, bronzene Halsringe mit Ösen, kleine Pufferringe, Hohlringe usw. (etwa 450-400).

I b (Altstetten, Bülach, Gurmels, Jona, Lunkhofen, Muri, Rheinau, Winkel): Fussende der Fibeln als Scheibe mit Emailbelag gebildet oder zu einer profilierten Spitze verlängert, gewellte Ringe usw. (etwa 400-325).

I c (Andelfingen, Bern, Dietikon, Lausanne, Mettmenstetten, Pfäffikon, Staefa, Villmergen, Windisch, Zürich): Fussscheibe mit Spitze, Vasenkopffibeln, Halsringe mit. Blutemail, stark geperlte und geknotete Ringe („Eierringe“, grosse Pufferringe usw.); Beginn der Eisenfibeln, deren Fussende öfters schon auf dem Bügelende aufliegt, aber noch unverbunden; nur in Andelfingen, Grab 27, zweimal wie beim Mittel-La-Tèneschema verbunden (etwa 325-250).

Die südwestdeutschen Funde stimmen mit den schweizerischen in allen diesen Entwicklungsstufen und im allgemeinen auch in den Grabgebräuchen so sehr überein, dass schon Viollier als Wiege dieser Kultur den Stromlauf von Basel bis Bodensee und die oberrheinische Tiefebene angenommen hat. ${ }^{3}$ ) Jedenfalls lässt sich erkennen, dass die gallischen Bewohner Südwestdeutschlands und der Schweiz schon in dieser Periode wie in La-Tène II in naher kultureller und stammlicher Verwandtschaft standen. Da die Gräber von ausgesprochenem Spät-Mittel-La-Tènecharakter (wie

1) F. Haug bei Pauly-Wissowa-Kroll VIII unter Helvetii (S. 210).

2) A. v. Domaszewski, Westd. Ztschr. 1902 S. 204. - E. Fabricius, Die Besitznahme Badens durch die Römer (1905) S. $18 \mathrm{f}$.

3) Vgl. auch die Literatur bei Déchelette, Manuel II. 3 (1914) S. 1083 u. VI. Jahresber: d. Schweiz. Ges. f. Urgesch. (1913) S. 96. 
Dühren, Ladenburg) in Südwestdeutschland ziemlich selten, in der Schweiz sehr häufig sind, darf wohl mit grosser Wahrscheinlichkeit vermutet werden, dass die Träger dieser letzteren Kultur die Helvetier (Tiguriner usw.) waren, die namentlich infolge des Cimbernzuges Süddeutschland verliessen und späterhin ihre Wolhnsitze in der Schweiz fanden.

Auch der Vergleich der zwischen Main und Oberrhein gefundenen keltischen Münzen, die für Württemberg F. Hertlein, Fundber. a. Schwaben XII (1904) S. 60-107, im Zusanmenhang behandelt, mit denen der Helvetier der Schweiz, über deren Prägungen R. Forrer, Kelt. Numismatik S. 304 f., nevie Aufstellungen gemacht hat, lehrt uns, dass die in Sïdwestdeutschland ang'esiedelten Helvetier kaum mit der selbständigen Münzprägung begounen hatten, als sie das Land verliessen, also lange vor den Prägungen der Ariovist'schen oder Orgetorix-Zeit. ${ }^{1}$ )

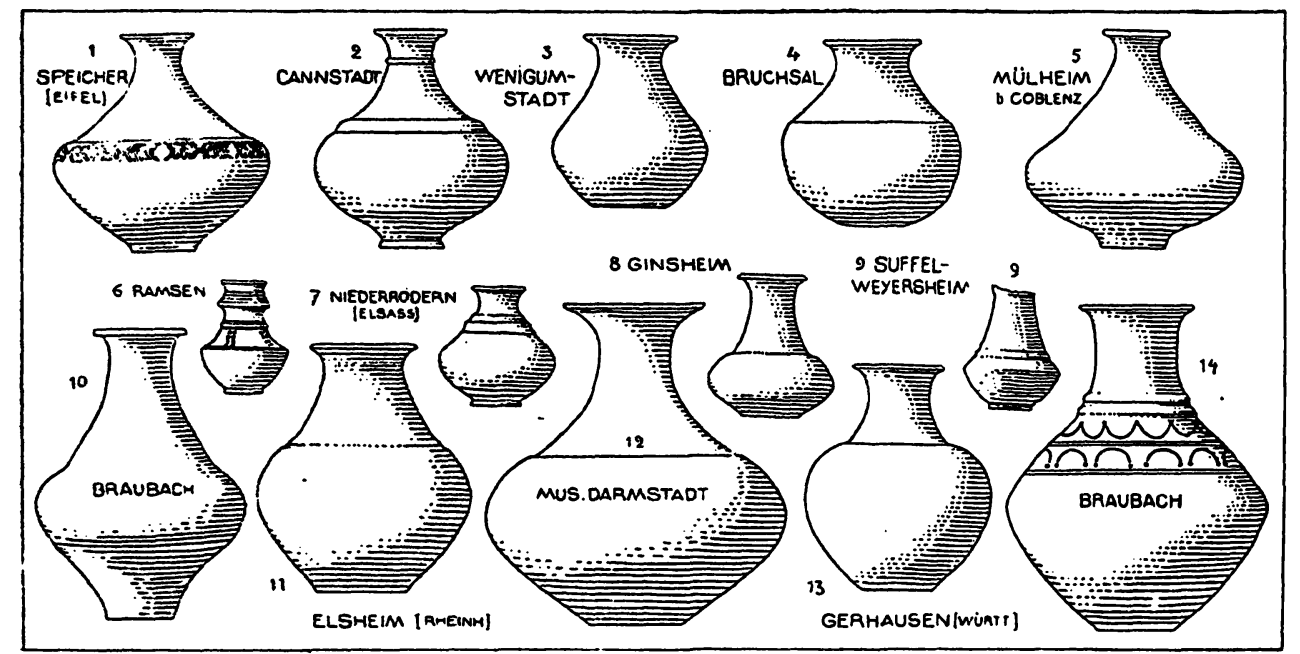

Abb. 6. Flaschenformen der älteren La-Tène-Zeit.

Ob man die Träger der Kultur I a-c in der Schreiz und Südwestdeutschland gleichfalls als Helvetier bezeichnen darf. steht noch dahin. Viollier betrachtet diese Bevölkerung in der Schweiz als Vorwelle der späteren helvetischen und gleichen oder nahe verwandten Stammes. ${ }^{2}$ ) Er kann Recht baben, doch warnen die archäologischen Verlı̈̈ltnisse in SüdwestDeutschland zu grösster Vorsicht. Längs des rechten Rheinufers, etwa vom Siebengebirge bis zur Neckarmündung und in angrenzenden Berglande (Westerwald, Taunus, Odenwald) hat die Frül-La-Tènegrabausstattung anderen Charakter als am Oberrhein und zeichnet sich wie die „belgische“ durch hiiufigere Waffenbeigabe und reichere Keramik aus, namentlich die hohe Flasche, welche in dieser Gestalt in den Grälern des "helvetischen“

1) Ygl. auch Fundber. a. Schwaben $X$ (1902) S. 28 f. (A. Schliz).

2) R. Forrer, Kelt. Numismatik S. 303, meint wegen der Ähnlichkeit der Münzen der "Protohelvetier" des IIl. bis II. Jahrhunderts mit denen der Arverner, dass sie ein Stamm des grossen Arvernerreiches gewesen seien. 
(jebietes bis jetzt fast ganz fehlt. Es genügt, auf die Flaschen von Mülı]hofen bei Engers (Präh. Mus. Köln), von Braubach und Simmern (Westerwald), Geisenheim, Schierstein, Wiesbaden, aus der Ungeloung Frankfurts, von Leebeim, Lorsch, der Rosenhöhe bei Darmstadt, ron Wal]stadt und Ladenburg an Neckar hinzuweisen (A. h. Vor\%. V S. 31 u. 336), deren nächste Parallelen in Rheinhessen und im Treverer Gebiet bis Koblenz in Menge vorhanden sind. Mit ziemlicher. Sicherheit darf daraus geschlossen werden, dass jener rechtsriheinisclie Streifen zwischen Siebengebirge und Neckar in der Früh- und beginnenden Mittel-La-Tènezeit von einem gallischen Stamme, der den Treverern nahestand, bewohnt war, wie übrigens für die Gegend von Oberlahnstein-Braubach schon Bodewig (Nass. Annalen 33, 1902 S. 28 f.) belsauptet hat. Das Land zwischen Main und Neckar können die Helvetier also erst im Verlaufe der Mittel-Ia-Tènezeit erobert haben.

Die Flaschenform begegnet zwar auch gelegentlich südlich des Neckars in Baden, ${ }^{1}$ ) Württemberg ${ }^{2}$ ) und im Elsass ${ }^{3}$ ), sie unterscheidet sich aber von dem eben erwähnten „belgischen“ Typus sowohl im Gesamtumriss als in der Art der Profilierung, wenn auch die meisten Exemplare schon der Mittel-La-Tèneperiode uäher stehen (vgl..unten S. 261). Fïr das 'Treverergebiet (Eifel und Hunsrück bis zum Rhein) charakteristisch ist die zierliche Kreissel- oder Zwiebelform (Abb.6 Nr.1, 5), für den Mittelrhein und das Mainzer Becken die streng gegliederte, hohe Birnform (Abb. 6 Nr:8, 14), fürr Südwestdeutschland eine einfachere, bauchigere Kürbisform (Abb. 3, 4), wobei natürlich die Formen nicht selten ineinander übergehen (Abb. 6 Nr. 10. 11). Wieder anders erscheint sie weiter östlich in Nordbayern und Böhmen als sog. Linsenflasche, die nach Reinecke (Festschr. d. Mainzer Zentr.-Mus. 1902 S. 101 Anm. 57 und.A. h. Vorz. V S. 287) durch die Bojer um 400 nach Pannonien (Syrmien usw.) verdrängt wurde. In diesen eigenartigen örtlichen Ausprägungen kann sie geradezu als Leitform für die Umgrenzung verschiedener keltischer Stämme und Kulturen betrachtet werden (vgl. auch P. Reinecke, Naichrichten über deutsche Altertumsfunde 1901 S. 47 f., A. h. Vorz. V S. 336). Aus der Schweiz ist mir keine der siidwestdeutschen ähnliche Form bekannt, jedenfalls wurde sie nicht wie am Rhein als bedeutsamstes Grabgefäss dem Toten mitgegeben. Die formähnlichen Weiterentwicklungen der Mittel-La-Tènestùfe in der Schweiz (Abb. 2 und 3) könnten aus Süddeutschland herübergenommen sein, doch ist zur Bildung einer sicheren Ansicht erst weiteres Fundmaterial abzuwarten. Deshalb möchte ioh die Frage, ob in der Früh-La-Tènezeit schon dieselbe Bevölkerung zwischen Neckar und Oberrhein wie in der Scliweiz wohnte, einstweilen noch offen lasseri.

1) Bruchsal (E. Wagner, Fundstätten II S. 155 Abb. 141), Sinsheim (ebenda II S. 357 Abb. 291).

2) Gerhausen-Rusenschloss (P. Gössler, Die Altert. d. Oberamts Blaubeuren [1911] S. 32 Abb. 9, 3), Cannstatt und Murr (Fundber. a. Schwaben XIII S. 42 Abb. 5).

3) Niederrödern (A. h. Vorz. V S. 331 Abb. 1 Fig. a, unsere Abb. 6, 7), Suffelweyersheim (Henning, Denkmäler Taf. X, 15), Schweighausen (Naue, Denkmäler Taf. VII, 55). 
5. Germanen in der Schweiz (Gaesaten)? Mchrere Forscher nehmen an, dass schon ror dem 2. Juhrhundert v. Chr. Germanen in die Schweiz eingedrungen seien. So schreibt J. Heierli in seiner vortrefflichen Urgeschichte der Schneiz (1901) S. 427: „Jene Reisläufer aber waren weder reine Germanen, noch reine Kelten, sonder'n ein Gemisch beider Volksstämme. Es scheint also, als ob in der Schweiz der keltischen Berölkerung eine ältere germanische vorausgegangen sei.“" ${ }^{1}$ ) Diese Ansicht grïndet sich hauptsächlich auf die angebliche Utberlieferung ü̈mischer Schriftsteller, dass unter den Galliern (Gäsaten), die, vou den Alpeu herabsteigend, 225 bei Telamon und 222 bei Clastidium von den Römern besiegt wurden, Germanen lämpften. ${ }^{2}$ ) Der Name German(e)i ist aber nach A. Holder u. a. „interpoliert an Stelle des nach der Etymologie der Alten symonymen Gaisat(e)is der Quelle“.

Die Bodenfunde haben bis jetzt m. E. keinen Anhaltspunkt dafür ergeben, weder in Wallis noch weiter nördlich, auch nicht die Skelette der Münsinger und anderer Gräber. Im Münsinger Totenfeld ist allerdings ein Grab (Wiedmer-Stern S. 78 Nr. 182) vorhanden, das sich von allen anderen unterscheidet: ein auf der rechten Seite liegendes Skelett mit den Händen vor dem Gesicht, ausgestattet mit einem Ösenbeilchen von Eisen nach. Art der bekannten germanischen (Taf. 18,9) und mit zwei eisernen MittelLa-Tènefibeln. Der hier Bestattete gehörte augenscheinlich einem anderen Stamme an als die übrigen Toten dieses und vieler ähnlichen gallischen Gräberfelder der Mittel- und Nordschweiz, denen nur Schwerter, niemals Beile ins Grab mitgegeben siud. Ein gleiches, noch geschäftetes Beil ist auch in La-Tène gefunden (P. Vouga', La-Tène, V. Ber. 1914 Taf. V, 4) und schon ron Touga als Schlachtbeil erklärt, was zur Vermutung führen könnte, dass eire bestimmte Truppe damit ausgerüstet war. Als Grabbeigaben sind Schlachtbeile (aber anderer Form) häufig in Ornavasso, ${ }^{3}$ ) ebenso aber auch in den Ostalpen, also bei den südalpinen Stämmen, $\left.{ }^{4}\right)$ und daher mag auch der Krieger jenes Münsinger Grabes gekommen sein, der aber eine Axt einheimischer Form benutzte. Die Germanen haben in dieser Periode, wenigstens in der Heimat, ihre Toten verbrannt.

Ferner ist in Giubiasco, wo auch einige Streitäxte wie in Ornavasso gefunden sind, ${ }^{5}$ ) in einem gallisch-römischen Grabe ein konischer Schildbuckel erhoben, ${ }^{6}$ ) von einer Form, die gewöhnlich als germanisch bezeichnet wird. Aber auch von Alesia liegt genau derselbe Typus vor (mit den grossen Nagelköpfen), den allerdings auch hier M. Jahın (Mannus V S. 89/90) den germanischen Hilfsvölkern Cäsars zuschreibt, indessen erscheint mir die gerInanische Entstehung dieser Form noch nicht gan\% gesichert ( $\nabla$ gl. auch uuten S. 273). Selbst aber wenn sie es wäre, wïrle daraus nicht \%u folgern

1) Vyl. auch J. Wiedmer-Stern, Das gallische Gräberfeld bei Münsingen S. 61., 87.

2) Stellen bei A. Holder, Altkejtischer Spracbschatz 1896 S. 1514 f. u. S. 2011.

.3) E. Bianchetti, $i$ sepolcrcti di Ornavasso (1895) lav. VJ. 8 u. 9.

4) Vgl. auch Déchelette. Manuel 11. 3 s. 1358.

j) R. Ulrich, Die Gräberfelder in der Gegend von Bellinzona (1914) S. 420.

fi) Urich, ebenda S. 421. Tal. LXXIX. 5. 
sein, dass in der: Nähe von Giubiasco ein germanischer Stamm sass, sondern höchstens könnte man auf einzelne germanische Krieger schliessen. Aber auch dieses ist sehr fraglich, da Waffen als Beutestücke, Geschenke wie als Handelsgegenstände oft weitab von ihrer Heimat verschlagen werden.

Also bis jetzt entbehrt jene Vermutung des sicheren Anhalts.

\section{Andere keltische Stämme des Oberrheingebiets}

1. Sequa in er und A eduer. Berührte das Gebiet der Sequa ner den Oberrhein auch nur auf einer kurzen Strecke, während das der A ed u e r vollständig jenseits der Rhein- und Rhonescheide lag, so waren sie doch für die oberrheinsiche und spez. helvetische Kultur dieser Periode nicht ohne Einfluss, so dass ihrer wenigstens in Kürze $\mathrm{zu}$ gedenken ist. Durch ihr Gebiet ging ja die grosse Handels und Völkerstrasse aus dem Innern Galliens nach dem Helvetierland und weiter an die Donau, und durch ihre Kämpfe wurde ja das Eingreifen der Germanen unter Ariovist veranlasst. - Jene uralte Handelsstrasse, deren beide von Lyon (Rhone-) und von Autun (Loiregebiet) kommenden Äste sich bei Cabillonum (Châlons sur. Saône), dem oben erwähnten Grenzort der Sequaner und Aeduer, vereinigten, führte über die Hauptstadt der Sequaner Vesontio (Besançon), Epomanduodurum (Mandeure), beide am Doubs, über Larga (bei Friessen an der Larg) nach Basel und weiterhin über Vindonissa (Windisch), Vitodurum (Winterthur), Brigantium (Bregenz), Cambodunum (Kempten) usw. an die Donau und brachte die Erzeugnisse von Kunst und Handwerk aus dem Herzen von Gallien bis nach Böhmen' und Ungarn.

Diesen auch in der Münzstreuung'1) sich abhebenden Weg benutzten wohl auch die Helvetier zwischen Vesontio und Cabillonum, als sie im Jahre 58 über den Jura durch das Sequanerland nach der Aeduerhauptstadt Bibracte zogen, und ebenso Caesar, wenigstens vom Südwesten bis Vesontio, während er nördlich von Vesontio durch das offenere Ognontal über Belfort nach dem Rheintal marschierte.

Die Grenzen des Sequanerlandes schwankten zu den verschiedenen Zeiten; in der zweiten Hälfte des letzten Jahrhunderts v. Chr. waren sie nach Caesar und Strabo im Süden durch die Rhone, im Westen gegen die Aeduer durch die Saône, nach Osten gegen die Helvetier durch Jura und Doubsfluss bestimmt, nach Nordosten ist sie zweifelhaft. Ihre Hauptstadt war Vesontio (Besançon) am Doubs, andere oppida Epo(a)manduo(tu)durum (Mandeure), Velatudorum (=Loposagium (o) q) u. a. (vgl. C. I. L. XIII. 2, 1 S. 66, Zangemeister), alle an Flüssen. Die Geschichte der Sequaner ist, wie wir schon gesehen haben, aufs engste mit der der Helvetier und Rauriker verknüpft, weswegen sie auch in der römischen Provinz- und Heereseinteilung mit jenen zusammengefasst werden (am obergermanischen Limes eine cohors Sequanorum et Rauricorum bei Oberscheidental-Schlossau, während bei Wimpfen-Jagsthausen eine coh. Helvetiorum lag). Wieweit die

1) Vgl. R. Forrer, Keltische Numismatik S. 273. 
Kulturgemeinschaft der Helvetier und Sequaver im einzelnen ging, lïsst sich aus dem archäologischen Materiale bis jetzt nicht zur Genüge erkennen, da es, abgesehen von den Münzen, sehr schwer zugänglich ist. Zwar lässt der Strassenknotenpunkt Epo(a)mandnodurum an der grossen Nordbiegung des Doubs mit sehr zahlreichen Funden (Schwertern, Glasringen, bemalten Vasen, Fibeln, gallischen Münzen) ein wichtiges Handelszentrum nach dem Oberrheine und Helvetiergebiet vermuten, ${ }^{1}$ ) das ohne Zweifel die oben erwähnten schönen Spät-La-Tènegefässe nach Basel vermittelt hat, über Ve(i)sontio und Cabillonum aus dem Innern Galliens ebenso vie Vesontio") selbst mit seiner direkten Verbindung über den Jura nach dem Newenburger See.

Di e A e d u e r besassen $u$. a. die oppida Cabillonum und Bibracte. Über Cabillonum (Châlons sur Saône), nebst Lugdumum (Lyon) eines der wichtig̣sten Strassenzentren Ostgalliens, war schon oben die Rede. ${ }^{3}$ ) Die hier in der Saône in der alten Hafenanlage gemachten gạllischen Funde, ${ }^{4}$ ) ganz in der Art derer 'ron der Station La-Tène, u. a. ungebrauchte Schwerter und Lanzen, Eisenbarren usw., gleichfalls also grossenteils Handelsware, reichen etwa vom 3. Jahrhundert v. Chr. bis in die römische Zeit (mehrere gladii und ein römischer Helm), gestatten aber leider keine genaue zeitliche Umsrenzung wie die Funde vom Mont Beuvray (Bibracte) mit ihrem sicheren terminus ante quem. Aus der ungeheuren Menge von Amphorenresten schliesst Déchelette (a. o. S. 163) mit Recht „très certainement l'importation des vins du Midi était à Châlons comme à Lyon le principal négoce alimentant la batellerie de la Saône", und manche dieser Amphoren wird ihren Weg über Mandeure bis Basel gemacht haben (negotiatores vinarii in Lyon bezeugt), ebenso wie auf der anderen, von Agrippa und Claudius ausgebauten Hauptroute über Andemantunnum (Langres) an die Mosel und an den Rhein, längs welcher auch mannigfache Erinnerungen an die rheinischen Iegionen gefunden sind. ${ }^{5}$ ) Beachtenswert aber ist, dass sich die bemalte Ware auf jener östlichen Strasse viel weiter verbreitet hat als auf der nördlichen.

Das Hauptoppidum der Aeduer (Caesar: oppidum maximae auctoritatis apud Haeduos) auf dem Mont Beuvray ( $\mathrm{Bibracte}$ ) mit seinem murus gallicus ist nach den vortrefflichen Untersuchungen Bulliots und Déchelettes erst zu Beginn der Spät-La-Tènezeit angelegt worden, als infolge dess

1) Funde in den Museen zu Mülhausen, Colmar, Belfort und Montbéliard, von den Ausgrabungen Enge] - Dollfuss 1882 u. a.; vgl. Rev. arch. 1904. S. 193 f. (A. Roux), L. G. Werner, Els. Monatsschrift 1913. Nach A. Holder, Altkelt. Sprachschatz I. S. 1446 .Epomanduj castellum“; Déchelette, Manuel II. 3 S. 1327 u. a.

2) Über Vesontio vgl. Chifflet, Vesontio und die Literatur: Rev. arch. 1904, 2 S. 52 f. (M. Piroutet). Cober ein ojpidum bei Pruntrul Déchelette, Manuel 11. 3 S. 992 Anm. 4 (Admagetobriga??).

3) Schnittpurkt der Strassen Lyon-Trier, Geni-Autun. Vgl. Déchelette, Manuel 1I. 2 S. j81. II. 3 S. 938 I.

4) In der Sammlung M. Millon und im städtischen Museum zu Chúlons s. S. (J. Déchelette, La Collection Millon 1913 S. 155 I.).

5) Vgl. E. Ritterling, Bonn. Jahrb. H. 114 (1006) S. 167 f., wo auch weitere Literatur. 
Cimbernzuges die Germanengefahr drohte, die auch anderwärts ständig bewonnte befestigte Siedlungen hervorrief. ${ }^{1}$ ) Da seine Bewohner um das Jahr 5 oder 2 v. Chr. von den Römern gezwungen wurden, in das etwa $24 \mathrm{~km}$ entfernte Augustodunum (Autun) überzusiedeln, geben uns die Funde von Bibracte wichtige chronologische Anhaltspunkte. Nicht ohne Interesse sind die in den dortigen Werkstätten erzeugten Eisen-, Bronze- und Emailwaren (Fibeln des sog. Nauheimer Typus, emaillierte usw., Déchelette, Fouilles S. 67), von besonderer Bedeutung aber die zallreichen keramischen Überreste, namentlich die bemalte Ware. Déchelette, Manuel II. 3 S. 1488 f., nimmt für letztere mit Recht verschiedene Fabrikationsorte mit leichten lokalen Abänderungen an, so in Montans (Tarn), Lezoux (Puy-de-Dóme), bei Roanne ustr., Vorläuferinnen der in römischer Zeit berühmten Töpfereien. ${ }^{2}$ )

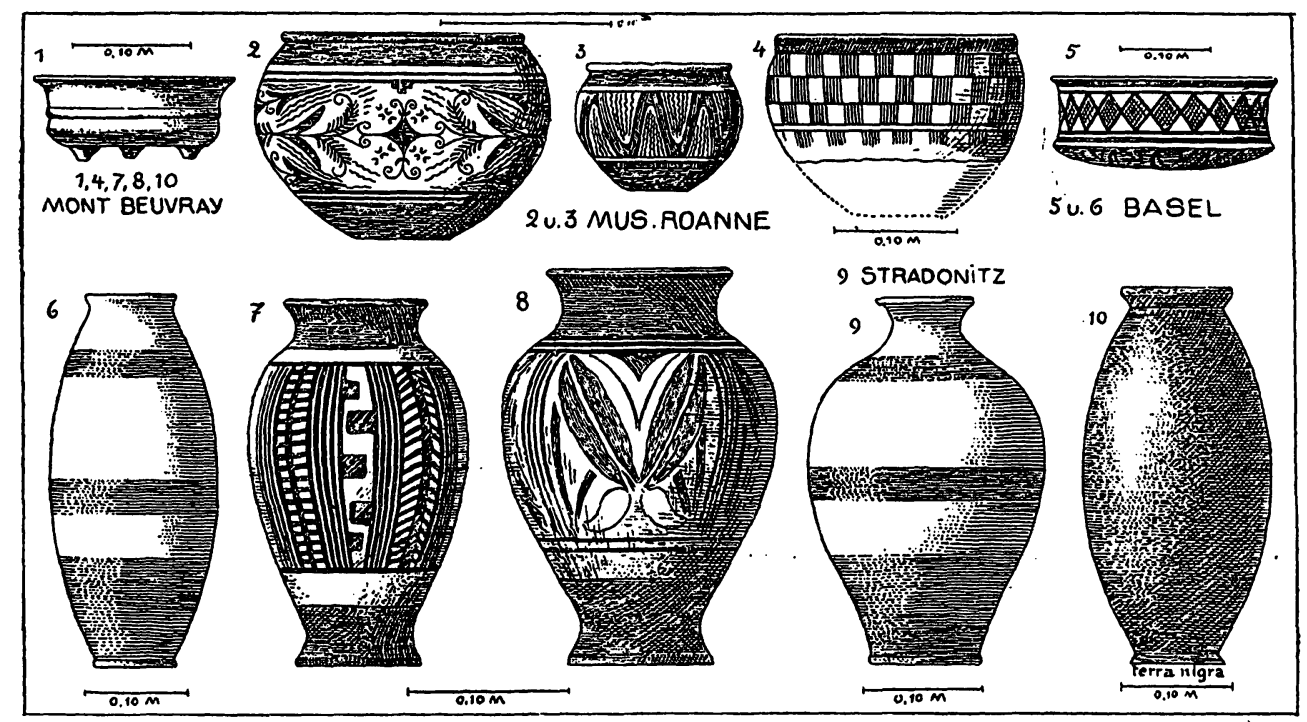

Abb. 7. Bemalte Gefässe der Spät-La-Tène-Zeit.

Die Formen der bemalten Gefässe aus der Gegend von Roanne und vom Mont Beuvray, meist kugelige Urnen, Kumpen ${ }^{3}$ ) und stark geschweifte

1) 0. Tischler, Schr. d. phys.-ök. Ges. Königsberg XXV (1884) S. 24 f. - J. G. Bulliot, Fouilles du Mont Beuvray, zwei Bände mit Album 1899. - J. Déchelette, Les fouilles du Mont Beuvray 1904 (wo S. 3 Anm. 1 weitere Literatur). - Derselbe, L'oppidum de Bibracte (Führer) 1903. - Derselbe, Manuel d'archéologie II. 13 (1914) S. 948 f. H. Dragendorff, Arch. Anz. 1910 S. 439-456.

2) Die Parallele mit der frührömischen - gallischen Sigillatafabrikation erscheint von grossem Interesse. In Montans, an der Grenze von Aquitania und Gallia Lugdunensis, hat A. Oxé (Arch. Anz. 19142 S. 63 f.) eine der ältesten gallischen Sigillatafabriken nachgerviesen, deren Erzeugnisse, teils italische, teils gallische Formen, gerade lïngs jener Hañdelsstrasse häufig sind, auf dem Mont Beuvray, in Mandeure usw. Auch die bemalte Spät-La-Tèneware von Montans (vgl. Déchelette, a. o. S. 1493) unterscheidet sich etwas von der von Lezoux, wie überhaupt die la-Tène-zeitliche Keramik Südfrankreichs ihr eigenes Gepräge hat, das vielfach an spanische Erscheinungen erinnert (vgl. L. Joulin, Rev. arch. XIX [1912] S. 1-80).

3) Déchelette, Rev. arch. 1895 I. pl. V-VI, Manuel II. 3 S. 1490 Abb. 682; Bulliot, Album Taf. VI, 1-2. 
Humpenbecher, ${ }^{1}$ ) unterscheiden sich von denen von Basel, soweit diese die feinsten - wicht Importstücke der Aeduer sind, ebenso gegenüber deuen vou Hradisch-Stradonitz durch lebhaftere, mehr an die hellenistischen Vorhilder erinnernde Umrisslinien und feinere Profilierungen der einzelnen Körperteile. In Basel treten an die Stelle jener schöngeschweiften und gegliederten Humpen mehr fass- oder tonnenförmige, in Stradonitz mehr krugartige Gefässe mit engem Halse und kleiner.Mündung, bei denen Mündungsr'and und Fuss oft nur geringe Durchbildung verraten. Und ähnlich verfügt die Ornamentik bei ersteren über viel mannigfaltigere Muster, auch der Pflanzen- und Tierwelt entnommene, wenn auch eigenartig umstilisiert, während in Basel und Stradonitz (abgesehen von der echten Importware in Basel) fast nur einfache geometrische Verzierung angewandt ist. Jene tonnenförmige Gefässe kommen allerdings auch auf dem Mont Beuvray vor (z. B. Album pl. XXII, XXVII u. s.), zeigen aber eine viel sorgfältigere Behandlung von Fuss und Mündung als in Basel. - Auch die terra-nigraWare vom Mont Beuvray bietet mannigfache Parallelen mit den ähnlichen Fundstücken im oberrheinischen Gebiet, während die des Mittel- und NiederRheins vou belgischen Fabriken abstammt (vgl. Dragendorff a. o. S. 451 und S. Löschucke, Mitt. f. Westfalen V [1909] S. 258 f., andererseits F. Drexel, O. R. L. Nr. 66 c, Kastell Faimingen S. 74 f.).

Auch ein Vergleich mit den Fundgruppen von Gergovia (auf dem Mont Gergoy bei Clermont-Ferrand), Alesia (Mont Auxois bei Alise-Sainte Reine, Semur), Noviodunum (Pommiers bei Soissons), Sainte-Geneviève (Nancy) 11. a. gallischen oppida, die uns grösstenteils durch Caesars bellum gallicum wohl bekannt sind, ${ }^{2}$ ) liefert ungemein wichtige chronologische und handelsseschichtliche Fingerzeige. Alle diese oppida sind offenbar erst zwischen Cimbernkrieg und Caesar als Festungen angelegt und zu ständiger Siedlung, auch der Zivilbevölkerung, geworden, und mehrere derselben, wie Pommiers, haben bald nach der Eroberung durch Caesar ihr Ende erreicht, während andere, wie Alesia, bis in die römische Kaiserzeit dauern. Besonderes Interesse erwecken die Funde aus der von Napoleon III 1861-1865 ausgegrabenen Umschliessungslinie Caesars bei Alesia des Jahres 52 v. Clur., ${ }^{3}$ ) zahlreiche Schwerter und Lanzen, Münzen (bis zum Jahre 54) u. a. m. So lassen die langen, wuchtigen Schwerter mit ihrem meist geraden oberen Klingenabschluss (vgl. z. B. Rev. arch. $X$ [1864] Taf. 2, Déchelette S. 961 $\Lambda$ bb. 401) im Vergleich mit denen von La-Tène gar keinen Zweifel darüber (r) walten, dass weitaus die Mehrzahl auch der jüngsten bei La-Tène gefundenen, viel zierlicheren Schwerter (mit ihrem abgerundeten oberen Abschluss) aus vorcaesarianischer Zeit stammen und auf eine lange vor dem HelvetierAusmarsch (58) liegende Katastrophe hinweisen, wiewohl auch in Alesia noch einige schlankere der letzteren Art vertreten sind. Dasselbe gilt von den Schildbuckeln, Fibeln usw. von Alesia, die alle der ausgesprochenen,

1) Bulliot, Album Tal. III-V, Déchelette, Rev. arch. 1895 IIl. V-VI Nr. 2; Manuel II. 3 S. 1490 Nr. 8.

2) Literatur bei Déchelette II. 3 S. 957 f.

3) Déchelette a. o. S. $958 \mathrm{f}$. 
namentlich durch Bibracte illustrierten Spät-La-Tènekultur angehöreu, wenn auch die Eisenfibeln das alte Mittel-La-Tèneschema in vereinfachter Form wahren. Wenn M. Jahn den bekannten konischen Schildbuckel von Alesia (Mannus V S. 89 Abb. 44 a, b) den germanischen Hilfsvölkern Caesars (bell. gall. VII 65) zuschreibt, so steht dem an und für sich nichts im W'ege, wie ich schon Praeh. Z. III S. 171 für den ähnlichen Schildbuckel und die Beilchen vom Grabfeld von Morsbach am Fusse des Herapels (Mus. Metz) germanischen Ursprung in Betracht gezogen habe (vgl. auch uuten S. 273). Ien Fibeln von Alesia hat 0 . Almgren in der Festschrift für Montelius 1913 S. 241-248 eine besondere Studie gewidmet (,fibules d'Alésia et de Bibracte, deux dates fixes dans l'histoire de la fibule en Gaule“). Wenn Almgrens Voraussetzung richtig ist, dass diese Formen, wie die Fibel mit gitterartig durchbrochenem Fuss, bisweilen mit flügelartigen Ansützen am oberen Teil des Bügels, aus den caesarianischen Gräben stammen und also

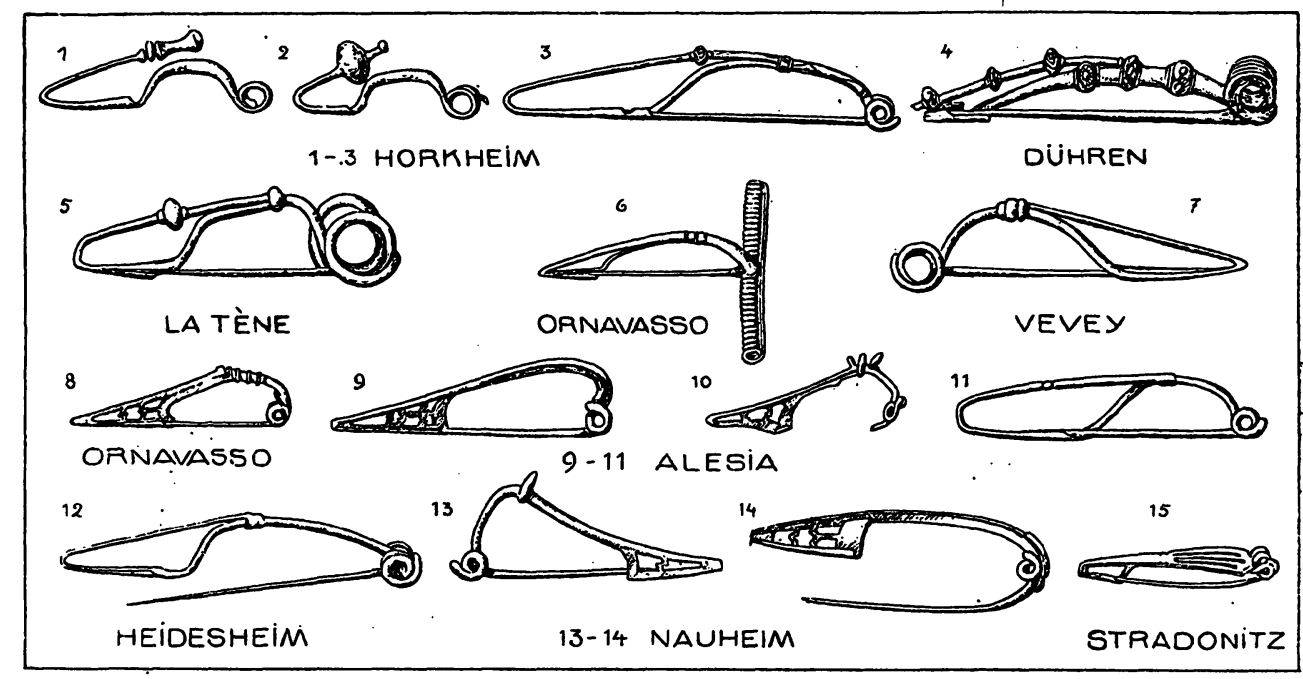

- Abb. 8. Fibeln der Mittel- und Spät-La-Tène-Zeit.

älter als 52 v. Chr. sind, so ist damit eine weittragende Datierungsmöglichkeit gegeben, auf die noch weiter unten zurückzukommen sein wird. Den Umstand, dass die Fibel vom „Nauheimer“ Typus in Alesia (und Pommiers, Déchelette S. 967) bis jetzt fehlt, möchte ich nicht wie Almgren (S. 246) erklären "ce qui prouve que des influences diverses ont dû se croiser à cette époque", sondern mit der jüngeren Entstehung dieses Typus zusammenbringen, da er ja in allen Teilen Frankreichs, aber in jüngeren Schichten gefunden wird (vgl. auch oben S. 240). Die Fibel von Alesia wie Festschrift S. 243 Abb. 6 ${ }^{1}$ ) entspricht ohne Zweifel der Zeit von Alesias Belagerung. Dies lehrt ror allem ein Vergleich mit den Fibeln von Ornavasso bei Bianchetti Taf. X. 6, 8, 9, 11 (vgl. Rev. arch. 1902 I S. 270 Abb. 14), welche die unmittelbare Vorstufe jener Alesia-Fibel darstellen und in einem Grabe mit Münzen aus dem

1) Auch Rev. arch. X (1864) Taf. 1, unsere Abb. 8 Nr. 9. Vgl. O. Tischler bei B. Meyer Gurina im Obergailtal (1885) S. 24 (Taf. V̇I, 3). 
Jahre $8 S$ und 84 v. Chr. zum Vorschein kamen (die dabei liegenden Gräber nit Münzen vom Jahre \$9, 64, 54, 43). (Vgl. auch die Fibel Brit. Mus. guide 1905 S. 101 Abb. 82.)

2. Vindeliker, Bojer usw. Gehören diese Völkerschaften im "resentlichen auch bereits dem Donaugebiete an, so müssen sie doch wichti«er Parallelen wegen wenigstens kurz in Betracht gezogen werden. D i e $\checkmark$ indeliker zwischen Bodensee, Donau- und Inntal, mit den oppida Cambodunum (Kempten), bei Manching (B.-A. Ingolstadt), 1) bei Augsburg (Augusta Tindelicorum) usw., unterscheiden sich in ihrer Kulturhinterlassenschafi renigstens für die Spät- und Mittel-La-Tènezeit auf den ersten Blick renig von derjenigen der keltischen Stämme der Rheinlande, ja des Marnegebietes (Déchelette a. u. S. 1072: „elles rappellent tout à fait les sépultures de Saint-Maur-les-Fosses et de Somsois“); auch hier lassen sich wie lort gegen das Ende der Mittel-La-Tèneperiode bereits Brandgräber beobachten. Doch sind die Formen der Tongefässe einfacher und plumper als dort. wemn sie auch im grossen und ganzen auf dieselben italisch-grierhischen Vorbilder zurückgehen, ohne Zweifel vielfach Metallgeräte. Für die Torlagen der Manchinger Tongefässe denkt Reinecke wohl mit Recht an Bronzeeimer usw. aus dem südlichen Alpengebiet, dem Tessin, Tirol usw.") Auch die Spät-La-Tènefunde aus dem Ringwall bei Manching, die jedenfalls Aer römischen Okkupation des Landes im Jahre 15 v. Chr. vorausliegen, zeigen grosse Utbereinstimmung mit denen vom Mont Beuvray und Stradonitz und ähnlichen (vgl. Déchelette S. 970 und die vergleichende Zusammenstellung Abb. 404). Aber auch hier treten eigenartige Erscheinungen entgegen, auf die schon P. Reinecke, A. h. Vorz. V S. 368 aufmerksam gemacht hat, wo er ähnliche Elemente bei der spätkeltischen Bevölkerung im nördlichen Noricum (Karlstein bei Reichenhall) bespricht ${ }^{3}$ ) und spätvindelikische, der frühesten Kaiserzeit angehörige Keramik abtrennt. Sogar noch der grosse Münzfund von Oberhausen bei Augsburg aus augusteischer Zeit mit seinem zahlreichen Lỵoner Altargeld und seinen Nemausus-Münzen. autonomen Prägungen gallischer Gaue usw., verrät jene engen Beriehungen mit Gallien (Ztschr. d. Ver. f..Schwaben und Neuburg 40 [1914], E. Ritterling). ebenso die bemalte und terra-nigra-Ware Vindeliciens und Raetiens (rgl. O. R. L. Nr. 66 c S. 74 f., F. Drexel). Umgekehrt lassen sich aher aurh einige rindelicisch-rätische Formen römischer Zeit noch gelegentlich in der Nordschweiz beobachten. Wie das Zurücktreten der bemalten Spüt-La-Tènekeramik in Rätien und Vindelicien, die doch an der Nord- und ()stumgrobung des Bodensees und in Böhmen sich noch bis in das ganze riste narhohristlicle .Jahrhundert geltend macht (Funde von Bregenz, Mess-

1) Literatur: Katalog d. röm.-germ. Zentr.-Mus. Nr. 5 (1913) S. 162; auch 1)échelette, Manuel 11. 3 (1914) S. 970, 1072, 1479.

2) A. h. Vorz.. V S. 292 f. (P. Reinecke), vgl. Festschr. d. röm.-germ. Zentr.-Mus. 1902 S. ifi. Dit stammnos- oder Eimeriorm in Tun 7. B. bei R. Ulrich, Die Gräberfelder in der Emgebung von Bellinzona 1914, Taf. Ll. 11 (Giubiasco).

3) Vgl. auch 0. R. L. Nr. 66 c Kastell Faimingen S. 89 und VIl. Ber. d. röm.-germ. Kommission 1915 S. 30 (F. Drexel). 
kirch, Hüfingen usw.), zu erklären ist, mag hier dahingestellt bleiben (vgl. O. R. L. Nr. 66 c S. 90,95 u. s.).

Der Hauptstamm der Bojer, welche, wie die Volcae, eine selur bewegte Geschichte hinter sich haben, wohnte im 2. bis 1. Jahrhundert östlich von den Helvetiern (Tacitus Germ. c. 28, „ulteriora Boii tenuere“, Posidonius lei Strabo VII. 293) im nördlichen Bayern, in Böhmen, das von ihnen seinen Namen hat (Tacitus „manet adhuc Boiohaemi nomen“) und noch dar- über hinaus. ${ }^{1}$ ) Von ihren oppida (Boiodurum, Eburodunum usw:) kenmen wir am besten den Hradischt bei Stradonitz, fast .von gleicher Grösse wie der Mont Beuvray (140, letzterer 135 Hektar), aber mit viel reicherem Fundmaterial. Hunderte von Münzen, Regenbogenschüsselchen, massaliotische Nachahmungen, vindelicische, helvetische, Sequaner- und Aeduermünzen beweisen ebenso bestimmt wie die zahlreichen bemalten Vasen nach $A r^{\hat{\imath}}$ derer vom Mont Beuvray den regen Handelsverkehr mit West- und Mittelgallien; zahlreiche Metallwerkstätten und Giessereien bekunden wie auf dem Mont Beuvray auch die lokale Gewerbetätigkeit. Mit Recht schreibt Déchelette: „...des relations commerciales regulières reliaient Stradonitz avec la Gaule orientale, à travers l'Helvétie et la Vindélicie. Entre Bibracte et l'oppidum boïen une route de caravanes, jalonnée de comptoirs et de marchés..." Ob er es mit gleichem Recht von Anfang bis zu Ende als ein bojisches oppidum ansieht, das wie Bibracte in der ersten Hälfte des 1. Jahrhunderts bei den ersten Germaneneinfällen befestigt und etwa $12-10 \mathrm{r}$. Chr. beim Markomanneneinbruch erobert wurde, muss erst künftige Forschung feststellen. Pič erklärt es bekanntlich als eine markomannische Anlage. Die historischen Nachrichten können in verschiedener Weise gedeutet werden (vgl. zuletzt L. Schmidt, Gesch. d. deutschen Stämme II. 2, 1913, S. 145). Die Eroberung Böhmens durch Ariovist etwa 80 v. Chr. wird keineswegs allgemein zugegeben, und der Abzug der Bojer um 60 nach Pallnonien und Gallien (mit den Helvetiern) braucht nicht ohne weiteres auf das oppidum bei Stradonitz ausgedehnt zu werden. Das ausschlaggebende Wort haben also die Bodenfunde zù sprechen. Aber auch sie sind nicht eindeutig. Wie bei den meisten Höhenstationen sind einige ältere Funde vorhanden, die überwiegende Masse beginnt aber und endigt mit der SpätLa-Tènezeit (auch noch Fibeln des sog. Mittel-La-Tèneschemas). Fibeln, Glasringe, bemalte, geglättete und geritzte Tonware usw. entsprechen nun vielfach der älteren und jüngeren rheinpfälzischen Gruppe der Spät-LaTènegräber, die, wie wir sehen werden, den Scharen des Ariovist (Wangionen usw.) zuzuschreiben sind und oft nur durch Grabriten und andere Umstände von den gallischen Gräbern unterschieden werden können. Man lıat nun - wie ich glaube, mit einem gewissen Recht - angenommen, dass das oppidum von Stradonitz von Haus aus den Bojern gehörte, aber schon gegen die Mitte des 1. Jahrhunderts von Markomannen besetzt wurde, die, wie die Scharen des Ariovist auf dem linken Rheinufer, die gallische Kultur stark

1) Literatur Bremer a. o. S. 38, F. Kaufimann, Deutsche Altk. I (1914) S. 220.

2) Literatur bei Déchelette, Manuel II. 3 S. 981. 
anf sich einwirken liessen. Bei der Behandlung der Sueben werde ich auf diese Frage zurückkommen. Die Besprechung der Grenzen der Bojer in Süddeutschland würde hier zu weit fülnren. - Die bojische Kultur der Mittel- und Früh-La-Tènestufe erhellt am deutlichsten aus den grossen Skelettgräberfeldern Böhmens. ${ }^{1}$ ) In der frühesten La-Tènezeit (5. Jahrhundert) geht ihr voraus die von $P$. Reinecke cingehend behandelte gallische Kụltw der „Linsenflaschen“ in Nordbayern und Böhmen, die durch die Bojer um 400 nach Pannonien (Syrmien usw.) verdrängt wurde. ${ }^{2}$ )

Die böhmisch-ungarischen Funde zeigen Beziehungen einerseits zur donauländischen, andererseits zur mitteldeutschen gallischen Kulturzone, doch können sie hier nicht näher besprochen werden. Erwähnt sei nur, dass die ungarisch-siebenbürgischen Gräberfelder wichtiges keramisches Material der späteren Früh- und der Mittel-La-Tènezeit ergeben haben, das für len gleichen Zeitraum gerade in Südwestdeutschland (abgesehen von Bayern! noch ziemlich selten ist. So sind in dem Gräberfeld von Apahida. eine grössere Anzahl von Flaschen, Urnen, Kesselchen, Schalen usw. entrieckt worden, die wichtige Parallelen zu deutschen Funden bilden.3)

\section{Die Belgen (Mediomatriker, Treverer u. a.)}

1. Über die Ausdehnungund Kulturder Mediomatriker wissen wir verhältnismässig recht wenig. Nach den Angaben bei Caesar, Strabo und Plinius, die ohne Zweifel auf Posidonius zurückgehen, wohnten sie vor dem Ariovisteinfall zwischen Sequanern und Treverern bis vor an den Rhein, also in Rheinhessen, der bayarischen Rheinpfalz und vielleicht auch noch im unteren Elsass. Von Caesar wurden sie dem römischen Reiche einverleibt und spätestens 12 v. Chr. in eine zur Belgica gehörige römische Volksgemeinde (civitas Mediomatricorum) mit dem Vorort Divodurum (Metz) umgewandelt. ${ }^{4}$ ) Ihre Westgrenze gegen die Viroduner und Leuker dürfte durch die beiden Fines des antonimischen Itinerars an der Strasse Reims-Verdun-Metz bei Aulnois (Frèsnes-en-Woëvre) und an der Strasse Reims-Bar-le-Duc-Toul bei St. Germain-sur-Mense ${ }^{5}$ ) gegeben sein; die Grenze gegen die Trererer und Nemeten ist noch unsicher.

1) R. v. Weinzierl, Das La-Tènegrabfeld von Langugest (1899) S. 151.. 71; P. Reinecke, Festichrift d. Zentral-Museums 1902 S. 101 Anm. 57; L. Schneider, Mlitt. d. k. k. (:-Kommission XXVIII (1902) S. $116 \mathrm{f}$.

2) A. h. Vorz. V S. 287 (P. Reinecke).

3) Dolgozatok, Travaux de la section numismatique et archéologique du musée national à Kolosvár II (1911) S. 20 f. (J. Kovács), Profile der Flaschen und Urnen S. 24.7 Z der Flasche S. 36 Abb. 40 Nr. 1 vgl. 2. B. die elsässische Abb. 6 Nr. 9 (Suffelweyershejnı). Ebenda S. 69 die Literatur über die anderen ähnlichen Gräberfelder Ungarns.

t) Literatur: 0. Bremer, Ethnographie der germ. Stämme (1899) S. (11, F. Kauffmann. Deutsche Altertumskunde 1914 S. 216 Anm. 1.

i) $\mathrm{Xu}$ letzterem vergleiche F. Liénard, Archéologie de la Meuse I (1881) $\mathrm{S}$. 45, zu trsterem 11 (1884) S. 78 . Bilden sie zu römischer Zejt auch nur die Grenzen von civitates: oder pagi (Tullensis, Vallensis usw:), so dürften sie doch noch auf gallische \%eit zurückgehen, wie sie auch im Mittelalter in der Diöcesan- und Gaueinteilung Nachwirlimg gehabt haben (vgl. Mainzer 7tsichr. 1913:14 S. 1081.). 
R. Forrer: (Zur Ur- u. Frühgeschichte Elsass-Lothringens 1901 S. 32-34; vel. anch A. I'uchs, Die Kultur der keltischen Vogesensiedlungen 1914 S. 101 Amm. 1) leitet ihren Namen, wie auch K. Christ, von der elsässischen Moder (Matra) al) und lïsst sie erst nach Ariovists Eindringen in das untere Elsass nach L Lothringen auswandern, das vordem vielleicht den Virodunern gehört habe. Dic Benennung der Sequani nach der Sequana (Seine), der Elvii (Helvii) nach dem Elaver (Allier) u. a. möchte zwar eine Zurückführung auf cimen Flussnamen empfehlen, doch könnte man vielleicht ebenso an die Matrona (Marne) denken, ${ }^{1}$ ) indessen fehlt jeder Anhaltspunkt. Glück und Mehlis bringen den Namen mit der mataris zusammen, der „Nationalwaffe der Mediomatriker und Aeduer“" (Bonner Jahrb. 77 S. 74, Westd. Ztschr. IV [1885] S. 297 Anm. 1, Lindenschmit, Handlbuch I S. 207), mit noch weniger: Sicherheit.

Es bleiben also die Bodenfunde zu befragen. In der Früh-La'Tèneperiode begegnen in $R$ heinhessen und der bayerischen $R$ heinp f aly sehr: zahlreich jene hohen Flaschen, die schon oben als charakteristisch für das.Trevergebiet und den rechtsrheinischen Streifen zwischen Siebengebirge (bzw. Lahn) und Neckar erwähnt wurden. Die im Trevergebiet bis Koblenz und Westerwald (Nass. Ann. 41 S. 125) so häufige Kreisselform (K. Koenen, Gefässkunde Taf. VII. 1, Abb. 6 Nr.1 u. 5) kommt südlich der Nahe allerdings nur noch gelegentlich vor (ein schönes Exemplar von Leeheim in Starkenburg im städt. Museum zu Mainz), auch dic hochhalsige Form, wie Abb. 6 Nr.10 (Osburg im Hochwald, Braubach) ist hier seltener (aber auch in Schierstein, Nass. Annalen 41 S. 125, und bei Frankfurt),, ) dagegen herrschen die schön geschwungenen Birnformen vor, wie Abb. 6 Nr. 8, 11, 12 (Budenheim, Nierstein, Zornheim, Mommenheim usw.). In der baverischen Pfalz, wo solche Flaschen nach freundlicher Mitteilung. F. Sprater's beim Jagdhaus Ramstein bei Altdorf, Otterberg, Dannstadt (Mus. Speyer, Mitt. d. hist. Ver. XXV [1901] S. 11) und bei Eisenberg (Mus. Dürkheim) gefunden sind, begegnen die gleichen Formen, doch wiegt der Typus Abb. 6 Nrr. 7 u. 11 vor, allerdings mit einer gewissen Iokalauspr:ägung. Die stark profilierte Flasche von Ramsen (Abb. 6 Nr.6) war vergesellschaftet mit einer Bronzefibel vom Früh-La-Tèneschema mit roter Korallenscheibe auf dem Fusse (A. h. Vorz. V S. 332 Nr. 1058, P. Reinecke), die der oben S. 246 geschilderten Stufe I b angehört. Die älteren Früh-Ta-Tèneflaschen zeigen im allgemeinen keine Wulstringe an Hals und Schulter uud keinen besonders abgesetzten Fuss, erst gegen die Mittel-La-Tènezeit $\mathrm{zu}$ bilden sich diese aus (vgl. Abb. 6 Nr.2, 7, 9).

Aus der Mittel-La-Tènezeit sind gesicherte gallische Skelettgrä̈uer in Rheinhessen und in der bayerischen Pfalz bis jetzt erst in geringer Zahl ermittelt, doch kommen ausser Hackenheim, Wolfsheim (Alt. h. Vorz. $T$ S. 80), Wachenheim (ebenda S. $104 \mathrm{Nr} .333$ ), Wiesoppenheim (Abb.9 Nr. 5)

1) Vgl. auch Metiosedum (Meudon) gegenüber der Marnemündung. A. Holder, Altkeltischer Sprachschatz II (1904) S. 522 u. 579.

2) Im hist. Museum zu Frankfurt, von Praunheim und Oberrad, vgl. G. Wolff, Frankfurt und seine Umgebung (Hendschels Luginsland H. 41, 1913) S. 48, Abb. 
now Heppenheim a. d. Wies (W. Ztschr. III S. 180), Eimsheim, Monsheim, ('sthofen. Ludwigshöhe $u$. a. in Betracht, wo zum Teil mitteu unter Brandgräbern auch Bestattungen lagen. Ausserdem sind kürzlich in der Gegend ron Speyer und in Oberbayern anch gesicherte Brandgräber festgestellt worden (Mainzer Ztschr. YIII-IS [1911] S. 112, P. Reinecke), welche einem allerdings sehr späteu Abschnitt der Mittel-La-Tènestufe angehören, so dass auch unter clen übrigen Brandgräbern Rheinhessens noch manches Grab hierher z.u rechnen sein wird. Immerhin fällt gegenïber den Hunderten roụ Gräibern der Früh- und Spät-La-Tènezeit ihre verhältnismässig geringe Zahl auf. Diese Lïcke, die sich zwar sicherlich durch schärfere Scheidung gallischer und germanischer Brandgräber noch etwas schliessen wird, mag mit Völkerbewregungen dieser Zeit zusammenhängen, vielleicht auch mit Einwirkungen cles Cimbernkrieges, der schon vor dem Ariovistzug (zwischen S0-70 v. Chr.) gerade dieses (iebiet stark betroffen hat. Die Beigaben der Skelettgräber, die gleichen Wafien bei den Männern, der sleiche Schmuck bei den Frauen, erimern eigentlich mehr an die Kultur der Helvetier als an die der Treverer (Gïrtelkette von Hackenheim, Metz usw., zahlreiche farbige Glasringe, selten Tongefässe), doch rurden Waffen wie Schmucksachen weithin ausgeführt, und den greichen charakteristischen Gürtelschmuck haben die gallischen Frauen Nordostfrankreichs, ganz Westdeutschlauds, der Schweiz, Barerns und Böhmens getragen (vgl. Déchelette, Manuel II. 3 S. $1230 \mathrm{f}$.).

Aus dem Elsass ist bis. jetzt wenig Früh-La-Tènekeramil bekannt. doch weisen die zwei Flaschen bei A. W. Naue, die Denkmïler der rorrömischen Metallzeit im Elsass (1905) Taf. VII Abb. 54 u. 55 u. a. ${ }^{1}$ ) anf eine Kultur. die der des Treverergebietes schon ferner steht. Auch aus der eigentlichen Mittel-La-Tènezeit sind im Elsass bis jetzt die Funde sehr diirftig. Im ganzen werden wir also sagen dürfen, dass das unterc Elsass (Modergehiet) schwerlich der alte Hauptsitz der Mediomatriker war, vielmehr Rheinhessen und Rheinbayern. Wenn sich hier in der Frül-La-Tènezoit ein den Treverern nahe verwandter Stamm nachweisen lässt, so können wir allerilings nicht ohne weiteres die Medionatriker in ihm erblicken, wenn sie anch späterhin der Belgica zugeteilt wurden, da wir nicht wissen. ol: sie von Haus aus zum Trevererverband gehörten. Wenn ihre Keramik leichte thänderungen gegenüber der treverischen zeigt, so kömnte z.un Vergleich ihro Münzprägung herangezogen worden, die bei aller Gemeinsambeit loch eine gewisse Selbständigkeit gregenüber dor treverischen bewahrt rvgl. R. Furrer, Kelt. Numismatik S. 370 unter Mediomatriker). Auch die Terbreitung der für das lothringische und luxemburgische NediomatrikerGebiet " charakteristischen ,Hïtengrabsteine“ spricht nicht für das Flsass

i) Vgl. It. Henning. Jenkmäler d. els. Alt.-Sammlung zu Strassburg 1912 S. 11 , Tat. X . Ir. 1 (Niederrödern) und 15 (Suffelweyershein). die sich aber schon mehr den Nittel-La-Tinseharaktrif nähern, namentlich die letztere, die auf der Drehscheibe hergotalli ist. 
als ihre urspr:iungliche Heimat, wenn jene Grabhäuser auch bis in die Gegend von Zabern vorkommen. Gehören sie anch der römischen Periode an, so wurzeln sie doch in älterer keltischer Anschauung (vgl. A. Fuchs, Die Kultur der keltischen Vogesensiedlungen 1914 S. 31, 166 u. s.). Weitere Grabfunde im Elsass werden die Frage wohl zur Entscheidung bringen.

Von ihren Hauptfesten sind bekannt Divodurum (Metz) ${ }^{1}$ ) am Zusammenfluss von Mosel und Seille, Tbliodurum am Utbergang der uralten Völkerstrasse Metz-Verdun über den Yron westlich von Mars-la-Tour," $)$ Ve(i)rodunum (Verdun) an der Maas. Es ist geradezu auffallend, wie wenige gallische Funde vorrörnischer Zeit an diesen Orten bis jetzt.entdeckt sind, doch gilt dasselbe ja z. B. auch für Mainz, wo die tiefgründige römische Bauweise gleichfalls mit den Utberresten der vorausgehenden Kulturen gründlich aufgeräumt hat. Vielleicht bringt die so dringend wünschenswerte Untersuchung des mächtigen Ringwalls auf dem Donnersberg, der ron Mediomatrikern und Wangionen herrühren dürfte, einiges nene Material, ebenso die verschiedener anderer Höhensiedlungen, auf die schon Keune (Korr.-Blatt d. Ges. Ver. 1911 S. 407) hingewiesen hat.

Auch das oppidum bei Sainte-Geneviève bei Essey-les-Nancy, das Beaupré untersucht hat, wird von Déchelette, Manuel II. 3 S. 968 f, den Mediomatrici zugeschrieben, wofür ja allerdings die vielen Münzen desselben sprechen (aber auch der Lenci). Wie auf dem Mont Beuvray begegnen auch hier viele „italísche“ Amphorenreste, Glasringe usw. und beschränken sich auf die Spät-La-Tènestufe, wie die Funde so vieler Ringwälle in Frankreich und Deutschland. Über andere oppida der Mediomatriker und Leuker vgl. J. Beaupré, Les études préhistoriques en Lorraine 1902 S. 125. - Mehrere Bruchstücke blauer und gelber Glasiinge, keltischer Münzen usw. der Sammlung Merciol aus der Umgebung von Vic-Marsal (im Museum zu Metz) beweisen, dass an dieser berühmten Salzsiedestätte auch zur späteren La-Tènezeit Mediomatriker sassen und den 'Seg'en des Bòdens auszubeuten verstanden. ${ }^{3}$ ) - In der bekannten Herapel-Höhensiedlung fellen dagegen bis jetzt geșicherte (Mittel- und) Spät-La-Tènegegenstände, abgesehen von den gallischen Münzen beim Heiligtum, so dass Keune die ständige Besiedlung erst seit Tiberius annimmt. ${ }^{4}$ )

1) Literatur über das vorrömische Divodurum(on) zuletzt bei Keune, Gesch. cl. Stadt Metz, Festschr. d. deutschen Technikerverbandes, Metz 1914 S. 188 f. (besonders der Artikel Keunes in dem Werke Lothringen und seine Hauptstadt 1913 S. 39-59). Vgl. auch Espérandieu, Rec. V (1913) S. 377 f. und die verdienstvolle Arbeit von A. Grenier, Habitations gauloises et villas latines dans la cité des Médiomatrices, Paris 1906.

2) Über die Lage von Ibliodurum vgl. F. Liénard, Archéologie de la Nleuse II (1884) Karte pl. I, Text III (1885) S. 139 unter Ibliodurum. Über Verdun S. 143 unter V. Die Station Fines des antoninischen Itinerars zwischen Virodunum und Ibliodurun, unmittelbar am Fusse der Felsenmauer des Woëvre-Gebirges, bezeichnet sicherlich eine uralte Stammesgrenze, sogut wie Fines am Vinxtbach zwischen Ober- und Untergermanien. Vgl. jetzt auch VII. Ber. d. röm.-germ. Kommission 1915 S. 212 f. (B. Keune).

3) Vgl. Jahresber. d. Ges. f. Lothringische Geschichte u. Altertumskunde II (1890) S. 370 f. u. s., VII. Ber. d. röm.-germ. Kommission 1915 S. 227.

4) Korr.-Bl. d. Ges. Ver. 1911 S. 408: 
2. Dass die Treverer an politischer und kultureller Bedeutung die anderen Belgen weit überragten, berichten die antiken Schriftsteller ${ }^{1}$ ) und bestätigen die Bodenfunde rollauf. ${ }^{2}$ ) Beiderseits des Mosel-, Saar- und Nahetales bis ror an den Rhein und jeuseits desselben, im Hunsrück und in der Eifel, bis in die Ardennen finden sich schon von der frühesten La-TèneZeit an Grabhïgelnekropolen von einer Zahl und einem Reichtum der Alusstattung, wie in wenigen Gegenden Deutschlands. Erinnert sei nur an die „Fürstengräber" mit ihren Goldschätzen von Besseringen und Weisskirchen an der Saar, Remmesweiler (Kr. St. Tendel), Schwarzenbach (Fürstentum Birkenfeld) bis $W$ aldalgesheim und Urmitz am Rhein, einen Teil der grossen Grabhügelfelder ron Hermeskeil, rom Priesberg, bei Birkenfeld, ron Moluren usw., die eine hohe Blüte der Landschaft gerade in der Früh-La-Tènezeit verraten. Besonders charakteristisch sind die Fasengefïisse, Flischen. Näpfe, Schalen, Humpen mit den hohen Füssen nach archaisch-griechisehen und frühhellenistischen Vorbildern (und namentlich Brouzegefässen) mit eingeritzter oder häufiger eingeglätteter und geschwärzter Metopen-oder Baniverzierung (Fischgräten- und Zickzackmuster, Dreiecke mit Strichelıng" oder Gitterung, kleine Kreise usw.), aber keine buntbemalte Gefaisse, wie sie in dieser Periode im Marnegebiet so häufig sind. Wie die mitgefundenen griechisch-italischen Bronzen und Vasen lehren, gehören sie dem Ende des: 6., dem 5. und 4. Jahrhundert an.

Das für Südwestdentschland so charakteristische Iuventar der Mitte]La-Tènezeit ${ }^{3}$ ) lässt sich für das Treverergebiet bis jetzt kaum heransschäilen. hauptsächlich, weil hier die sog. Früh-La-Tèneformen sich in grosser Zähị̆keit bis weit in die Mittel-La-Tènezeit hinein halten und dann eine grosse Störung eintrat. Unter den gewöhnlich der Frühstufe zugeschriebenen Flaschen sind mehrere, die durch ihre starkgeschweiften Profile, die Holllkehlen bzw. Rippen, besondere Fussringe usw. ihre jüngere Entstehung. verraten. Dies wird auch durch ein (noch nicht veröffentlichtes) Grab vou Braubach bestätigt, das eine solche Flasche und Omphalosschale nach Hodrwigs Beobachtung mit Leichenbrand enthält (Abb. 9 Nr. 4, 10). Auch dic Schale dieses Grabes unterscheidet sich von den älteren durch etwas schärfere Bauchkante und weniger wulstigen Mündungsrand, ebenso wje durch die Farbe. Auch andere Gefässe und zahlreiche S(herben des Colblen\%er und Oberlahnsteiner Museums weisen durch feinere schwarze Technik, breite grewölbte Wïlste usw. schon auf die Mittel-Lá-Tènezcit hin, desgleichen mehrere starkgeschweifte Flaschen aus Rheinhessen und vom rechten Rheinufer (vol. anch die Mittel-La-Tèneflasche Abb. 3). Ein Grab) aus dem Walcle Klopp hei

1) 0. Bremer a. 0. S. 38 f., 63 f. - A. Kiekebusch, Ner Einfluss der rönischen liultur auf die germanische 1908 S. 58 f. - F. Kauffmann, Deutsche Altertunskunde 1 S. 212 f.. 237 .

2) Materialien z. B. bei: F. Hettner, llustr. Führer, Trier (1903) S. 123 f. - H. Lelwer. Jahresber. d. Ges. f. nützl. Forschung zu Trier 1894. - H. Baldes-G. Behrens, Kalalogr Birkenfeld 1914 S. 50 1. - A. Günther, Mannus III (1911) S. 13 f. (Coblenyer Gegen(1). - Vgl. auch Déchelette, Manuel 11. 3 S. 1064.

3) Vereinzelte Beispiele sind natürlich vorhanden, so die farbigen (ilasringe ('Trier(.) Jahresber. II [1909] S. 161. E. Krüger). 
Birkenfeld enthielt „auf einer breiten Holzkohlenschicht“ eine ähnliche Flasche (allerdings ohne Fussing) und eine gleichverzierte Omphalos-Schale wie das von Braubach (Baldes-Behrens, Birkenfelder Katalog S. 42 Abb. 12). Auch die (etwas ältere) Flasche von Hirstein mit ihren Schulterriefen und dem leichten Fussansatz (Birkenfelder Katalog Taf. XIII, 4) gehört bereits einem späteren Abschnitt der Früh-La-Tènezeit an, wie auch die mitgefundenen Gefässe und Schwerter verraten (Text S. 51). Das Vorkommen des, wie es scheint, gut beobachteten Leichenbrandes sowohl bei Birkenfeld wie Braubach in einer noch verhältnismässig frühen Zeit ist noch nicht völlig aufgeklärt. In Nordostfrankreich herrschte am Ende der HallstattPeriode Leichenbrand, wie namentlich die 78 sorgfältig ausgegrabenen tumuli von Haulzy (nördlich von Vienne-la-Ville am Argonnenwald) lehren, sowohl mit Spät-Hallstatt- als bereits Früh-La-Tène-Inventar im allmählichen Ưbergang (vgl. G. Goury, L'enceinte d'Haulzy et sa nécropole 1911 S. 59 f.). Ähnliches ist auch in der Eifel (Mehren und Mayen) und im Hunsrück (Hermeskeil) festgestelt. Z. B. enthalten die wirklich gesicherten Brandgräber von Mehren (Trierer Jahresber. 1894 Taf. I 31-34) noch Spät-Hallstatt-Typen, ebenso in Hermeskeil (Taf. VI, 8-11), während die noch erkenntlichen Skelettgräber (wie Taf. IV, 17-24) Früh-La-Tèneformen bringen, doch ist.. nach Hettners und Lehners Bericht mehrfach eine Mischung vorhanden. Auch in Mayen bergen Brand- und Skelettgräber bisweilen das gleiche Grabinventar (vgl. Mainzer Ztschr. 1913/14 S. 108). Während Déchelette (Manuel II. 3 S. 1015 f.) einen allmählichen Übergang von Verbrennung zur Bestattung innerhalb desselben Volkes annimmt, namentlich durch die Eroberungszüge veranlasst, denken andere Forscher an Stammesverschiedenheit (Ligurer und Kelten usw.), doch kann diese Frage hier nicht weiter erörtert werden (vgl. röm.-germ. Korr.-Bl. 1913 S. 42). Es genügt die Feststellung, dass im Belgen- bzw. Treverergebiet Leichenbrand bis in die Früh-La-Tènestufe hineinragt, so dass in den oben genannten Fällen nicht ohne weiteres ein Zusammenhang mit den gallischen und germanischen Brandgräbern der Mittel-La-Tènezeit erblickt werden muss. Doch bedarf die Frage des Grabritus im ganzen Belgengebiet eingehenderer Untersuchung, die zweifelsohne zu wichtigen Ergebnissen führen wird.

Auf unserer Abb. 9 sind Nr. 3-5 und Nr. 10 noch keltische Mittel-LaTènetypen, wobei aber Nr. 3 (aus einem [keltischen?] Brandgrab bei Dudenhofen, Mus. Speyer) schon etwas jünger als Nr. 5 (Wiesoppenheim, Mus. Worms) ist; alle anderen gehören der germanischen Spät-La-Tènezeit an.

Die Entwicklung der hohen Fussschalen (Fussschüssel bzw. des Kelches) steht bereits von der Früh-La-Tènezeit an ziemlich klar vor Augen, da das Marnegebiet eine Reihe Exemplare ergeben hat. Im Trevererland sind sie schon etwas abgeändert; nicht gerade häufig in Rheinhessen und Rheinbayern, treten sie rechtsrheinisch in Manching wieder zahlreicher auf und halten sich bis in die Spät-La-Tènezeit hinein (Déchelette, Manuel II. 3 S. 1487 Nr. 3, in einem Grab von Speyer, Elsheim, Mainzer Ztschr. 1913/14 S. 135 Abb. 19 usw.). 
In der späteren Mittel-La-TèneZeit zeigt sich eine grosse Veränderung im ganzen Treverergebiet: die Zahl und Grösse der Grabhügel verringert sich ausserordentlich, die Konstruktion derselben wird einfacher, die Ausstattung der Toten dürftiger, an Stelle. der Skelettbestattung treten Brandgräber, neue Gefässformen tauchen auf. Dieser Wechsel beruht, wie ich mehrfach anderweitig hervorgehoben habe, 1) wenigstens teilweise auf dem Einfluss der Germanen, die um diese Zeit in das Gebiet der Belgen eindringen und sich mit ihnen mischen, wie auch Timagenes, Caesar, Tacitus u. a. erkennen lassen.2) Die Funde vom Prieslierg bei Bosen, im Walde Klopp bei Birkenfeld, im Walde Brand bei Dienstweiler $u$. a., die aus kleinen (von den übrigen geschiedenen) Gräbergruppen stammen (A. h. Vorz. V S. 32, Taf. 8 Nr. 145-147, Birkenfelder Katalog S. 38 Abb. 9, S. 121), ebenso wie im Trierer Gebiet verschiedene Fundorte, unterscheiden sich in ihrer ganzen Art von der bisherigen Grabausstattung und enthalten kessel- und eimerförmige Gefässe und Näpfe mit scharfen Bauchkanten und umlanfenden Rippen, Omphalosschalen einfacherer Art und andere Gefässformen, die zwar auch meist auf gallische Vorbiller zurückgehen, aber nicbt selten Ubertreibung oder Verflauung der ursprünglichen Profile ver-

1) Vgl. Ber. d. rüm.-germ. Kommiss. 1955/06 S. 18, Germanenkatalog 3. Aufl. S. 103, Fraeh. Z. IV (1912) S. 101 f. und H. Baldes, Mainzer Ztschr. VI (1911) S. 44 f., Birkenfelder Katalog 1414 S. 121.

2) Vgl. F. Cramer, Röm.-gern. Sludien 1914 S. 551.

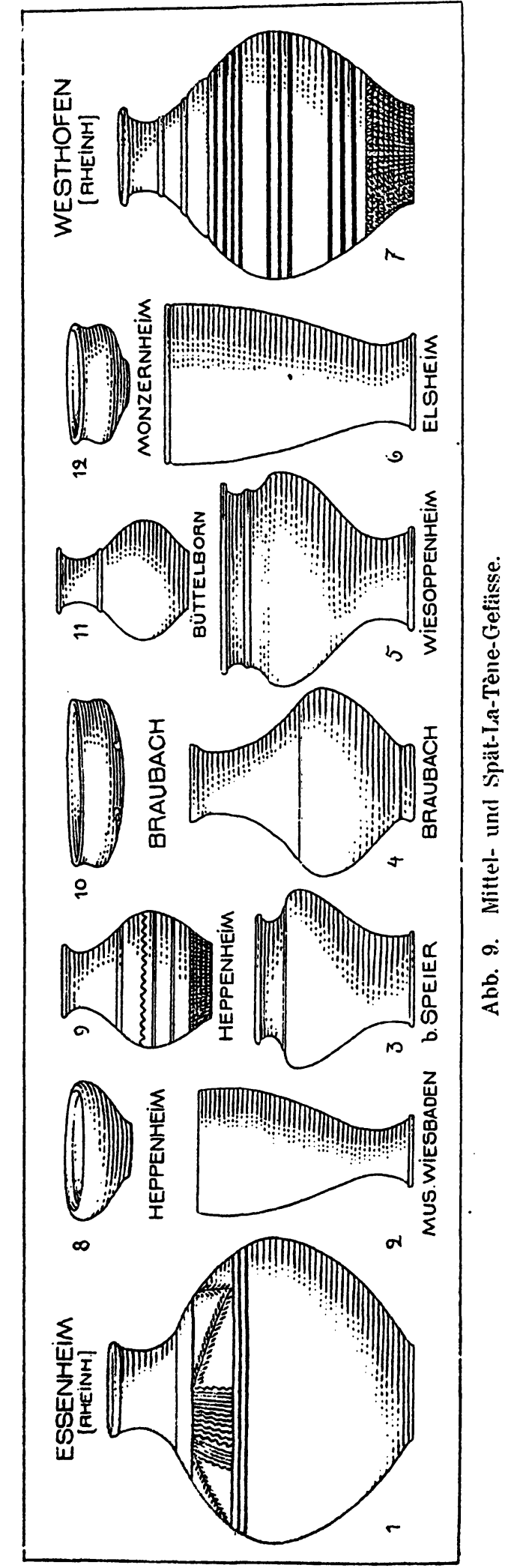


raten; auch rein germanische Formen begegnen, wie sie auf dem rechten Rheinufer geläufig sind.

Fïr die Spät-La-Tènezeit kommen vor allem in Betracht die Gräber von Biewer (nach E. Krüger, röm.-germ. Korr.-Bl. 1913 S. 17,22, etwa 50 -30 v.Chr.), Grügelborn (Korr.-Bl. d. Westd. Ztschr. XVII [1898] S. 17 f., H. Lehner), Hüttigweiler (nach Krüger a. o. etwa 30-10 v. Chr.), Roden a. d. Saar (Korr.-Bl. Westd. Ztschr. 1907 S. 69 f., E. Fölzer), ${ }^{1}$ ) Hirstein (Birkenfelder Katalog S. 62, Taf. XIV), die, wie namentlich Sötern (Trierer Jahresber. II [1909] S. 95 f., H. Baldes), allmählich schon in die römische Zeit übergehen, älnulich wie auch Mühlbach am Glan (Westd. Ztschr. IV S. 283 f., Taf. XV bis XVIII, W. Harster), Maxfeld u. a. In der Besprechung des Gräberfeldes von Roden a. d. Saar hat E. Fölzer (a. o. S. 72) bereits darauf hingewiesen, dass im ganzen Trevererland bemalte Gefässe nach Art derer vom Mont Beuvray im allgemeinen nicht. gefertigt wurden, wenn auch einzelne daran erinnernde Ausnahmen, wie der bemalte Krug von Roden (a. o. S. 72 Abb. 6) oder die Krüge von Grügelborn, Lauterbach usw. mit roten Farbstreifen (Trierer Jahresber. III [1910] S. 20-21, E. Krüger) usw., namentlich in dem südwestlichen Landesteil vorkommen; die noch auf die Keramik frührömischer Zeit Einfluss übten.

Auch in Nordgallien (Armorica) und Britannien erscheinen von der Früh- bis zur Spät-La-Tènezeit keine bemalten Gefässe wie in Mittelfrankreich usw., dagegen mit sehr reicher gravierter Verzierung versehene, die ebenfalls südliche Vorbilder vor Augen hatten (J. Déchelette, Rev. arch. 1901 II S. 51 f. und Manuel II, 3 S. 1467 f.). Die Verzierungsweise ist bei den bemalten wie bei den gravierten Gefässen rein gallisch; Form und Technik ist bei beiden durch italisch-griechische Vasen und Bronzegeräte beeinflusst. Die Treverer-Gruppe bildet durch ihre eingeritzten, eingeglätteten und schwarzaufgemalten geometrischen Muster eine Zwischenstufe, die aber weit hinter der Mannigfaltigkeit jener zurücksteht und im allgemeinen schon mit der Mittel-La-Tènezeit ihr Ende hat. Die Hauptverkehrsader mit Gallien war auch in der späteren La-Tènezeit für das Treverergebiet die grosse gallische Mittelstrasse vom Atlantischen Ozean über Lutetia (Paris)-Durocortorum (Reims)_Orolaunum (Arlon) oder Divodurum (Metz), die jenen Töpfereien der bemalten Spät-La-Tènekeramik des Aeduerlandes schon ferner lag.

$\mathrm{Ob}$ die feinen Drehscheibeschüsselchen von Roden (a. o. Abb. 7 u. 8) ebenso wie die von Hirstein (Birkenfelder Katalog Taf. XIV 23-25) und die feineren geschwungenen Kelchgefässe wie von Hirstein (Taf. XIV 18) eingeführt oder an Ort und Stelle nach fremden Mustern hergestellt sind, mag einstweilen dahingestellt bleiben. Auch hier lässt sich eine ältere und eine jüng'ere Gruppe unterscheiden, nach den Fibeln und Tongefässen, ähnlich wie an Rhein. Die Fibeln von Biewer (röm.-germ. Korr.-Bl. 1913 S. 18 und 19 Abb. 7 und 8) bekunden mit ihrem Querbalken über der Spirale schon eine etwas fortgeschrittenere Entwicklung gegenüber denen des Jahres 52

1) Vgl. auch F. Hettner, Trierer Jahresiber. 1898 S. 34 f. 
aus den Gräben von Alesia (Montelius-Festschrift S. 243 Nr. 5 u. 6) und der älteren Schicht von Nauheim; die auf dem Brandplatze bei Hirstein gefundenen Fibeln (Birkenfelder Katalog S. 64 Abb. 29, 1, 2) sind noch voraugusteisch, aber nach etwa 50 (vgl. die Scharnierfibel von Alesia, Montelius-Festschrift S. 242 Abb. 1). Die in Roden, Hirstein, Mühlbach a. Glan, im Mittel- und Oberrheingebiet so häufigen tonnenförmigen Gefässe, in ihrem südwestlichen gallischen Heimatland wie in Basel und auf dem Mont Beurray noch feinste bemalte Drehscheibearbeiten, sinken im Treverer-Belgengebiet zu oft recht plumpen, höchstens sorgfältiger geglätteten, aber meist unbemalten Nachahmungen herab, bei denen die Füsse bzw. Standflächen und Mündungsränder nur noch in einigen wenigen, meist etwas älteren Beispielen (Roden, Geisenheim) sorgfältiger ausgearbeitet sind. Und Ähnliches ist bei den Kelch-

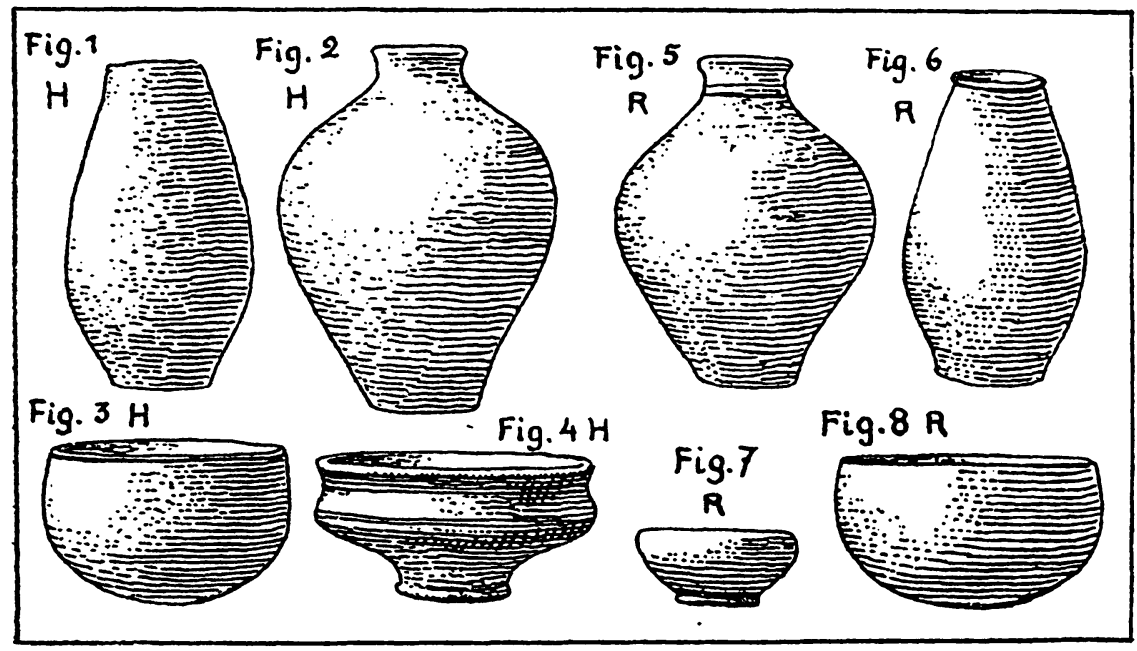

Abb. 10. Tongefässe von Hirstein und Roden.

gefässen. Krügen und anderen Formen (Schüsseln, Eimerchen usw.) zu beobachten, wenn auch gelegentlich bei sorgfältigen jüngeren Arbeiten die feinere Profilierung der älteren Zeit sich wiederfindet. Auch treten nun häufiger Vermengungen zweier ursprünglich verschiedenen Gefässformen auf. So zeigen die tonnenförmigen Humpen, welche auf dem Mont Beuvray und in Basel, auch noch zum Teil bei den älteren und besseren Exemplaren in Roden und ähnlichen ihre grösste Ausladung meist im unteren Teile des Bauches hatten, dieselbe nun auch im oboren Teile, offenbar unter dem Einfluss von Kelchen und anderen Humpenformen; in Hirstein enthält ein Grab heide Formen nebeneinander (Birkenfelder Katalog Taf. XIV. 8, 11). Dje Hirsteiner Gräber sind so typisch in ihrer Ausstattung mit förmlichen .Servicen“ (grosses Vorratsgefäss, verschiedenartige Humpen, Trinkschalen, Schüssel, kleine Kugclurne usw.), dass man an eine Fortsetzung früherer keltischer Gebräuche denken möchte, also noch an eine keltische, aber kulturell zurückgegangene Berölkerung. Allerdings kommen in den reicheren Nanheimer Gräbern, die doch sicher germanisch sind (wie bei Quilling Nr. 29, 
$38,54,75,83$ ), ähnliche Sätze verschiedener Tongefässe (etwa vier bis fünf) vor, doch fehlen bei den Hirsteiner Gräbern die hier so beliebten Eimer und, wie es scheint, auch die Waffen.

Im alten Trevererlande nördlich der Nahe bis vor an den Rhein habeu sich die keltischen und keltisch-germanischen Formen der Spät-La-TènePeriode viel zahlreicher in die römische Zeit hinüber gerettet als südlich der Nahe im Wangionen- und Nemetergebiet, wo die Kelten früher und kräftiger von den Germanen verdrängt wurden. Doch können wir nicht näher auf diesen Gesichtspunkt eingehen und begnügen uns mit dem Hinweis auf die tonnenförmigen Urnen (wie Westd. Ztschr. XIX Taf. X. 6, 11), auf die kelch- und humpenförmigen Becher (Nass. Annalen 40, 1912 S. 341), die so zahlreichen henkellosen Krüge, Vorratsgefässe, Kochtöpfe, Schüisselu und Schalen (vgl. z. B. die vortreffliche Behandlung der ,belgischen“ Ware ron S. Iöschcke, Mitt. f. Westfalen V, 1909, S. 258 f.).

Dass auch in der rechtsseitigen Rheinebene noch in der Spät-La-TèneZeit Gallier ungestört unter den Germanen sassen, beweisen die Funde ron Braubach (Nass. Annalen XXXIII S. 28 f.), das gesicherte Skelettgrab ron Winkel (Nass. Annalen, Mitt. XIII [1910] S. 121) und einzelne Gräber ron Ladenburg. An letzterem Orte deckte z. B. im Jahre 1906 der Vorsitzende des Mannheimer Altertumsvereins, Major von Seubert, ein Spät-La-TèneGrab auf mit leichtzusammengebogenem Schwert, .Messer, Schildbuckelrest, Schere, zwei Tonschalen und einem Teller, das, wie ich selbst an Ort und Stelle mich überzeugen konnte, ein Brandgrab war, obwohl es genau'wie ein Skelettgrab viereckig und 1,65 $m$ tief in den Boden eingeschnitten war, doch hatte die Grube nur 1,30 $m$ Länge bei 0,60-0,65 m Breite. ${ }^{2}$ ) Diese Tatsache lässt sich doch wohl nur in der Weise erklären, dass die betreffenden Jeute als Gallier noch kurz vorher die Leichenbestattung ausübten, aber unter germanischem Einfluss zur Verbrennung übergingen. Von den Galliern, die nach den Bodenfunden und den Inschriften im Maintal noch in römischer Zeit inmitten der germanisch-römischen Bevölkerung lebten, wollen wir hier nicht jeden und nur auf das allerdings nicht einwandfreie Skelettgrab des letzten Jahrhunderts v. Chr. von Heidingsfeld hinweisen (Mus. Würzburg; zuammengebogenes Schwert, Lanze, kegelförmiger Schildbuckel, Schere, vgl. Korr.-Bl. f. Anthr. 1901 S. 27 f., Mainzer Ztschr: 1913/14 S. 113, P. Reinecke).

3. Die übrigen Belgen liegen ausserhalb des Rahmens dieser Arbeit und können nur kurz g'estreift werden. Zu Caesars Zeit bewohnten die Belgen das Land zwischen Seine-Marne (bell. gall. I. 1, Gallos ... a Belgis Matrona et Sequana dividit), Nordsee und Rhein, allerdings in dem Gebiete

1) Auch der Krug und der Humpen A. h. Vorz. I. VI Taf. 6 Nr. 4 und 8 unbekannten Fundorts der Umgebung von Wiesbaden dürften wie die Gefässe des Grabes von Winkel gallische Erzeugnisse sein.

2) Vgl. A. h. Vorz. V S. 375 (K. Schumacher), Mannheimer Geschichtsblätter 1909 S. 33 Grab VI (K. Baumann). Neuerdings (Sommer 1914) hat E. Wahle in Heidelberg zwei gleiche Brandgräber für die städtische Sammlung erworben, das eine ein KriegerGrab mit ganz ähnlicher Ausstattung, das andere wohl ein Frauengrab mit zwei Tonkrügen. 
zwischen Schelde und Rhein stark mit Germanen durchsetzt. Die Südgrenze der Marne haben die Belgen indessen erst im Verlauf der späteren Mittel-La-Tènezeit erreicht, wahrscheinlich unter dem Druck der Germani cisrhenani von Norden her, da in der Frül-La-Tèneperiode zwischen Marne und Aisne noch Gräber von ganz anderem und viel reicherem Char'akter begegnen (vgl. Déchelette, Manuel II. 3 S. 1019). Die Remi werden damals noch weiter nördlich zwischen Maas und Schelde gesessen haben. Die aus der Champagne und dem Marnegebiet verdrängten Stämme sind bis jetzt unbekannt; man könnte an die Mediomatriker denken, falls ihr Name mit Recht von der Matrona abgeleitet wird, ähnlich wie es auch den Sequanern erging; doch spricht der oben geschilderte archäologische Befund in der Früh-La-Tènezeit nicht gerade dafür.

Die ärmliche Kultur der nördlichen Belgen (Caesar, bell. gall.. I. 1: proptera quod a cultu atque humanitate provinciae longissime absunt minimeque ad eos mercatores saepe commeant) ebenso wie die von Caesar geschilderte Mischung mit Germanen wird durch die Bodenfunde vollanf bes1ätigt. In der Früh-La-Tènezeit begegnen zwar noch im Maastal (wie bei Hygenbilsen und (Mook)') Ausläufer jener reichen Kultur, wie sie das Marnegebiet und die Rheinlande zeigen, späterhin aber herrscht ziemliche J)ürftigkeit sowohl in Holland ${ }^{2}$ ) und Belgien ${ }^{3}$ ) wie für das Gebiet der nördlichen Rheinprovinz.

Wie in Mittel- und Südfrankreich (vgl. oben S. 252) und in der Schweiz (z. B. Solothurn, Eschenz), dürfte auch für Belgien eine Kontinuität frührömischer und spät-la-Tènezeitlicher Töpfereien anzunehmen sein, wofür die Bodenständigkeit dieses Gerrerbes und das Fortleben mancher Formen sprechen. Eine solche Töpferei ist z. B. in der Umgebung von Longwy nahe der belgisch-luxemburgischen Grenze anzunehmen. Prof. Dr. F. VolbachTübingeu, der im letzten Kriege längere Zeit in jener Gegend sich aufhielt, macht mir über einige dortige Privatsammlungen, die neben der bekannten belgischen Ware schöne frührömische Krüge mit den starken Halsriefen enthalten, wie sie auch im Treverergebiet öfters begegnen, folgende Mitteilungen, die für die weitere Forschung Beachtung verdienen. „Die gallischrömischen Gefässe (der Sammlungen in Villette, Schloss Colmy usw.) sind sicher alle hier in der Gegend geformt und gebrannt. Noch heute ist ja diese Industrie in Longwy, das in der Nähe liegt, in höchster Blïte. Es werden in Longwy ganz originelle und sehr schöne Fayencen, die unan hier in allen Häusern sieht, im grossen angefertigt, charakteristisch durch die v. undervolle blaue Farbe. Das Material scheint mir ganz dasselbe wie bei den alten Sachen, der Platz der antiken Fabrik aber noch nicht erforscht zu sein."

Ain Schnitte der (auch bei F. Liénard, Archéologie de la Meuse II [1884] harte pl. I eingezeichneten) Römerstrasse Marville-Flassigny-Charency-

1) Literatur bei Dechelette 1I. 3 S. 1069 and 1606.

2) Vgl. J. H. Holwerda, Zur frühhistorischen Keramik (Nederlands vroegsto Beschaving, Leiden 1907 S. 100 f.).

3) A. de Loë, Annal. de la soc. arch. de Namur XXI (1895) S. 7 f. u. s. 
Tellancourt-Longwy mit einem Nebenweg nach Longuyon, auf der Hochebene nordöstlich Villette, konnte Volbach eine römische Ziegelei in der Nähe eines römischen und merowingischen Friedhofes feststellen: Auch die merowingischen Gefässe zeigen denselben feingeschlämmten, schabbaren, grauen Ton („terra nigra“) wie die römischen und späteren La-Tènegefässe und bekunden die Kontinuität der Töpfereien durch alle diese Perioden hindurch.

Auch die zahlreichen Sigillata-Manufakturen des Argonnenwaldes bei Lavoye ${ }^{1}$ ), Avocourt, Les Allieux, Lochères, Florent usw., ${ }^{2}$ ) westlich von Verdun, nahe der grossen römischen Verkehrsstrasse.Verdun-Reims und ihrer Seitenverbindungen, dürften in gallischer Zeit Vorgängerinnen haben, ebenso wie La Madeleine bei Nancy, Mandeure u. a. Sie liegen meist an oder in kürzerer Entfernung von bedeutenden vorrömischen und römischen Verkehrsstrassen, namentlich an Knotenpunkten, wo guter Töpferton ansteht.

Dass in den Argonnen auç die bemalte Ware hergestellt wurde, schon von der frühen La-Tènezeit $a b$, ist bei der Nähe des Marnegebiets fast selbstverständlich; aber auch in den Ardennen. ist sie vertreten, z. B. eine sehr charakteristische Urne von Saulces-Champenoises (bei Déchelette, Manuel II. 3 S. 1465 Abb.661, 2), doch dürfte sie hier wohl importiert sein aus dem Aisnetal, wo namentlich im forêt de Compiègne ein lebhafter Töpfe reibetrieb statthatte, oder aus der Gegend von Reims. Die bekannten Hauptfundplätze bemalter Vasen in der Umgebung von Reims (Prunay, Beine, Caurel-les-Lavannes, Bethény u. a.) ${ }^{3}$ ) liegen alle an gallischen und römischen Strassen, die von Reims (Durocortorum, Remi) ausgehen und die Einträglichkeit und Dauer des Töpfereigewerbes gewährleisteten. Reims selbst (mit Umgebung) ist wie Verdun sicher sowohl in der La-Tène- als in der römischen Zeit ein bedeutendes Zentrum des Töpferhandwerkes gewesen (ähnlich wie Trier) und hat schon in der Früh-La-Tènezeit Ware bis in die Eifel und den Hunsrück ausgeführt (z. B. vermutlich die schöne, auf der Töpferscheibe hergestellte Vase von Hirstein, Birkenfelder Katalog Taf. XIII. 1, verglichen mit Britisch Museum, guide 1905 S. 66 Abb. 57 u. a.). In der Spät-La-Tènezeit tritt hier allerdings die bemalte Keramik zurück gegenüber der des Aeduerlandes.

1) Röm.-germ. Korr.-Bl. 1909 S. 90 f. (W. Barthel), R. Forrer, Die röm. TerrasigillataTöpfereien von Heiligenberg (1911) S. 226 f., E. Fölzer, Die Bilderschüsseln der ostgall. Sigillata-Manufakturen 1913 S. $37 \mathrm{f}$.

2) Rev. arch. 1908 I S. 391 f., 1911 I S. 51 if. (G. Chenet).

3) Vgl. Album Caranda, L. Morel, La Champagne souterraine 1898, Britisch Museun guide 1905 S. 66 f., J. Déchelette, Man. II. 3 S. 1460 f. (wo Anm. 3 weitere Literatur). Auch die Erdbefestigung von Haulzy (oben S. 262) hat bemalte Früh-La-Tènekeramik ergeben. Sie liegt in der Nähe der römịschen Station Axona-Axuenna (= Vienne an der Aisne) an der grossen Strasse Reims-Verdun und dürfte als deren gallische Vorgängerin zu bezeichnen sein. 


\section{Die linksrheinischen Germanen: 'I'riboker, Nemeter, Wangionen, Ubier}

Die Bodenhinterlassenschaft der links he in is chen Germanen bietet uns die Möglichkeit, die Aingaben der alten Schriftsteller ${ }^{1}$ ) nicht nur nachzuprüfen, sondern auch in einigen Punkten zu erweiteru. Caesar macht zwar hinreichende Angaben über die Zeit der ariovist'schen Besitznahme des linksrheinischen Gebietes, ]ässt uns aber über die Ausdehnung derselben im unklaren und schweigt sich völlig aus über die Gestaltung der Dinge nach der Niederlage des Ariovist, wenn auch spätere Literaturberichte und die römischen Inschriften manche Rückschlüsse über die endgültige Ansiedlung: jener Stämme am linken Rheinufer durch die Römer gestatten.

Hier helfen mun die Bodenfunde ein gut Stück weiter. Von der Nahe bis südlich ron Strassburg, in der Rheinebene und am Gebirgsrande, sind viele Brandgräber (und Wohnstätten) der Spät-La-Tènezeit festgestellt, die sich durch Grabritus und Ausstattung von den gleichzeitigen gallischen wesentlich unterscheiden und mit Sicherheit den Scharen des Ariovist und deren Nachfolger zugeschrieben werden können. Am zahlreichsten sind sie in Rheinhessen, weniger häufig bis jetzt in Rheinbayern, verhältnismäßig selten im Unterelsass gefunden.

Leider hat das ausserordentlich umfängliche Material bis jetzt keine Znsammenfassung, ja sogar nur auffallend wenige und meist dürftige TeilVeröffentlichungen erfahren. ${ }^{2}$ ) Und doch wäre es bei der grossen Zahl geschulter Arbeitskräfte gerade in diesem Teile Deutschlands nur eine Geldirage, die wohl am ersten mit Hilfe der röm.-germ. Kommission in Frankfurt odcr einer wissenschaftlichen Akademie (z. B. der Heidelberger) zu lösen wäre. Infolge der Zersplitterung der Fundstücke und der Unbekanntschaft mit den Fundverhältnissen ist bis jetzt auch nie ein ernsterer Versuch zu einer schärferen chronologischen oder ethnischen Einteilung gemacht worden, die noch durch die Unzuverlässigkeit der vorhandenen Berichte erschwert wird. Weitaus der grösste Teil des älteren Bestandes ist bei gelegentlichen Weinberg- und Feldarbeiten zum Vorschein gekommen und entbehrt der Angaben über die Zusammengehörigkeit der Gegenstände. Namentlich aus Rheinhessen sind diese Zufallsfunde älterer Zeit in sehr

1) Aus der sehr zahlreichen Literatur seien nur hervorgelioben: R. Much, Die Südmark der Germanen (in Sievers Beiträgen z. Gesch. d. deutschen Sprache u. Literatur XVII (1898i S. 101 f.), Th. Burckhardt-Biedermann, Ztschr. f. d. Gesch. d. Oberrheins N. F. XXIV S. 394 f., O. Bremer, Ethnographie der germanischen Stämme $1899 \mathrm{~S}$. 57 f., L. Schmidt, Gesch. d. deutschen Stämme bis zum Ausgange der Völkerwanderung 11. 2 (1913) S. 1421., F. Kauffmann, Deutsche Altertumskunde I (1914) S. 239 f.

2) Die Bodenaltertümer der Wangionen sind in den Museen zu Mainz, Worms, Bingen, Kreuznach, Ingelheim, Alzey, auch in Darmstadt, Speyer und Wiesbaden aulbewahrt; die der Nemeter in Speyer und Dürkheim, der Triboker in Hagenau und Strassburg. Das rheinhessische Waterial ist zum Teil veröffentlicht in den Alt. heidn. Vorz. I-V, der Museographie der Westd. Ztschr., in der Mainzer Ztschr. 1-JX; dus rheinbayerische in den Jahresberichten des hist. Ifuseums der Pfalz (Milteilungen d. hist. Ver.), bei F. Sprater. Jie Urgeschichte der Pfalz, Speyer 1911. im "Pfälz. Museum" u. s.; tuber das elsässische vgl. Jorr.-Bl. f. Anthr. 1907 S. 59. Mainzer Ztschr. VI (1911) S. 14. 
grosser Anzahl vorhanden und fehlen nur bei wenigen Leutigen Dörferu. Sie beweisen, dass der fruchtbare und sonnige Landstrich gegenüber der Mainmündung nicht nur der Ausgangspunkt, sondern auch das Herz der germanischen Besitzergreifung war und blieb.

Dies dürfte auch die chronologische Untersuchung bestätigen, die aber bei der angedeuteten Beschaffenheit des Materials und der bäufigen Kontinuität der Besiedlung mit äusserster Vorsicht zu führen ist. Beispielsweise enthielten die (abgetragenen) Grabhügel bei Hahnheim.(Westd. Ztschr. XIV [1895] S. 380 f., L. Lindenschmit) gallische Skelettgräber der Frülh- und gerraanische Brandgräber der Spät-La-Tènezeit, die sich selbst bei sorgfältiger Ausgrabung nicht scharf scheiden liessen, nach unserer heutigen Kenntnis der Formen aber leicht zu trennen sind. ${ }^{1}$ ) Ferner liegen bei mehreren Friedhöfen gallische Skelettgräber der Mittel-La-Tène- und gallische und germanische Brandgräber der Spät-La-Tènezeit bunt durcheinander (vgl. oben S. 259), so dass auch wegen der völkischen Zuteilung grosse Schwierigkeit besteht, sobald nicht die ganzen Gräberinventare scharf auseinandergehalten sind.

Für eine nähere zeitliche Gliederung der. Spät-La-Tène-Brandyrä̈ber geben namentlich die Fibeln und Gürtelhaken, die Schwerter und die Keramik einige Anhaltspunkte. Obwohl die sog. Mittel-La-Tène-Fibel mit verbundenem Schlussstück bis in die römische Kaiserzeit hineinragt, wie ich sclion Anz. f. schweiz. Altk. 1892 S. 54 (vgl. A. h. Vorz. V S. $80 \mathrm{Amm}$.) dargelegt habe, lassen sich doch. bei näherem Zusehen verschiedene Entwicklungsstufen derselben erkënnen. Von der richtigen MittelLa-I'ènefibel aus Bronze und Eisen (gelegentlich auch Gold und Silber), wie sie so häufig in der Station La-Tène und den geschilderten helvetischen Skelettgräbern wie in dem von Dühren vorkommen, unterscheiden sich die jüngeren Formen der Spät-La-Tène- und römischen Zeit im allgemeinen durch gestreckteren und gedrückteren Bügel, feruer durch geringere Profilierung des Bügels und des Schlusstückes, welches allmählich ganz mit dem Bügel verwächst und dem Fuss der sog. Nauheimer Spät-La-Tènefibel gleicht, so dass das ganze Aussehen dem dieser Fibelform und ihren Weitergestaltungen nahekommt ${ }^{2}$ ) Weniger klargestellt ist noch die Abrwandlung des Gürtelhakens, obwohl auch für sie schon genügend Material zur Verfügung steht.

Ferner ist an den Schwertern, Lanzen, Schildbuckeln, Messern usw. eine ähnliche allmähliche Entwicklung von der Mittel- zur Spät-La-Tèneform zu beobachten, wiewohl auch hier bei der Langlebigkeit mancher Erscheinungen und in Anbetracht des Unterschieds zwischen Gross- und Kleinbetrieb der Herstellung grösste Vorsicht geboten ist, die bei der Anwendung des bekannten Tischler'schen Schwertschemas zum. Teil noch vermisst wird, während Tischler selbst stets zur Vorsicht mahnte.

1) Vgl. Korr.-Bl. f. Anthr. 1901 S. 28.

2) Ztschr. f. Ethn. 1911 S 685 (R. Beltz), oben S. 254; Déchelette, Manuel II. 3 (1914) S. $1253 \mathrm{Abb} .535$ und S. $1258 \mathrm{Abb} .538$. 
Beispielsweise ist das schöne Schwert von Heiligenstein (B.-A. Speyer, abgeb. A. h. Vorz. II. VII Taf. 6, 3) mit dem gleichen Stempel, den mehrere in La-Tène selbst und anderwärts gefundene Schwerter zeigen (VI. Pfahlbanbericht Taf. X. 7, XI. 23 und 24, Heierli, Urgesch. S. 346 Abb. 336), ohne jeden Zweifel aus weiterer Ferne eingeführt, wohl anch das Schwert des grleichen Typus mit verzierter Scheide aus einem (germanischen) 13randgrab bei Heidesheim (A. h. Vor\%. II. VII Taf. 6, 4), wiibrend mehrere andere ähnliche Schwerter aus germanischen Brandgräbern Rheinhessens durch ihre Plumpheit lokale Schmiedearbeit verraten. Und das gleiche gilt für die Lanzen, Messer, Scheren usw., von denen in Rheinhessen völlig gleiche wie die schönsten Exemplare von La'Tène zum Vorschein kamen, wenn auch olne Verzierung. Bei manchen dieser Funde wird crst eine spätere vergleichende Zusammenstellung, wie ich sie durch diesen Aufsatz anregen möchte, die Frage entscheiden können, ob sie aus einem gallischen oder germanischen Brandgrab stammen. Für die „germanischen“ Schwerter des Mittel-J_a-Tènetypus ist der tiefere Sitz ler Scheirlenöse (für den Tragriemen) charakteristisch, wie in Norddeutschlanı fast allgemein offenbar wegen der grösseren Länge der Schwerter (wie bei den richtigen Spät-IJa-Tèneschwertern), während bei den meisten Schwertern aus der Station La-Tène, die kürzer und zierlicher sind, jenc Gurtschleife weiter oben angebracht ist.

Deutlicher lassen sich in der Keramik ältere und jüngere SpätLa-Tène-Typen auseinunderhalten, die ersteren zum Teil natürlich mit grösserer Anlehnung an die Mittel-La-Tène-Typen in Form und Verzierungsweise. $\mathrm{Da}$ ein Teil der Tonware auf gallischen Import, ein anderer auf germanische Hausarbeit zurückgeht, ist der Gesichtspunkt grösserer oder geringerer technischer Vollendung ethnisch und chronologisch weniger massgebend, doch führt der Verglejch mit geschlossenen Gruppen, namentlich des rechten Rheinufers (Kultur der Ubier, Sueben usw.), häufig etwas weiter. Auf unserer Abb. 9 (oben S. 263) verrät z. B. die Kelchform aus dem germanischen Gräberfeld von Elsheim (Nr.6) und ähnliche von Essenheim und Heppenheim a. d. W. u. a. mit ihrer leichtgeschweiften Kontur und dem besonders abgesetzten Mündungsrand und Fuss noch deutlich das ältere Stadium ler Spät-La-Tènezeit, während die so zahlrejchen jüngeren germanischen Kelchformen meist fast geradwandig sind.1) Ehenso begeguen in diesen ilteren germanischen Brandgräbern noch mehrfuch Gefüisse, die der Form Nr. 3 (ron Dudenhofen) gleichen; dic späteren sind über der Standlïichle weniger reingezogen und entbehren der Wulstprofilierung an Miindung und

1) Schüne Beispiele der Früh-Ia-Tènezeit Album Caranda IlJ pl. 135 (Rev. arch.

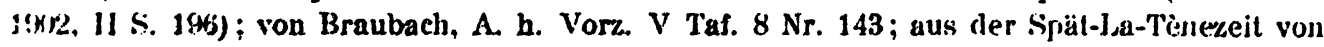
(irügelborı, Jnttigwejler (Mus. Trier), Flürshcim (A. h. Vorz. V Tuf. $70 \mathrm{Nr}$. 1311), Geisenlieim (A. h. Vorz. 1. VI Tai. 6, 9), (iaualgesheim (W. Ztschr. XX Tuf. 12, 11), lisselhorn (A. h. Vorz. IIl. VI Tal. 4, 3), Uilhofen, Bermersheim, Battelborn usw., doch komnt auch die geschwungene: liorm noch in der Spät-Ia-Tènczeit vor (\%. B. Hirstein, Birkenfelder Katalog Taf. XIV. 18 und wohl auch Abb. 9. 2, vom Iheingau. Mus. Wiesbaden). 
Fuss. $\left.{ }^{1}\right)$ Auch die Krüge, wie Abb.9 Nr.1 und 7, mit ihrer mehrfachen Halsund Schulterriefelung und den schwarz eingeglätteten Mustern ${ }^{2}$ ) stehen den gallischen Mittel-La-Tèneformen noch entschieden näher als die so zahlreichen einfachen Krüge von Heppenheim, Büttelborn (Abb.9 Nr.11), Nauheim usw. Dasselbe gilt von den Kesselchen, Schalen (vgl. Abb.9 Nr.12 und 8) und manchen anderen Gefässtypen.

Nach diesen Gesichtspunkten möchte ich als älteste dieser linksrheinischen Germanenstätten betrachten (abgesehen von den oben S. 263 f. erwähnten) noch folgende Fundstätten: Albig: A. h. Vorz. III. VI. Taf. IV.4; Alzey: VII. Ber. d. röm.-germ. Kommiss. (1915) S. 149 Abb. 68; Elsheim: Mainzer Ztschr. VIII/IX (1913/14) S. 135 Abb. 19; Essenheim: Mainzer Ztschr. III (1908) S. 24; Hahnheim: ebenda S. 25; Heidesheim: ebenda S. 26, A. h. Vorz. III. II. Taf. I. 1-4, 6-8; Niederolm: ebenda S. 32; Nierstein: ebenda S. 34; Mölsheim: Westd. Ztschr. XII (1893) S. 393; A. h. Vorz. III. VI Taf. IV. 2-3, 5-7, 9-10.3)

Diese älteren Gräber, alle Brand- bzw. Brandgrubengräber, öfters noch mit kleinen Hügelchen bedeckt (wie Hahnheim, Heidesheim, Oberolm usw., vielfach auch Nachbestattungen in älteren Grabhügeln), in unregelmässigen kleineren Gruppen vereinigt, enthalten noch zahlreiches gallisches Geschirr von feinerer Drehscheibenarbeit, nicht selten bemalt (wie Albig, Heidesheim, Mölsheim usw. $)^{4}$ ) oder mit schwarz eingeglätteten oder eingekerbten Mustern verziert (Mölsheim, Essenheim, Westhofen usw.), genau wie die älteren Gefässe vom Mont Beuvray, Stradonitz und von Basel, also um die Mitte des 1. Jahrhunderts v. Chr. Die mitgefundenen Fibeln zeigen das spätere Mittel-La-Tèneschema; Fibeln vom Nauheimer Spät-La-Tènetypus kommen dabei noch selten vor (ausser in späteren Gräbern desselben Friedhofs). Auch die Schwerter bekunden noch häufig die etwas schlankere Mittel-La-Tèneform, oben mit bogenförmigem (nicht geradem) KlingenAbschluss, und sind zum Teil wohl reinkeltische Fabrikate (vgl. A. h. Vorz. II. 7, Taf. VI. $4 \mathrm{a}-\mathrm{c}$ ), ebenso wie der keltische Flügelschildbuckel vorherrscht. Seitdem allerdings durch die Funde von Dudenhofen bei Speyer, Manching usw. gallische Brandgräber aus dem Ende der Mittel-La-Tènezeit bekannt sind, ${ }^{5}$ ) müssen wir uns ernstlich fragen, ob nicht ein guter Teil dẹ

1) Vgl. z. B. Manching, A. h. Vorz. V Taf. 51 Nr. 935 (Eimerfórm), 936 (mehr Becher), 933 (Fussschale) und Oggersheim (Pfälz. Mus. 30, 1913, S. 7 Abb. II. 3).

2) Vgl. z. B. Hahnheim (W. Ztschr. XIV Taf. XV. 7) und zum eingeglätteten Ornament das Gefäss von Mühlhausen in Thüringen (Jahresschr. 10 [1911] Taf. VIII. 1), Westhofen (A. h. Vorz. I. VI Taf. 6, 12), Leeheim (W. Ztschr. XXII Taf. 5, 21).

3) Ausserdem: Westhofen, A. h. Vorz. I. VI Taf. 6 Nr. 11, 12; ferner Bermersheim, Ei m sh ei m, Esselborn (A. h. Vorz. III. VI Taf. 4, 1), Monzernheim (W. Ztschr. 1903 S. 415, bemalte Gefässe), $0 \mathrm{~s}$ th of $\Theta \mathrm{n}$. Fast überall sind aber auch jüngere Gräber vorhanden.

4) Auch Déchelette, Manuel II. 3 S. 1491.f. hält sie für gallische Importware aus dem Gebiet der Aeduer, Arverner u. a.

5) Mainzer Ztschr. VIII-IX (1914) S. 111 f. (P. Reinecke). Déchelette (Manuel II. 3 S. 1037) bringt, wie Kossinna, Korr.-Bl. f. Anthr. 1907 S. 58, in Nordosttrankreich den Übergang von Bestattung zur Verbrennung .am Ende der Mittel-La-Tènezeit mit dem Ein- 
genannten rheinhessischen Gräber noch von einer gallischen, ev. durch Germanen gemischten Bevölkerung herrühren könnte. Dem widerspricht aber, renigstens für die Mehrzahl, der Umstand, dass genau dieselben Gräber auch rechtsrheinisch im Rheingau und in Starkenburg begegnen (Geisenheim, Grossgerau usw.), wo sich die Gallier in geschlossenen Gruppen unmöglich solange gehalten haben können; auch weisen gewisse Beigaben bestimmt auf Germanen hin, sowohl Tongefässe, als Münzen, Schmuckgegenstände und Waffen. Unter den Tongefässen sind es namentlich die oft stark gerieften Kesselchen und einfachen Eimerformen, die auch im rechtsrheinischen Germanengebiet um diese Zeit sehr beliebt waren, wenn sie auch auf gallische Vorbilder zurückgehen (vgl. unten S. 278 und 289), ferner die degenerierten Omphalosschalen, Klappern usw. in Vogelgestalt ${ }^{1}$ ) usw. (so von Essenheim, Nackenheim, ebenso allerdings Winkel); von den Fibeln z. B. die mit kreuzförmiger Emaileinlage, wie eine von Niedermodern bei Hagenau (vgl. Korr.-Bl. f. Anthr. 1907 S. 60, G. Kossinna), gewisse Gürtelhaken (ebenda S. 58), kleine Messerchen mit eigenartig gekrümmtem Griff (z. B. von Heidesheim), von den Waffenstücken die konischen Schildbuckel und gewisse Schildhandhaben (Mannus V S. 89 f., M. Jahn, oben S. 249). Auch unter den Münzbeigaben begegnen nicht selten neben echt gallischen Prägungen germanische, die von R. Forrer, Kelt. Numismatik S. 185, 222 f., 286 f. wohl mit Recht den Nemetern, Wangionen usw. zugeschrieben werden, wenn im einzelnen auch noch manche Unsicherheit herrscht. Diese germanischen Stämme galten bekanntlich schon zu Caesars Zeit als gute Reiter, und vielleicht ist es kein Zufall; dass gerade im Wangionengebiet zahlreiche Pferdetrensen in Brandgräbern dieser Periode erhoben wurden (z. B. Hahnheim, Niederolm), einmal auch ein, wenn auch etwas späterer, Sporn (Niederolm).

O. Bremer hat meines Wissens zuerst eingehender die Aufstellung zu begründen versucht (Ethnographie der germanischen Stämme 1899 S. 59 f.), dass Ariovist zwischen 80-75 v. Chr. gleich den Cimbern dem Elblauf folgend in Böhmen eingedrungen und nach dessen Eroberung den Main herabziehend zwischen 75-72 den Rhein bei Mainz überschritten und sich in der Rheinpfalz und im Elsass festgesetzt habe. Diese Ansicht wird von L. Schmidt, Gesch. d. deutschen Stämme II. 2 (1913) S. 145 scharf zurückgewiesen, wobei er auch meinen Hinweis auf einen germanischen Posten dieser Zeit an der alten Rheinfurt bei Mainz-Weisenau (Mainzer Ztschr. III S. 37, VI S. 10) ${ }^{2}$ ) nicht gelten lässt. Schmidt ist vielmehr der Meinung, dase Ariovist als König der (suebischen) Triboker vom mittleren und oberen Neckartal aus in Jahre 71 mit 15000 Germanen den Rhein überschritten

dringen der Germanen in Belgien zusammen; dieselbe Veranlassung könnte am Oberrhein und an der Donau vorliegen, doch sind die diesbezüglichen Beobachtungen noch zu unsicher.

1) Andersartig sind die der Früh-La-Tènezeit, vgl. P. Reinecke, Festschr. S. 80 Anm. 95 (von Braubach, Hagenau).

2) Wieweit die vorrömische, von Gräben umgebene Anlage Mainzer Ztschr. VIII-IX S. 38 damit zusammenhängh, lasst sich noch nicht sagen. 
und sich in das Sequanerland begeben habe, um ihnen gegen die Aeduer zu helfen. Er stützt sich hauptsächlich wohl auf die Darlegungen Kossinnas, Korr.-Bl. f. Anthr. 1907 S. 59 u. f., obschon Kossinna selbst schreibt, „der Hauptstrom der germanischen Einwanderung ergoss sich sichtlich an der Mainmündung sogleich über linksrheinisches Land, namentlich Rheinhessen“", und obwohl im Elsass germanische Spuren dieser Zeit bis jetzt selır geringfügig sind, wie Kossinna selbst zugibt (S. 59), wenn auch die norḍdeutsche Spät-La-Tènefibel von Niedermodern bei Hagenau nicht ohne Bedeutung ist. ${ }^{1}$ )

Den Ausschlag gäbe natürlich eine scharfe zeitliche Umgrenzung jener älteren germanischen Schicht in der Umgebung von Mainz, die jetzt schon wenigstens annähernd möglich sein dürfte. Das Aufhören der gallischen Skelett- und Brandgräber der Mittel-La-Tènezeit in der Rheinpfalz (vgl. oben S. 259) bietet leider noch keine näheren Anhaltspunkte, wenn sie auch einige jüngere Anzeichèn als z. B. das Grab von Dühren. enthalten. Dagegen lehrt ein Vergleich einerseits mit den Funden vom Mont Beuvray (auch Alesia und Basel), andererseits mit der weiter unten zu behandelnden rechtsrheinischen Germanenkultur ubischen und suebischen Charakters, dass diese linksrheinische germanische Gruppe in ihrem älteren Niederschlag wahrscheinlich zwischen den ältesten Funden vom Mont Beuvray (etwas nach c. 80 v. Chr.) und der suebischen Schicht von Nauheim (Beginn c. $60-55$ v. Chr.) liegt. Im einzelnen dies auszuführen, würde hier zu weit führen und muss einer zusammenfassenden Veröffentlichung der angedeuteten Art vorbehalten bleiben.

Bemerkt sei nur noch, dass die bemalten Gefässe des linken Rheinufers keineswegs alle durchaus gleichzeitig sind, wie sowohl die Gesamtform als die Gestaltung von Mündung und Standboden (bzw. Fuss) zeigen. Die Exemplare von Albig (A. h. Vorz. III. VI Taf. 4, 4, ebenso die etwas anders verzierten von Mölsheim, ebenda Nr. 5 und 6) und Geisenheim (A. h. Vorz. I. VI Taf. 6, 5, vgl. ebenda Nr. 20) sind wohl älter als die von Monzernheim (Mus. Worms), wiewohl in Geisenheim auch verhältnismässig junge Typen rertreten sind.

Kurz besprochen sei auch noch der Umstand, dass sich Brandgräber der Spät-La-Tènezeit mit germanischen Waffen auch im Hinterland der bayerischen Rheinpfalz und im Saargebiet finden (Mühlbach am Glan, Forbacher Hof bei Neunkirchen, Praeh. Z. III S. 171, Saar- und obere Ruwertalgegend, Trierer Jahresber. 1899 S. 34, Taf. III, 14, 15 Schildbuckel germanischer und gallischer. Form, ${ }^{2}$ ) die ich schon (Ber. d.

1) Vgl. auch die Funde von Hönheim, Anz. f. els. Altk. 1909 S. 46 (R. Forrer), 1910 S. $129 \mathrm{f}$. (A. Riff) und die Ausführungen von A. Fuchs, Die Kultur der keltischen Vogesensiedlungen (1914) S. $80 \mathrm{f}$.

2) Die im städtischen Museum zu Mainz befindlichen Funde, geschenkt von Herrn Kommerzienrat Boch in Mettlach, sollen nach einer Notiz des Mainzer Handkatalogs aus Ober- oder Nieder-Zerf im oberen Ruwertal stammen. Es sind ein Schwert, Schildbuckèl, 'Fibel vom sog. Mittel-La-Tènecharakter und zwei Schwerter, Schildbuckel, Fibeln usw. des sog. Spät-La-Tènetypus. 
röm.-germ. Kommisssion 1905/06 S.20f.) auf Scharen des Ariorist (Wangionen, Haruden, Caeracaten?) znrückgeführt habe (vgl. auch Mainzer Ztschr. $\mathrm{VIJ}^{\mathrm{r}}$ und IX S. 110). Wenn nach Caesar bell. gall. 1, 37 im Jahre 58 v. Chr. sich die Aeduer bei Caesar beschwerten, dass die Haruden ihr Gebiet vermiisteten (quod Harudes, qui nuper in Galliam transportati essent, fines eorum popularentur), müssen jene ariovistischen Scharen schon sehr weit nach Westen rorgedrungen sein. Die Grenzen gegenüber dem gallischen Besit\% lassen sich an Hand der Bodenfunde allmählich erkennen, wenn auch bei der starken Mischung der beiden Kulturen grösste Vorsicht geboten ist (rgl. Trierer Jahresber. 1909 S. 105 f., H. Baldes). ${ }^{1}$ Die Frage ist von weitergehendem Interesse, da ihre Lösung auch zur Grenzbestimmung der Prorin-

1) Auch die Brandgräberfunde rom Geyersberg bei Kusel im Iluseum zu Speyer (blaue Glasringe, blaue Perle, Bronzeringe, drei Bronzefibeln wie in dem (irabfund von Uffhofen bei hreuznach, kleines Beilchen wie Nühlbach, Eisenschwert usw.) könnten von einer gemischten gallisch-germanischen Bevölkerung herrïhren (vgl. Mitt. d. hist Ver. d. Plalz XXV [1901] S. 20 s. Tal. 1 9-12, Westd. Ztschr. 19(r) S. 413).

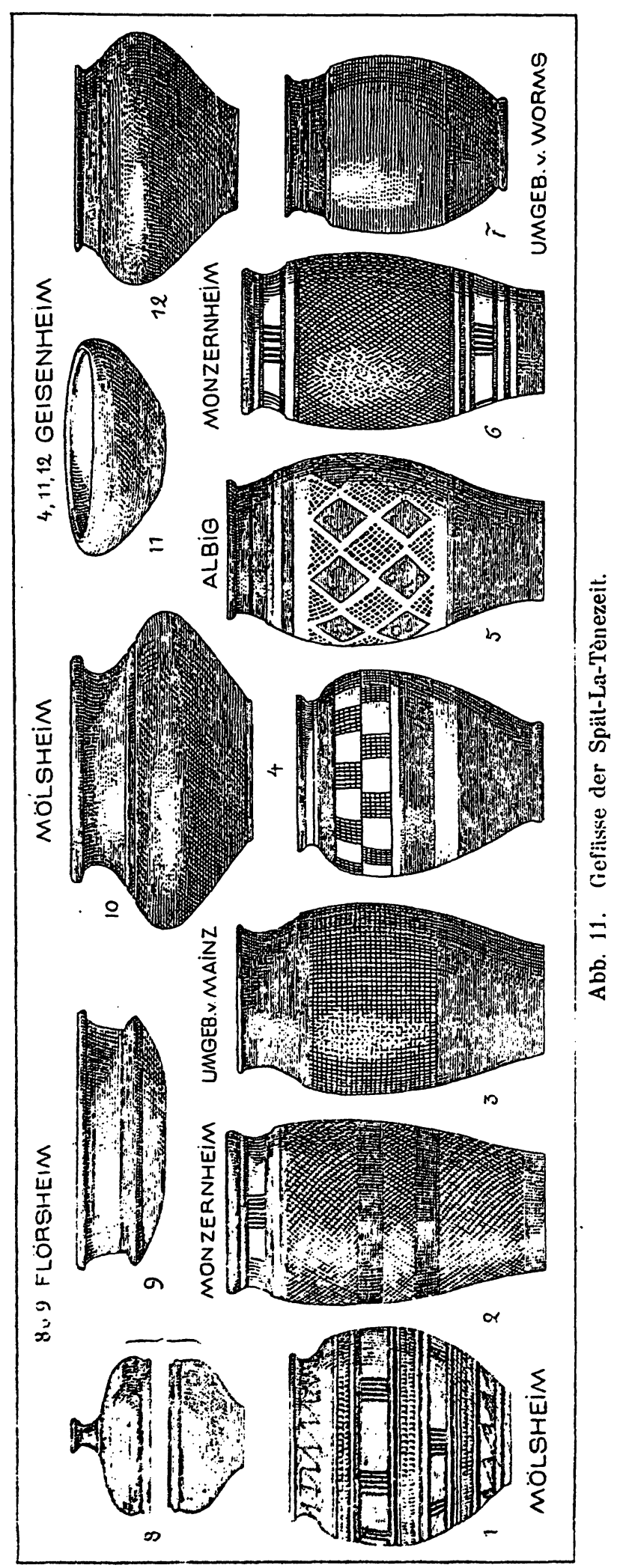


zen Germania Superior und der Belgica beitragen wird (vgl. Mainzer Ztschr. 1913/14 S. 109 f.).

2. Wenn die Wangionen an der unteren Nahe auch noch über den Fluss hinüber an den Hängen des Hunsrücks gesessen haben dürften, wie frührömische und mittelalterliche Erscheinungen nahelegen, so sind weiter rheinabwärts doch andere germanische Stämme anzunehmen. Die Funde aus dem Coblenzer Stadtwald ${ }^{1}$ ) stimmen in bezug auf Form und feinere Technik so ziemlich mit den ,ubischen“ des gegenüberliegenden Ufers überein (vgl. unten S. 278), doch lässt sich für sie und ähnliche noch nicht mit Bestimmtheit sagen, ob sie von germanischen Ubiern oder Treverern herrühren, die mit Germanen (Ubiern, Sueben usw.) durchsetzt waren. Jedenfalls tritt dabei das gallische Element noch sehr hervor.

Das Brandgräberfeld von Ettring e $n$ bei Mayen, das an einem vorrömischen Verkehrswege nach der Eifel liegt (Mainzer Ztschr. 1913/14 S. 106), lieferte mit seinen über zwei Dutzend Brandgräbern hauptsächlich die fässchenförmigen Gefässe in verschiedenen Grössen; ausserdem zahlreiche Kumpen mit eingezogenem Rande (Aschenbehälter, wie übrigens auch die ersteren), kleine kesselförmige Schalen, feiner gearbeitete kleine Krüge (ohne Henkel), nur einmal einen Humpenbecher und zweimal einen grauen „belgischen“ Becher mit doppeltem Gitterband, der die Dauer des Gräberfeldes bis in die römische Zeit erweist (noch nicht veröffentlicht, in der Sammlung zu Mayen und im präh. Mus. zu Köln). Im ganzen aber stehen sie den oben genannten Funden vom Coblenzer Stadtwald und denen von Arzheim auf dem rechten Rheinufer (Mannus III Taf. VI. 5-12) näher als denen von Biewer oder Hirstein und lassen wohl auf eingewanderte Germanen des letzten Jahrhunderts schliessen, allerdings auch auf enge Berührung mit gallischer Kultur. Das bestätigt auch ein Schildbuckel von Ettringen, der in dem S. 266 erwähnten Grabe von Heidelberg eine Parallele hat (ähnliche allerdings auch in Alesia, vgl. M. Jahn, Die Bewaffnung der Germanen in der älteren Eisenzeit [1914] S. 38 f.).

Nur .streifen 'können.wir die frührömischen Gräberfunde von Andernach, Urmitz, Coblenz-Neuendorf, Mainz, Weisenau, Strassburg, $\left.{ }^{2}\right)$ die in der Nähe römischer Kastelle liegen und wahrscheinlich wenigstens zum Teil von einer milizartig organisierten einheimischen Bevölkerung herrühren. ${ }^{3}$ ) Neben gutkeltischen Gefässformen, wie Bonn. Jahrb. H. 107 S. 79 Abb. 4, 1 und 8, begegnen germanische Waffenstücke, wie die kegelförmigen Schildbuckel, Schildfesseln mit hakenförmig gebogenen Enden (Mannus V S.90 Anm. 2), während zwei andere Schildbuckel den Ubergang vom keltischen zum germanischen bzw. römischen darstellen (M. Jahn, Bewaffnung der Germanen 1914 S. 41); die übrige Ausrüstung besteht meistens in

1) Westd. Ztschr. XIX (1900) S. 32 f. (R. Bodewig), Mannus III (1911) S. 15 f. (A. Günther), Taf. VI, 1-4.

2) Literatur: Mitt. aus Westfalen V (1909) S. 293, Mainzer Ztschr. III S. 37, Anz. f. els. Altk. 1912 S. 299 f., Mestwerdt, Die röm. Tongefässe der Altertumssammlung in Cleve II (1906) S. 8 . usw.

3) E. Ritterling, Bonn. Jahrb. H. 114/15 S. 187. 
Lanzen, selten in einem gladius. Auch aus anderen linksrheinischen Gebieten sind ähuliche Funde bekannt (vgl. Trierer Jahresber. N. F. II (1909) S. 105, H. Baldes). Sie rühren ja zweifelsolıne von Germanen her, die aber auch von den Römern teilweise aus abgelegenen Gegenden dort angesiedelt sein können, wie z. B. der Name der germanischen Siedlung bei Weisenau (vicus [M?] aresacensis) vermuten lässt (Mainzer Ztschr. VI S. 10).

Bei dieser unverkennbaren Schwierigkeit, in linksrheinischen Germanengebiet gallische und germanische Erzeugnisse schärfer zu unterscheiden, werden nur umfassende Vergleiche einerseits der verschiedenen Denkmälergattungen in ihrer Entwicklung, andererseits der Abweichungen in der Form der Gräber und in den Grabgebräuchen, des verschiedenen Hausbaues und des ganzen siedlungsgeschichtlichen Materials zu einem sicheren Ziele führen. Schon jetzt lassen sich eine Reihe von Gefässformen, wie die Humpen, Kessel, Eimer, Flaschen usw., in ihrer zusammenhängenden Entwicklung von den Früh- und Mittel-La-Tèneformen der Champagne oder des Treverergebiets bis in die Spät-La-Tènezeit mit all den charakteristischen $A b$ wandlungen der einzelnen Gefässteile aufs eingehendste verfolgen und zu chronologischen wie etlınologischen Schlüssen heranziehen. Auch für die Schwerter, Schildbeschläge, Fibeln usw. liegen schon ähnliche wichtige Beobachtungen vor. Am meisten vernachlässigt ist noch das Studium des Grab- und Hausbaus dieser Periode, wenn auch in einzelnen Gegenden bereits erfreuliche Ansätze dazu gemacht sind. In Rheinhessen hat man z. B. um die Grabhügel der La-Tènezeit öfters Ringgräben mit Durchgängen beobachtet, die mit ähnlichen Erscheinungen der Rundhütten in Beziehung stehen. A uf die kleinen Steinplattenkisten mit Leichenbrand ron Mühlbach am Glan, die für germanische Sitte charakteristisch sind, hat schon Kossinna (Korr.-Bl. f. Anthr. 1907 S. 59) aufmerksam gemacht, und leicht liessen sich die Beispiele vermehren. Bei Ausgrabungen sollte auf diesen Punkt mehr Gewicht gelegt werden.

\section{Die rechtsrheinischen Germanen: Ubier, Usipier, Mattiaker, Sueben, Markomannen}

1. Was Caesar bell. gall. 4, 3 über die U b i er sagt: Ubii, quorum $\mathbf{f}$ u it civitas ampla atque florens, ut est captus Germanorum et paulo, quam sunt e i usdem generis et ceteris humaniores, propterea quod Rhenum attingunt multumque ad eos mercatores ventitant et ipsi propter propinquitatem Gallicis sunt moribus assuefacti, findet in den Bodenfunden seine vollständige Bestätigung. Von der gallischen Frühund Mittel-La-Tèneschicht, wie sie namentlich die Funde von OberlahnsteinBraubach vorführen (vgl. oben S. 248), und andererseits von der Spät-LaTènekultur des Nauheimer Typus hebt sich deutlich eine Gruppe ab, die der besprochenen älteren Kultur der linksrheinischen Wangionen ziemlich genau entspricht und der ersten Hälfte und der Mitte des letzten Jahrhunderts r. Chr. angehört. Es sind Wohn- und Grabfunde von Oberlabnstein-Brau- 
hach, Geisenheim (Grabhügel!), Wiesbaden, Flörsheim usw., ${ }^{1}$ ) die sich etwa von der Wied bis zum unteren Maintal erstrecken und die Ausdelunuug der Ubiersitze bezeichnen. ${ }^{2}$ ) Hier wie dort begegnen dieselben Fibeln und Schwerter des späteren Mittel-La-Tèneschemas, dieselben teils echten, teils nachgeahmten gallischen Vasen, namentlich die feinpolierten und öfters bemalten Drehscheibenarbeiten wie von Geisenheim (A. h. Vorz. I. VI Taf. 6 Nr. 5), Flörsheim (A. h. Vorz. V S. 409 f.). Besonders charakteristisch sind die Eimer (A. h. Vorz. V Taf. 70 Nr. 1309), kesselförmigen Schalen (ebenda Nr. 1310), Näpfe mit Deckeln (Nr. 1312), welche zwar auf gallische Vorbilder zurückgehen, aber zum Teil durch eine gewisse Ubertreibung der Einzelgliederung ihren germanischen Ursprung verraten.

Besonders lehrreich ist die Geisenheimer Grabausstattung. ${ }^{3}$ ) Jedes Grab (in Hügeln) enthielt ausser dem Aschenbehältter (Schüssel, Napf oder Eimer) mehrere Beigefässe (Humpen bzw. Kelche, Schalen, Kesselchen, kleine und grosse Krüge usw.), also genau wie bei Hirstein, wo aber die Totenasche, frei im Boden zwischen den Gefässen lag. Doch lassen die Eimerformen und Schalen, Schlüssel und Schlossfeder von einer Truhe, der Grabritus usw. keinen Zweifel am germanischen Charakter. Die neun eisernen Mittel-LaTènefibeln (in einem Grabhügel?) ohne Vergesellschaftung mit irgendeiner Spät-La-Tèneform bestätigen wohl die Ansetzung kurz vor dem Nauheimer Stadium und die Zuweisung an die Ubier. Auch im Flörsheimer Fund erscheinen nur Mittel-La-Tènefibeln, auch zwei eiseine Schlüssel vou Truhen, in denen feinere Grabbeigaben, in Geisenheim z. B. wohl die kleine Bronzeciste, niedergelegt waren. Eine solche Truhe mit Schloss ist auf Metope 9 des Denkmals von Adamklissi dargestellt.

1) Vgl. die Literatur A. h. Vorz. V S. 413, wo ich die Frage ausführlicher besprochen habe.

2) Ưber ihre Münzprägung vgl. Lothr. Jahrb. 22 (1910) S. 465 f. (R. Forrer).

3) Im städtischen Museum zu Mainz; bis jetzt sind allerdings leider erst drei Stück davon veröffentlicht, A. h. Vorz. I. VI Taf. 6 Nr. 5, 6, 9 (vgl. Abb. 11 Nr. 4, 11, 12 L. Lindentschmit), welche wohl echtgallische Arbeiten sind. $\mathrm{Zu} \mathrm{Nr} .5$ (Abb. 11, 4) vergleiche eine ähnlich gemusterte von Heidesheim in Rheinhessen, das auch sonstige Parallelen hat, und die spätere „belgische“ Form von Haltern, Mitt. für Westfalen V (1909) Taf. XXIV Nr. 19, Text S. 280 (nach S. Löschcke Fabrikationszentrum in Nymwegen). Von grösstem Interesse sind die Überreste einer kleinen Bronzeciste, d. h. einer mit Bronzeblech überzogenen Holzbüchse, wie sie in Gallien und England von der Früh- bis Spüt-La-Tènezeit, wenn auch bis jetzt sehr selten, gefunden sind. Am bekanntesten sind die allerdings viel grösseren Exemplare von Aylesford und Marlborough (Déchelette, Man. II. 3 S. 1456 Abb. 658, 1, 2), welche keltische Arbeiten der späteren La-Tènezeit darstellen. Vereinfacht kommt die Cistenform auch in Ton vor, und zwar in allen La-Tènestufen; ebenso wie die Bronceciste (ebenda S.1462 Abb.659, 9). Die kleine Geisenheimer Ciste (H.tiber $10 \mathrm{~cm}$, D. $16 \mathrm{~cm}$ ) unterscheidet sich von diesen durch eine Rankenverzierung rein griechisch-italischen Charakters, wie sie auf späthellenistischen und arretinischen Metall- und Tongefässen begegıet. Im selben Grabhügel Überreste von 9-10 eisernen Mittel-La-Tènefibeln (wie Abb. 8 Nr. 12) und ein Tonvogel (Ente?) mit éingraviertèm Gefieder (vgl. A. h. Vorz. V Taf. $8 \mathrm{Nr}$. 144 und Déehelette, Man. II. 3 S. 1467). Alles weist auf gallisch-italische Einflüsse hin. In einem offenbar etwas jüngeren Grabhügel ist zusammen mit $\mathrm{Abb} .11 \mathrm{Nr} .11$ und 12 auth ein Fässchenbecher gefunden wie Abb. 10 Fig. 1 (Hirstein). (Vgl. Period. Blätter 1854 Nr. 4 S. 121). 
Auch für die Funde des rechten Rheinufers wird die Scheidung gulliseher und germanischer Tonware durch den Umstand erschwert, dass die suebischen Völker Mitteldeutschlauds unter dem Einfluss der dortigen Gallier ausgezeichnete keramische Arbeiten herstellten, namentlich tiefschwarze Drehscheibegefässe mit eingeglätteten Mustern, wie uns ältere und jüngere Funde ron Kleincorbetha (Mus. Halle), Mühllhausen i. Th. (im dortigen Museum), Reinsbrunnen (Mus. Göttingen) u. a. lehren, auf die wir weiter unten näher eingehen werden. Für diese „ubischen“ Funde ist auch charakteristisch, dass gegenüber den schwarzen, auf der Drehscheibe hergestellten Gefässen die grauen handgemachten verhältnismässig selten sincl, während sie in der: Nauheimer Kultur überwiegen.

Bei manchen Gräbern ist eine nähere Datierung und völkerschaftliche Zuweisung bei den sehr verwickelten ${ }^{\top}$ erhältnissen zurzeit noch wenig ratsam, zumal auch die Usipier in Betracht kommen. So schliesst L. Schmidt, Gesch. a. deutschen Stämme II. 2 (1913) S. 142, aus Caesars Worten bell. gall. IV. 1 und 4 (Usipetes et Tencteri ... qui complures annos Sueborum vim sustinuerunt. ad extremum tamen agris expulsi et multis locis Germaniae triennimm vagati ad Rhenum pervenerunt), daß die Usipier und Tenkterer bis zum Jahre 58 in Oberhessen gewohnt haben, wo sie von den Sueben rertrieben wurden.1) Die Bodenfunde geben zwar noch keine sicheren Anhaltspunkte, loch liegen immerhin einige Erscheinungen vor, die besondere Beachtung verdienen. So wird der bekannte Münzfund von Mardorf von Forrer mit diesem Ereignis bzw. den cäsarianischen Einfällen zusammengebracht (Lothr. Jahrb. 22 [1910] S. 460 f.). So fällt unter den Spät-LaTènefunden der Wetterau der von Heldenbergen (Kr. Friedberg, A. h. Vorz. T Nr.1317-1324) auf. Nach der halbgallischen Urne Nr.1317 und der Mittel-La-Tènefibel Nr. 1322 ist er vielleicht etwas älter als im allgemeinen die Nauheimer Kultur, aber nach den rohen Gefässen Nr. 1318-1321 schwerlich ubischen Ursprungs. Die Form der Urne Nr.1318 begegnet zahlreich in Mitteldeutschland (Leipziger Gegend, Thüringen, vgl. unten S. 288 f.) und könnte einen Hinweis anf das Ausgangsgebiet dieser neuen germanischen Einwanderung enthalten, doch miissen für eine sichere Beurteilung erst weitere Fnnde ähnlicher Art abgewartet werlen.

Eine Reihe von anderen Gräberfunden, wie von Arzheirn (bei Ehrenbreitstein, Mannus III Taf. VI 5-12), von Sayn-Stromberg (Mus. Bonn, Beilchen!), können nach unserem heutigen Wissen ebensowohl auf Ubier wir. Sueben, Sugambrer usw. zurückgefülırt werden, wenn ihr Inhalt sich auch zum Teil nur wenig von den Funden des Coblenzer Stadtwalles unterscheidet.

‥ Die Möglichkeit der Abstammung der M a t tiaker von den Chatten, die gewöbnlich aus der wahrscheinlichen Ableitung von dem caput centis Jiattium (hei Metze an der Metzoff oder Matzoff) erschlossen wird,

1) L. Wirtz, Bonn. Jahrb. H. 122 (1912) S. 194 f., macht dic Usipier zu nürdlichen Nachbarn der (ihnen verwandten) Mattiaker und leugnet mit Müllenhoff u. a. den Zusammenhang zwischen Mattiakern und Chatten. Vql. jetzt auch L. Schmidi, (iesch. d. d. Stämme II. 3 1!11: $\leq$. : : 4 i $\mathrm{f}$. 
hat ihre archäologische Bestätigung erhalten durch die völlig gleichartigen Spät-La-Tènefunde von der Alteburg bei Metze, dem Dünsberg und Hausberg bei Giessen und Butzbach und zahlreichen Gräberfunden der Gegend von Wiesbaden, ${ }^{1}$ ) die sich von der feineren halbgallischen Ubierkultur wesentlich unterscheiden und ausgesprocheneren germanischen Charakter verraten. Da ich erst kürzlich in den A. h. Vorz. V S. $413 \mathrm{f}$. die Funde ausführlicher besprochen habe und inzwischen keine neuen ausschlaggebenden gemacht worden sind, will ich nur kurz auf dieselben eingehen.

Erwähnt sei vor allem die Behandlung dieser Gruppe durch E. Ritierling in seiner prächtigen Publikation des Erdlagers Hofheim (Nass. Annàlen 40 [1912] S. 378 f.). Ritterling schreibt auch die Nauheimer Kultur wegen ihrer Dauer „bis in die mittlere Zeit des Augustus“ und wegen der grossen Menge derartiger Funde in der Wetterau und in der unteren Maingegend einer chattischen, nicht suebischen Bevölkerung zu (S. 384 Añm. 428). Bei Behandlung der Sueben werde ich darauf zurückkommen. Hier möchte ich nur bemerken, dass ich die von Ritterling als A bezeichnete Gruppe (vgl. die Abbildungen S. 387 Fig. 102, S. 388 Fig. 103) noch für wirklich hallstättisch halte und für vorgermanisch. Die Hallstattformen sind zwar etwas verwischt und erinnern an die niederrheinische Hallstattkultur, doch lassen sich aus der mittelrheinischen Gegend manche Parallelen mit echten Hallstattbeigaben anführen. ${ }^{2}$ )

$\mathrm{Zu}$ warnen ist vor einem Versuche, die roheren Tongefässe vom Ringwall auf dem Dünsberg, aus den Wohngruben von Eberstadt ${ }^{3}$ ). usw. etwa der einfacheren chattischen Kultur zuzuweisen; es ist eine allgemeine Erfahrung, dass Tongefässe dieser Periode aus Wohngruben etwas roher sind als die aus Gräbern und bisweilen einen etwas älteren Eindruck machen.

Auch in römischer Zeit lässt sich diese germanisch-mattiakische Kultur im unteren Maintal ausserhalb der römischen Städte und römischen Siedlungen in mannigfachen Funden erkennen. ${ }^{4}$ ) Namentlich bei einem Flörsheimer Grabfund aus der Mitte des 1. Jahrhunderts n. Chr. fällt die grosse Ähnlichkeit mit der gleich zu besprechenden Kultur der Suebi Nicretes zwischen Main und Neckar auf.

3. Di e Su eben. Über die ursprünglichen Sitze des Volkes, das Gebiet der Semnonen im nördlichen Brandenburg und in Mecklenburg-Strelitz, kann kaum ein Zweifel sein. ${ }^{5}$ ) „Von dem Stammlande aus haben sie zu-

1) Vgl. Mitt. d. Nass. Ann. 1902/03 S. 55 f. (E. Ritterling), 1914 S. 120 f. (E. Brenner); A. h. Vorz. V S. 413 f. (K. Schumacher), F. Kauffmann, Deutsche Altk. I (1914) S. 243 f.

2) Z. B. von Höchst an der Nidder (Mus. Friedberg), aus der Umgebung von Giessen (Mus. Giessen), von Braunfels (Saalburgmuseum) u. a. m.

3) Röm.-germ. Korr.-Bl. 1914 S. 38 Abb. 21 (W. Bremer), Mitt. d. oberhessischen Geschichtsver. XXII S. 151 (Kramer).

4) Vgl. z. B. Flörsheim: Nass. Mitteilungen 15 (1912) S. 105 f. (E. Brenner), Hofheim: Nass. Annalen 40 (1912) S. 378 f. (E. Ritterling).

5) Literatur: Kossinna, Ztschr. f. Ethn. 1905 S. 389 f., Korr.-Bl. f. Anthr. 1907 S. 58 f., Mannus III (1911) S. 325, O. Bremer a. 0. S. 62 f., A. h. Vorz. V S. 414 (K. Schumacher), Kauffmann S. 238 und L. Schmidt, Gesch. d, deutschen Stämme II. 2 (1913) S. 139 f. 
nächst die Westhälfte der Niederlausitz, die Provinz Sachsen um Halle, Thüringen und das Königreich Sachsen besiedelt" (Kossinna, Korr.-Bl. f. Anthr. 1907 S. 58, Schmidt S. 141) und lassen sich dann von Thüringen durch das Lahntal an den Mittelrhein und durch die Wetterau an die Mainmündung sowohl an Hand der literarischen Nachrichten als der Bodenfunde genau verfolgen. Die Scharen des Ariovist, die auch nach der Niederlage durch Caesar in ihren alten. Quartieren beiderseits des Rheins von Bingen bis südlich Strassburg als römische Grenzwehr verblieben, wurden durch immer neue Suebennachschübe aus dem Innern Germaniens verstärkt, auch am Mittel- und Niederrhein, so im Jahre 58 durch die „centum pagi“ des Cimberius und Nasua gegenüber dem Treverergebiet an derLahnmiündung (Caesar bell. gall. I. 37) und später (bell. gall. 4, 3), wodurch sich die Obier und wohl auch die Mattiaker zu ihrem Anschluss an Rom um das Jalır 56 veranlasst sahen. Über die Verhältnisse zwischen Main und Neckar und weiter südlich sind keine bestimmten literarischen Quellen vorhanden, offenbar weil die Massnahmen Caesars sich nicht auf sie erstreckten, so dass wir hier fast ganz auf die Sprache der Bodenfunde beschränkt sind. Diese ist allerdings nicht so ganz leicht zu verstehen und verschiedener Deutung ausgesetzt. Auch hier liegt eine ältere Schicht vor, wenn auch erst in wenigen Anzeichen, so von Gross-Gerau (Privatbesitz Darmstadt), Ladenburg (Wagner, Fundstätten II S. 216 f.), Heidelberg, Reilingen bei Hockenheim (Wagner S. 201) u. a.,1) alle Brandgräber, welche Schwerter und Fibeln vom MittelLa-Tèneschema, bemalte gallische Gefässe usw. enthalten, ganz wie die besprochenen älteren Wangionen- und Ubiergräber. Da auch einige Schriftsteller- und Inschriftenangaben in diesem Sinne gedeutet werden können, ${ }^{2}$ ) ist nicht unwahrscheinlich, dass Wangionen und Nemeter ursprünglich in der Rheinebene beiderseits des Rheins gewohnt haben, bevor sie von den Sueben verdrängt wurden. Wann dies geschah, ist noch zweifelhaft. Da aber z. B. das Gräberfeld von Büttelborn bei Gross-Gerau ${ }^{3}$ ) mit reichem keramischem Inhalt vollständig mit dem jüngeren von Heppenheim in Rheinhessen,4) also im Wangionengebiet, übereinstimmt und wie dieses Fibeln des Nauheimer Spät-La-Tènetypus aufweist, könnten die Wangionen auch das rechte $R$ heinufer bis nahe an die augusteische Zeit heran festgehalten haben. Weitere Funde in Starkenburg werden bei der regen Tätigkeit ron E. Anthes die Sache wohl bald aufklären.

Dieser Schicht folgt die Kultur des Nauheimer Typus, die bis jetzt reichlich in der Wetterau bis Giessen nnd am unteren Main, scltener zwischen

1) Z. B. VII. Ber. d röm.-germ. Kommission (1915) S. 137 f. (H. Gropengiesser).

2) E. Fabricius, Die Besitznahme Badens durch die Römer 1905 S. 12 f., 23, L. Schmidt a. o. S. 143 t. Vgl die Angabe Caesars, dass der hercynische Wald vom Gebiet der Nemeter beginne und Ptolemaeus' Aufzählung der Var( = n ?)giones am rechten Rheinufer; C. 1. I.. XIII 6433, Dieburg, wurde civitas U(lpia) V(angionum) vermutet, man könnle ebensogut an Viviscorum usw. denken.

3) Arch. 1. hess. Gesch. IX S. 303 (E. Martin), Jahresber. d. Denkmalpflege 1914 S. 38 (E. Anthes).

4) Westd. Ztschr. XVI (1897) S. 339, Korr.-Bl. 111 (1884) S. 9-10 u. s. (K. Köhl). 
Main und Neckar und darüber hinaus vertreten ist. ${ }^{1)}$ Die Nauheimer Funde, ${ }^{2}$ ) bei denen nur noch wenige Fibeln des Mittel-La-Tèneschemas, dagegen schon mehrere Münzen aus dem letzten Drittel des 1. Jahrhunderts v. Chr. vorkommen und echt gallische Importware verhältnismässig selten ist (nur wenige Gefässe und Metallsachen kommen in Betracht, wie die grossen krugartigen Urnen Quilling S. 42, die Bronzebüchse mit Doppelmaske, Festschr. d. Zentralmus. 1902 Taf. VI. 7, S. 89, der „Spiegelgriff“ Quilling Taf. XVI 133 b, allerdings vielleicht viele Eisenschwerter), ${ }^{3}$ ) können nur den Chatten-Mattiakern oder den Sueben angehören (A. h. Vorz. V S. 414), ineines Erachtens wahrscheinlicher aber den letzteren, da zahlreiche Verbindungslinien einerseits zu den Suebi Nicretes, ${ }^{4}$ ) andererseits zu der SuebenKultur im Innern Deutschlands führen. ${ }^{5}$ ) Indessen ist es im Hinblick auf die weitreichenden Kulturübertragungen der Spät-La-Tènezeit und bei der zuvermutenden Ähnlichkeit der mattiakisch-chattischen und der mainneckarsuebischen Kultur vielleicht ratsamer, diese Frage bis zur Gewinnung reicheren Materials; namentlich aus sicher chattischem Gebiet, offen zu lassen.

Die Funde von Nauheim selbst gehören auf. Grund der Münzen, Fibeln und Gefässformen einem verhältnismässig kurzen Zeitraume an. Die vier Münzen, die allerdings mit einer gewissen Vorsicht zu benutzen sind, da sie keinen geschlossenen Grabfunden entstammen (Nemaususmünzen mit der Überstempelung Imp., eine mit den Köpfen des Augustus-Agrippa), weisen auf die Zeit nach 49 bzw. nach $28 \mathrm{v}$. Chr. Unter den so zahlreichen Fibeln ist das Spät-Mittel-La-Tèneschema der ariovist'schen und ubischen Schicht nur noch in wenigen Exemplaren vorhanden; dass der (von Krüger zwischen 50-30 datierte) Biewerer Typus mit Stützbalken fehlt, könnte mit andersartigen Handelswegen zusammenhängen. Am zahlreichsten sind die Fibeln, die, unmittelbar aus dem Mittel-La-Tèneschema entstanden, noch mannigfache Überbleibsel jenes zeigen, und ihre nächsten Entwicklungen, aber noch keine Aucissa-Scharnierfibeln und verschiedene andere Fibelformen, die in den Gräbern und Kastellen augusteischer Zeit der Rheinlande auftreten. Der von Tischler als „Nauheimer Fibel“ benannte Typus kommt im Nauheimer Gräberfeld nur in wenigen Exemplaren vor (Schr. d. phys.-ök. Ges. Königsberg 1884 S. 28, Quilling a. o. S. 100), eine Erscheinung, die sowohl chronologisch als kommerziell wichtig ist. Wie die obigen

1) Korr.-Bl. f. Anthr. 1907 S. 59 ; A. h. Vorz. V S. 375, 414; Kat. d. röm.-germ. Zentral-Museums Nr. 5 S. 105; Nass. Annalen 40 (1912) S. 384 f.; G. Wolff, Die südliche Wetterau (1913) öfters.

2) F. Quilling, Die Nauheimer Funde, Frankfurt 1903, und P. Helmke, Röm.-germ. Korr.-Bl. 1912 S. 40 f.

3) Vgl. M. Jahn, Mannus V (1913) S. 82, Dịe Bewaffinung der Germanen, Diss. inaug. Berlin 1914 S. 9.

4) Doch fällt auf, dass in Nauheim die Schwerter so häufig, bei den Suebi Nicretes so selten sind. Das erstere könnte (zusammen mit dem Fehlen von Pferdetrensen) mehr auf Fussvolk hinweisen, während die Suebi Nicretes lanzenschwingende Reiter waren (später exploratores).

5) Vgl. Korr.-Bl. f. Anthr. 1907 S. 58:" 
Bemerkungen (S. 254) und die Typenkarte der La-Tènefibeln von R. Beltz (Ztschr. f. Ethn. 1911 S. 664, 688) zeigen, ist diese wohl in Frankreich entstandene Form fast nur über Süddeutschland (einschliesslich Wetterau) und Schweiz bis Böhmen verbreitet, während sie in Nordddeutschland seltener und meist etwas abgeändert auftritt, wo das sog. Mittel-La-Tèneschema bis in die Kaiserzeit vorherrscht. Am häufigsten sind in Nauheim einfache Formen der Fibeln mit dem gitterartig durchbrochenen Fuss (meist noch olme Sehnehaken, Quilling a. o. S. 100), die auch in den cäsarianischen Gräben bei Alesia gefunden sind. ${ }^{1}$ ) Das Grabfeld wird also von jenen ersten unter Caesar eingewanderten Sueben herrühren und bis zur Zeit des. Drusus herabreichen. Auch unter den feineren Tongefässen, die etwa als gallischer Import und Nachahmungen derselben in Betracht kommen, begegnen meist etwas jüngere Formen, selten jene älteren der ubischen Schicht. Es ergibt sich daraus, dass die bis jetzt aufgedeckten, sehr zahlreichen Gräber bei Nauheim sämtlich der Zeit etwas nach der Mitte des letzten Jahrhunderts bis zur römischen Okkupation unter Drusus angehören. Dabei ist natürlich an und für sich vicht ausgeschlossen, dass erst der jüngere Teil des Friedhofs bis jetzt gefunden ist. Dasselbe Bild gewähren mehrere ähnliche Fundstellen, wie bei Giessen (Rodberg), Eberstadt (röm.-germ. Korr.-Bl. 1914 S. 38), Rumpenheim-Fechenheim, Hofheim usw. (vgl. A. h. Vorz. V S. 414).

In Nauheim usw. enthalten die meisten Grabstätten ausser der Schale, dem Napf oder Eimer mit der Totenasche nur wenige Beigefässe, wie die gleichzeitigen Suebengräber in Mittel- und Norddeutschland, doch sind einige mit vier bis fünf Gefässen ausgestattet (vgl. oben S. 265). Diese reicheren zeigen dieselbe Zusammenstellung wie die von Geisenheim, doch sind die Formen plumper und mit wenigen Ausnahmen wohl von den Sueben selbst angefertigt. Namentlich die eimerförmigen Näpfe, die Tonnenbecher, Omphalosschalen usw. bekunden bereits einen starken Rückgang gegenüber denen ron Geisenheim und Hirstein und würden vielfach ihre gallischen Torbilder in Basel und vom Mont Beuvray kaum mehr erschliessen lassen. senn nicht die ganze Entwicklungskette klar vor Augen läge und durch gewisse Profilierungen und eingeglättete oder schwarzaufgemalte Ornamente der Zusammenhang deutlich wäre. Es ist übrigens woll kein Zufall, dass die geradwandigen oder leicht gescbwungenen Humpenbecher, die in der ..ubischen“ Kultur in Flörsheim, Geisenheim usw., ebenso in der „wangionischen" von Büttelborn wie am linken Rheinufer öfters begegnen, in der .suebischen" von Nauheirn bis jetzt ganz fehlen und durch die tonnenförmigen Becher ersetzt werden, aber nur durch einfache niedrige, nicht die grossen gallischen wie in Basel, Hirstein und auch noch in Geisenheim und Wiesbaden (Nassauer Ring).

Die Kultur der Suebi Nicretes des 1. Jahrhunderts v. Chr., die ich A. h. Vorz. V S. 374 f. u. S. 414 ausführlicher behandelt habe, ${ }^{2}$ ) verrät sich

1) Vgl. auch 0 . Tischler bei Meyer, Gurina S. 24-25.

2) Neue Materialien von Nauheim (Kr. Gross-Gerau in Starkenburg) Jaluresber. d. Denkmalspnege im Grossh. Hessen 111 (1914) S. 43 f. Taf. II u. III (E. Anthes).

Praehistoriscbe Zeifechrift VI Heft:3's 1914 
nur: noch in einigen Punkten als stammverwandte Nachfolgerin jener: Nauheimer (Sueben-) Kultur, da sie bereits stark romanisiert ist. Immerhin weisen noch folgende Erscheinungen darauf hin:

1. der Aschennapf einheimischer: Form mit Schale als Deckel wie A. h. Vorz. V Taf. $70 \mathrm{Nr}$. 1332; neben ihm begegnen aber fast zahlreicher Aschenurnen römischer bzw. belgischer Form (vgl. z. B. Mannheimer Geschichtsblätter X [1909] S. 35 Abb. 1, H. Gropengiesser);

2. die Waffenbeigaben, besonders die kleinen runden Schilde mit germanischem Griff und römischem umbo (A. h. Vorz. V S. 372, S. 373 Nr. 1189), die schmalen scharfer Lanzen (a. o. Nr. 1186, 87 u. s.) und die Beile (Nr.1176). In den römischen und gallorömischen Gräbern dieser Periode und Gegend fehlen im allgemeinen Waffen;

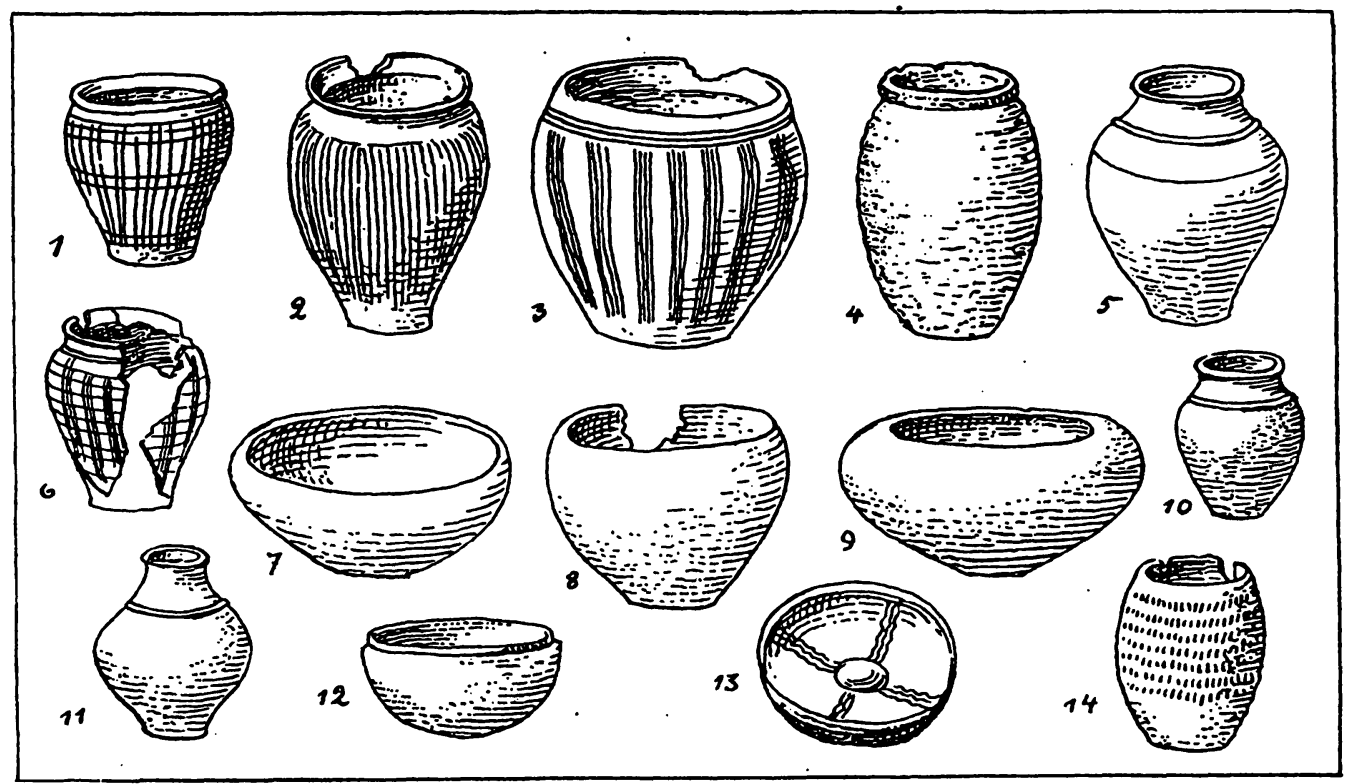

Abb. 12. Spät-La-Tène-Gefässe von Nauheim.

3. die Vorliebe für die situla und die Trinkhörner, die geschweiften kleinen Messerchen und Scheren (Nr. 1184, 1185), gewisse Schnallen (1197) usw., wie sie völlig identisch in derselben Periode nur im Mutterland der suebischen Kultur im Elb- und Saalegebiet und bei den Markomannen in Böhmen vorkommen (vgl. A. h. Vorz. V S. 376).

Schon diese Tatsachen allein machen es unmöglich, in dieser Bevölke: rung sitzengebliebene Gallier oder Nemeter zu vermuten, wie es manche Forscher getan haben. ${ }^{1}$ ) Wangionen und Nemeter mögen allerdings vor ihrem Ubertritt über den Rhein kurz zwischen Main, Neckar und Murg gesessen haben - dein widersprechen die Bodenfunde keineswegs (vgl. oben S. 281) -, aber unsere Suebi Nicretes können wegen der genannten Beziehungen mit der Elb- und Saalekultur niemals Überreste der rechtsrheinischen

1) Vgl. die Literatur Mannh. Geschichtsblätter 1910 S. 213, 237, 261 u. s. (K. Christ und L. Wilser); L. Schmidt, Gesch. d. deutschenen Stämme II. 2 (1913) S. 143, 154. 
Nemeter sein. Es sind nur zwei Möglichkeiten vorhanden: entweder ist es derselbe (suebische) Stamm, von welchem die Nauheimer Kultur herrïhrt, oder - was wahrscheinlicher - eine neue suebische Welle, die von den Römern als socii dieses Gebiet erhielt, unbekannt zu welcher Zeit, vielleicht zu gleicher als die Ubier auf das linke Rheinufer verpflanzt wurden, oder erst später im Zusammenhang mit der Okliupation und Organisation des rechtsrheinischen Gebietes in der Zeit von Augustus bis Claudius. Für dic letztere Aunahme könnte die Zeit der Nauheimer (Starkenburg!) Gräber, die gegen die Mitte des 1. Jahrhunderts beginnen (Anthes a. o. S. 45), angeführt werden, doch ist die Auffindung einer älteren Gräbergruppe nicht ausreschlossen.

L. Schmidt (a. o. S. 142 f.) hält übrigens Wangionen, Nemeter und Triboker für Sueben und Ariovist für den König der Triboker, die vor ihrer Ubersiedlung nach Gallien in der Gegend von Stuttgart gewohnt hätten. I)ie Unterlagen für diese Hypothese sind bis jetzt sehr schwach; die Marbacher Inschrift C. I. L. XIII. 6448 (Deanae exploratores Triboci et Boi), die N'eustadter Inschrift 6482 (civitas S[uebor:um] T[ribocorum??] vgl. Schmidt $\therefore$ 164) und einige Schriftstellerandentungen sind keineswegs zwingend. Auch die Bodenfunde versagen bisher völlig. Die bekannten Funde von der Cluss'schen Brauerei in Heilbronn, ${ }^{1}$ ) die von Schliz den Suebi Nicretes zugewiesen werden, die Wohngrubenfunde von Ingelfingen, ${ }^{2}$ ) ein schönes SpätLa-Tèneschwert aus der Fils bei Göppingen,3) eine Fibel des Nauheimer Typus aus der Bettelmannshöble bei Gundelfingen (O.-A. Münsingen, Mus. Stuttgart), einige dürftige Brandgräber (unter Hügelchen), wie im Oberamt Münsingen (Oberamtsbeschreibung 1912 S. 226 f.), feruer einige Wohngrubeufunde. die zum Teil noch gallisch, aber auch schon germanisch sein können (Kornwestheim, Fundb. XXI S. 26), Emmingen (Fundb. XIX S. 10) usw. sind Anzeichen, dass das mittlere und obere Neckargebiet auch in der SpätLa-Tènezeit nicht ohne Besiedlung war, geben aber bis jetzt keinen sicheren Anfschluss über die Nationalität der Träger dieser Kultur. ${ }^{4}$ )

4. Marko un a nen usw. Die Nameu der germanischen Völker, die in der Spät-La-Tènezeit in der Rheinebene südlich voun Neckar und weiter ostlich sassen, können wir noch nicht mit Sicherheit angeben, da die antiken Nachrichten vieldeutig und die Bodenfunde für diese Periode noch sehr dïrftig sind. Der römische Name für den Schwarzwald, silva Marciana (keltisch Albnoha), beweist für diese Periode gar nichts, gleichgültig, ob er mit den Markomannen zusammenhängt oder nicht. Diese scheinen vielmehr damals an den Grenzen der keltischen Vindelicier und Bojer gesessen zu haben, nach L. Sclimidt (Gesch. d. deutschen Stümune II. 2 S. 141) zwischen Bamberg und Regrensburg. Sie zogen sich unter dem Druck der Römer in

1) Fundber. a. Schwaben X (1902) S. 26, XIII (1905) S. 38 Anm. 5. Vgl. aber aur'h 1. Reinecke, Festschr, d. röm.-germ. Kentralmus. 1902 S. 101 Anm. ifi.

2) Schliz, Heilbronner Festschrift 1911 S. 55.

3) Schliz-Fraas, Urgesch. Württernbergs S. 144 (Abb. 54).

4) Vgl. auch P. Huber, Dje Glaubwürdigkeil Caesars in seinr'II liericlul iibcel den gallischen Krieg. Bamberg 1913 S. 30 \%. 
augusteischer Zeit nach Osten zurück, ähnlich wie die Chatten, wälırend die Suebi Nicretes und Mattiaci sich der römischen Herrschaft fügten.

Die von mir öfters betonte grosse Übereinstimmung der markomannischen Kultur in Böhmen mit derjenigen der Suebi Nicretes (A. h. Vorz. V S. 376, 414) führt O. Almgren (Mannus V 1913 S. 278) nur auf Handelseinflüsse zurück, indem er annimmt, dass viele dieser Typen in den germanischkeltischen und provinzialrömischen Werkstätten Böhmens entstanden und durch die damalige Machtstellung des böhmischen Markomannenreichs über das ganze freie Germanien verbreitet seien. ${ }^{1}$ ) In einzelnen Punkten mag Almgren recht haben, mit dieser allgemeinen Schlussfolgerung aber schwerlich. Wenn jener Kulturapparat der Suebi Nicretes (Augenfibeln, Gürtelbeschläge, Schildfesseln, Trinkhörner usw.) nur aus Böhmen eingeführt wäre, wie kommt es, dass die so charakteristische norisch-böhmische Fibel (a. o. S. 267/68 Abb. 3 und 4) im Gebiet der Suebi Nicretes fast ganz fehlt? Etwas anders urteilt G. Kossinna, Die deutsche Vorgeschichte eine hervorragend nationale Wissenschaft, Mannusbibl. Nr.9 (2. Auflage 1915) S.150: „Die eigentliche Frühstufe der Augenfibel wurde, wi e manch e andere Charakterform der Kultur der gesamten Elbgermanen ( $\mathrm{S}$ we b e n), von den Markomannen in Böhmen und den angrenzenden ostthüringischen Hermunduren im Saalegebiet geschaffen. Die späteren, aber noch der ersten Hälfte des 1. Jahrhunderts n. Chr. angehörigen Formen der Augenfibeln sind diejenige Gruppe, die in der ausserordentlich rasch sich entwickelnden Folge ihrer einander ablösenden Gestaltungen von den im römischen Heere dienenden germanischen Soldtruppen am allerhäufigsten in das römische Rheingebiet gebracht wird." Die Frage ist noch nicht ganz spruchreif, doch erscheint mir eine breitere Grundlage im Zusammenhang mit den Elbsweben, wie sie Kossinna voraussetzt, natürlicher.

\section{Die Beziehungen der rheinischen Stämme mit den gallischen und ger- manischen Kulturen Mittel- und Norddeutschlands}

Im Vorstehenden haben wir die Ausstrahlungen des späteren gallischkeltischen Kulturkreises eingehender verfolgt, dessen Mittelpunkt im Herzen Frankreichs liegt, dessen Peripherie die rechtsseitige Rheinlande eben noch berührt. Aber wie ein durch Steinwurf entstandener Wellenkreis sich ganz allmählich nach den sich erweiternden Rändern einebnet und verflacht, so sind auch in den Rheinlanden die letzten gallischen Kulturwellen bereits sehr abgeschwächt und von denen eines anderen Kreises, dem germanischen, überschnitten. Gefässtypen, die in Mittelfraukreich durch. Form und Verzierung ihre Abstammung aus der hellenistisch-italischen Kunst noch deutlich verraten, vereinfachen und verändern sich nach Osten immer: mehr, am meisten gegen Nordosten, dem Belgengebiet, wo die keltische Bevölkerung sich von der innergallischen wesentlich unterschied und wo am frühesten die germanische Vermischung eintrat, am wenigsten gegen Süd-

1) Vgl. auch Lüneburger Museumsblätter H. 9 (1914) S. 43 f. .(G. Schwantes). 
osten, wo die uralte Rhone-Rhein-Donaustrasse echtgallische Erzengnisse in grossen Mengen bis nach Böhmen brachte und wo die Germanen am spätesten festen Fuss fassten.

Die ausgedelnteste und intensivste Berührungsfläche bieten die beiden Kulturkreise in den mittleren Rheinlanden, wo sie sich vielfach derartig durchdringen und mischen, dass das beiderseitige Eigengut oft sich kaum erkemnen oder höchstens durch die Begleitumstände vermuten lässt. Allerdings würde eine eindringendere Behandlung des germanischen Kulturlireises. sorreit er seine Formen aus dem suebischen Binnenlande bis an die Gestade des Rheius getragen hat, noch manche weiteren Anhaltspunkte für jene Scheidung ergeben, doch muss diese ausführlichere Untersuchung einer anderen Gelegenheit vorbehalten bleiben.

Hier sei - gewissermassen anhangsweise - nur auf einige wichtigeren Erscheinungen Mittel- und Norddeutschlands hingewiesen, welche das oben gezeichnete Bild in manchen Zügen zu ergänzen in der Lage sind. Vor ailem ist nicht genügend bekannt, dass jene germanische Wellen, die im Terlaufe des 1. Jahrhunderts n. Chr. aus dem Innern Deutschlands bis an den Rhein vordrangen, keineswegs völlig unberührte germanische Kultur brachten. sondern vielfach eine durch gallische Elemente bald mehr bald minder stark beeinflusste.

1. Die Kelten und Germanen in Thüringen. Die Gebirgsnamen Hercynia (Ercunia), Taunus, Semana, Gabreta, Sudeta usw. sind ohne Zweifel keltisch, ebenso wie die Namen von Rhein, Main, Lahn, Sieg, Ruhr, Lippe (vgl. F. Kauffmann, Deutsche Altk. 1913 S. 69), und deuten an, dass ror den Germanen hier Kelten gesessen haben, wenn die Ableitung des Namens Thüringen ron den keltischen Teurones-Turones auch noch dahingestellt sein mag (O. Bremer, Ethnographie der germ. Stämme 1899 S. 44, P. Höfer, Arch. Probleme in der Provinz Sachsen 1903 S. 21 f.). Dies bestätigen die archäologischen Bodenfunde mit aller Sicherheit. Namentlich G. Kossinna hat nach den Grabfunden die Grenzlinien zwischen Germanen und Kelten soweit als bisher möglich festgelegt und das allmähliche $\mathrm{Zu}$ rückweichen der letzteren nach Süden und Westen verfolgt. ${ }^{1}$ )

Doch sind die keltischen Namen für Flïsse, Gebirge, Ortschaften in Thüringeu, Hessen, Westfalen ,mit dentschen Bildungen in einem Masse durchsetzt worden, wie dies im Rheinland und in Süddeutschland nicht der Fall ist. Hier herrscht in den topographischen Benennungen der Gegenwart das keltische Element unbestritten" (Kauffimann a. o. S. 212). Auch hier gibt die archäologische Hinterlassenschaft der beiden Völker eine wjchtigre Bestätigung und Erweiterung jener Vorstellung.

In der Früh-La-Tènezeit hatten die Gallier noch die Nordahbänge des deutschen Wittelgebirges inne. Dies bewcisen am dentlichsten dic Funde

1) Zt.chr. d. Ver. f. Volkskunde VI S. 1 f., Beiträge zur Geschichte der deulschen Sprache u. Literatur XXVI (1901) S. 282 f., Korr.-Bl. f. Antbr. 1905 S. 109, 1907 S. 57 f., Zischr. f. Ethn. 1905 S. 389 u. s. Vgl. auch P. Reinecke, Ztschr. f. Eihn. 1900 S. (489) f., E. Wahle. Jahresichr. f. d. Vorg. d. sächs.-thür. Jänder 10 (1911) S. 127 f. 
im Ringwall von Rittershausen in Westerwald, ${ }^{1}$ ) die zahlreichen Skelettgräberfelder (mit kleinen Hügelchen) im Saalegebiet bei Ranis, Pössneck usw. ${ }^{2}$ ) bis Mittel- und Oberschlesien, Böhmen und Mähren. Aus dem Innern Thüringens und vom Südfusse des Thüringer Waldes sind rie Funde dieser Periode nicht gerade besonders häufig, abgesehen vom Ringwall auf dem kleinen Gleichberge bei Römhild. ${ }^{3}$ ) Kropp (a. o. S. 121/122) hat bereits auf die engen Beziehungen dieser keltischen Kultur einerseits zu der der Jheinischen Stämme, andererseits mit den Bojern Böhmens aufmerksain gemacht. Schmuckgegenstände, wie Fibeln, Ringe usw., sind weitwaudernde Handelsartikel; wichtiger ist die (allerdings nicht allzu häufige) Keramik. Schon durch diese grössere Seltenheit der Tonware in der Grabausstattung unterscheiden sich diese Gallier von den „belgischen“ Stämmen des linken und rechten Rheinufers, ebenso durch das gänzliche Fehlen der hohen Flaschen- und Humpenformen. Charakteristisch für dieses Gebiet sind Flaschen, Krüge wie Kropp a. o. S. 16 Abb. 9 und Kesselchen wie S. 18 Abb. 12, S. 42 Abb. 67, Urnen wie S. 33 Abb. 50, die ibre nächsten Verwanrlten in Hessen, Nordbayern bis herab zu den Mittel-La-Tènefunden ron Manching und Aislingen, ferner in Schlesien und Böhmen (vg]. oben S. 255 f.) haben. ${ }^{4}$ ) Auch die feineren Ornamente des Früh-La-Tènestils begegnen auf dieser ganzen Linie, wie am Rhein (bei Braubach und Frankfurt), ja in Nordfrankreich (Déchelette, Man. II. 3 S. 1469, 71), und sind eben durch die italischen Vorbilder, namentlich Brouzegefässe veranlasst. ${ }^{5}$ ) Bei einigen Gefässformen muss man sich fragen, ob nicht germanischer Einfluss vorliegrt, wie bei Kropp a. o. S. 25 Abb. 36 und bei manchen Kesselchell. was in Anbetracht des engen Zusainmenlebens der beiden Völker in dieser Gegend eigentlich selbstverständlich ist.

Gallische Mittel-La-Tènefunde sind aus diesem Gebiete sehr selten, da wälnrend dieser Periode die Germanen bereits den grössten Teil des Limdes besassen. Schon aus der späteren Früh- bzw. Mittel-La-'lènezeit sind im Tal der Weissen Elster bei Gera Brandgräber vorhanden, die Kropp a. o. S. 116 mit Recht als germanische erklärt und die ihre Fortsetzung in der Ungebung von Leipzig haben. ${ }^{6}$ ) In (liesen anch durch die Metallbeigaben als germanisch erwiesenen Brandgräbern begegnen drei Gruppen von Ge?ässen:

1) Röm.-germ. Korr.-Bl. 1912 S. 95 f., Korr.-Bl. d. Ges. Ver. 1913 S. 99 (E. Brenner), Kataloge d. röm.-germ. Zentralmuseums Nr. 5 S.' 153, 165 (Nr. 275).

2) Korr.-Bl. f. Anthr. 1907 S. 58 (G. Kossinna), Ph. Kropp, Mannusbibliothek Nr. 5 (1911) S. 1-90 bzw. 128.

3) Vgl. Götze-Höfer-Zschiesche, Die vor- u. frühgeschichtl. Altert. Thüringens 1909 S. XXXIII, Kataloge des röm.-germ. Zentralmus. V S. 165/66 Nr. 276 (K. Schumacher).

4) Das „Räuchergefäss“ mit Bogenverzierung bei Kropp S. 21 Abb. 19 u. 20 ist sicherlich nicht aus Italien importiert, aber nach einem südlichen (Metall-?) Vorbild irgendwo auf gallischem Gebiet geschaffen (vgl. die Flasche von Ramsen Abb. 6, 6).

5) Vgl. Festschrift d. Zentr.-Mus. 1902 S. 76 (Thumau in Oberfranken), S. 83 (Braubach) usw. (P. Reinecke).

6) K. Jacob, Die La-Tènefunde der Leipziger Gegend, Jahrb. d. Mus. f. Völkerkunde zu Leipzig II (1907) S. 57-97 und „Zur Prühistorie Nordwest-Sachsens“ 1(9)11 S. 巳n: f. Zu den Funden von Leimbach vgl. A. h. Vorz: V S. 105 Nr. 340 (P. Reinecke). 
1. germanische Formen, die auf Spät-Lausitzer 'Typen usw. zurïckgehen, wie die Amphorenkriige und Stamnosurnen mit Henkeln (Jacob Taf. IV. 26, V. 32, VIII. 44, X. 57 usw.), Urnen von Hallstattform und -verzierung; roher 'lon, ohne Drehscheibe, mit Kamınstrichverzierung;

2. gallische Formen, wie sie aus Südilentschland geläufig sind, aus feingeschämmtem Ton, öfters terra-nigra-artig, auf der Drehscheibe hergestellt, mit feinen Profilierungen wie der Flaschenkiug (Jacob II. 7), Urne (XII. 70), Kesselchen (II. 14, XII. 71), Iimer (XII. 69), Omphalosschale (XII. 72). Jacob hält sie „für Handelsware, die nicht Jier gefertigt, sonclerı aus keltischen Gebieten eingefühırt wurde“ (S. 90/91);

3. germanische Nachahuungen qaallischer Formen: kelchtörmige Gefässe wie Taf. III. 15, 17, 20, gerippte Kessel wie III. 19, XI. 67 ॥. a., bei denen die Profilierungen teils übertrieben, teils verflacht sind.

In einzelnen besteht natïrlich eine gewisse Unsicherheit wegen der Zuteilung zu Gruppe 2 oder 3, da selbstverständlich anch die Gallier nachlässige orler ungeschickte Ware hergestellt haben.

ron besonderem Interesse ist das germanische Brandyräberfeld von Klein-Corbetha (am rechten Ufer der Saale zwischen Merseburg und Weissenfels), ${ }^{1}$ ) das vou der Frïh-La-'Tène- bis zur: Spät-La-I'ènezeit danert. Ein Teil der Gefässe (wic Jacob Taf. XVIII. 115, XIX. 117, 119, 121) sind rcht germanischen Ursprungs, anclere (wie XVIII. 109, 113, XX. 124, 125) haben gallische Form und vielleicht zum T'eil sogar gallische Entstelıung. wie wohl auch die mitgefundenen feinen Fibehn mit Korallenschmuck und die Brouzepinzette.") Mit grośser Wahrscheinlichkeit ist laraus $\% 11$ folsern, dass auch hier nach dem germanischen Vordringen einige Gallier "uhig sitzen blieben und sich mit den Germanen mischten, wie ähnlichlses in iren Rheinlanden und im Belgengebiete beolachtet wurde. Die starke itbertreibung der Wülste und Riefen bei Taf. XVIII. 109. 113, 124, 125 и. a. fehlt

1) Mitt. aus dem Provinzialmuseum zu Halle 11 (190)(0) S. 43 f. (O. v. Förtsch), Jacob a. o. S. 76-79. P. Hüfer schreibt sie (Jahresschrift f. d. Vorg. d. sächs.-thǜ. luänder 1904 $\therefore$ 140) den Hermunduren $z u$, doch wollen wir hier auf die ethnologische Frage nicht eingehen.

2) Die mit einer Tierdarstellung in Trenolierstich geschmückte Bronzej)inzette (Jacob Taf. XVIII. 112), welche mit den genannten Fibeln Taf. XVIII. 110, 111) in einer starkwulstigen Tonurne lag, hat Init einem ähnlichen Exemplar von Voigtstedı (Mitt. aus dem Prov--Mus. zu Halle II [1900] S. 48) wie die Korallenfibeln dic meislen Parallelen auf gallischen Boden. In der Zusammenstellung Déchelettes (Man. II. 3 s. 1271 f.) fehlen die in Deutschland gefundenen, wie z. B. fünf Stück im städtischen Museun zu Mainz, das eine (oben etwas schmäler und profiliert) aus einem gallischen Skelettgrab der Mittel-lá-Tènezeit bei Wolfsheim, ein Bruchstück eines ähnlichen aus einem germanischen. Brandgrab von Heidesheim, drei gleicher Form wie das von Corbetha, das eine aus einem germanischen Brandgrab der Spät-Ja-Tènezeit von Essenheim (auch verziert), das andere unbekannten Fundorts, aber aus Rheinhessen, diese beiden aus Bronze, ein gleiches aus lisen in dem oben S. 261; erwähnten Späl-La-Tènegrab von Ileidelberg, Ierner ein schmäleres von liikeıl au einem germanischen Spuil-Ja-Ténegrab von Hahnheim. 
allerdings im allgemeinen auf reinkeltischem Boden1) und dürfte teilweise aluf Kosten jener germanisch-keltischen Mischung zu setzen sein.

Auch die Spät-La-Tènegefässe von Mühlhausen in Thüringen aus germanischen Brandgräbern, ${ }^{2}$ ) bei denen auch eine Fibel des Nauheimer Typus gefiunden wurde, bestätigeu diese starke Beeinflussung der germanischen Töpfereien durch gallische. Es sind neben rohen handgemachten dünnwandige, glänzend schwarze, scheibengedrehte Gefässe mit eingeritzter oder eingeglätteter oder schwarz aufgemalter Linienverzierung, wie sie fast röllig übereinstimmend so zahlreich in den mittleren Rheinlander gefunden werden (vgl. namentlich Taf. VIII. 1). Ganz ähnlich sind die Funde von Reinsbrunnen am Hainberg bei Göttingen (in der dortigen Sammlung). Alle diese Spät-La-Tènefundstellen zeigen neben dieser feinen schwarzen Ware rohe tonfarbige (namentlich Eimer- und Kumpenformen), wie sie in ïhnlicher Mischung in Nauheim vorkommt, wenn auch hier die feinen schwarzen Gefässe vielleicht etwas seltener sind. · Für manches Gefäss dieses Gräberfeldes dürfte der Nachweis nördlicher oder südwestlicher Herkunft schver fallen.

Die Verbreitung jener mitteldeutschen germanisch-gallischen Töpferarbeiten hat zuletzt G. Kossinna verfolgt (Die deutsche Vorgesch. 1 S. 58, 2. Aufl. S. 169 f.). Ausser an der Mainmündung sind sie in wesentlichen auf Thüringen beschränkt, von Eisenach und Mühlhausen bis nach Halle und Leipzig, wenn auch Ausläufer bis zur Elbe (Dresden-Pirna) und nordöstlich über dieselbe hinausreichen (Anhalt, Provinz Sachsen, Brandenburg, Westhavelland), also bis an die Stammsitze der Sueben heran (auch Mannus II. S. 242 f.).

Derartige Beeinflussung der einheimischen Keramik durch die gallische ist im ganzen Umkreis der gallischen Herrschaft wahrzunehmen, in England, Spanien, Oberitalien, auch im Osten (Schlesien, Böhmen usw.), doch würde deren Besprechung unserem Thema zu fern liegen.

2. Die Kultur der Sueben in ihren Stammsitzen sei renigstens insoweit kurz angedeutet; als sie für die in Vorstehendem behandelten Fragen in Betracht kommt, namentlich inbezug auf die Keramik. Die germanische Töpfereikunst Norddeutschlands wird vielfach jetzt noch interschäitzt. Von den vortrefflich verzierten Arbeiten der nordwestdeutschen neolithischen Tiefstichkeramik wollen wir hier ebensowenig reden wie von den eigenartigen Formen des bronzezeitlichen Lausitzer Typus, da die ethnologische Frage noch Zweifeln unterliegt. In der Hallstattperiode ist sowohl eine westliche Gruppe (Rheinprovinz, Westfalen, westliches Hannover) wie eine östliche (Schlesien, Posen) stark beeinflusst durch die siir-

1) Doch liegen auch aus der Schweiz und Frankreich einige Beispiele vor. Vgl. z. B. zu dem Krug yon Klein-Corbetha (Jacob a. o. Taf. XVIII. 109) den von Gempenach (Anz. f. schweiz. Altk. 1897 Taf. 11/12 Nr. 7); aus Schlesien das Gefäss von Oberhof (Schlesiens Vorzeit 111 [1904] S. 55 Abb. 11) u. a. m.

2) Jahresschr. f. d. Vorgesch. d. sächs.-thür. Länder X (1911) S. 61-70 (Selınann), wo weitere Literatur S. 66. Auch bei Kossinna, Die deutsche Vorgeschichte (Mannusbibl. Nr. 2) 1. Aufl. S. 56 Abb. 124, 2. Aufl. (1914) S. 169 Taf. XXVI Abb. 332. 
liche Hallstatt-Keramik mit ihren schönen Formen und ihrer bunten Bemalung. Eine dazwischenliegende Kulturgruppe (Schleswig-Holstein, östliches Hannover, Harzgebiet, Altmark und Mecklenburg) bildete wahrscheinlich schon in der älteren und mittleren Hallstattzeit eine grössere (zweifelsohme germanische) Volksgemeinschaft (Wessenstedter Typus), die sich in der jüngeren Hallstatt- und Frülh-La-Tèneperiode (Jastorfer Typus usw.) nach allen Seiten ausbreitete. Der Nienburger und Harpstedter Typus lässt sich bereits über Bielefeld und Dortmund bis Duisburg verfolgen und bedeutet das erste Auftreten der Westgermanen am Niederrhein. ${ }^{1}$ Eine zweite, jener gleichalterige Kulturprovinz wird in der Lausitz, in der Mark bis in die istlichen Teile der Provinz Sachsen usw. durch den Billendorfer Typus bezeichmet, der aus dem Lausitzer Typus und südöstlichen hallstättischen Einflüssen entstanden und allmählich weiter gegen Nordwest vordringend?) nach $C$. Schuchhardts u. a. Annahme die Heimat und den Siegeszug der semmonisch-suebischen Völker bekundet. ${ }^{3}$ ) Die Grundformen der Gefässe sowohl der Wessenstedter-Jastorfer wie der BillendorferA uriether Kultur setzen sich auch in der älteren La-Tènezeit in den beiderseitigen Gebieten fort, werden aber allmählich nach Form und Verzierung monotoner, reun auch neue, den südlichen La-Tèneformen entsprechende auftauchen. Erst von der Mittel-La-Tènezeit ab, wo in ganz Norddeutschlaud der gallische La-Tène-Einfluss bemerkbarer wird, erhält auch diese germanische Keramik, neues Leben (späterer Ripdorfer und Seedorfer Typus usw.). Die Flaschien, Kessel, Schalen, Eimer, öfters sorgfältig geglättet und tiefschwarz geschmaucht, aber ohme Drehscheibe hergestellt, unterscheiden sich von ihren südlichen Verwandten oft nur durch geringe Veränderungen, namentlich Vereinfachung der Profile oder Utbertreibung derselhen. Namentlich die Übertreibung der Wülste und Neigung zu scharfkantiger Profilierung (auch zur Henkelbildung) lässt sich schon rom Jastorf-Todendorfer Typus ab verfolgen. ${ }^{4}$ ) In der Spät-La-Tène- und Kaiserzeit hat diese Keramik ihren Höhepunkt erreicht in den schönen (Mäander-1 Trnen, oft mit dem scharfen Bauchknick, die namentlich in Mechlenburg. in der Altmark usw. beliebt waren und den Vergleich mit den sïdlicheren Drehscheibearbeiten aushalten, hinsichtlich der Verzierungsreise sic sogar übertreffen.

Aus deu bisherigen Darlegungen ergibt sich, dass die Sueben des Ariovist, die um das .Tahr $\delta 0$ v. Chr. ihre Heimat im Elb-Saaletale verliessen, zu Hause schon zweierlei Geschirr benutzten, germanischer unrl gallischer Herkunft. ersteres ans der Hand oder mit Formschablonen gefertigt, das andere

1) Jahresschr. f. d. Vorgesch. d. sächs.-thür. Länder X (1911) S. 109 (E. Wahle), c. Schuchhardt. Die Umenfriedhöfe Niedersachsens I (1911) S. 4 f. (G. Schwantes), Prach. Z. V (1913) S. 571 (K. Schumacher).

2) Ztsrhr. f. Fthu. 1903 S. 161-212 (A. Voss), Praeh. \%. 1912 S. 334 (A. Götze).

3) Praeh. Z. 1 (1910) S. 364 u. s.; zuletzt: Der Goldfund von Eberswalde 1914 S. 49 f. Vgl. auch H. Seger, Mitt. d. schles. Ges. 1. Volkskunde XVI. 2 (1914) S. 174/175.

4) Vgl. z. B. C. Schuchhardt, Die Umenfriedhöle in Niedersachsen 1 (1911) S. 104 (r.s. Sichwantes). 
anf der Drehscheibe fast so schön und gut wie die frührömische Ware gearbeitet. Über letzteres sind die Hinweise schon oben S. 290 gegeben. Die „ermanische Keranik des mittleren Elbgebietes bis zur. Oberhavel und nach Mecklenburg zu Beginn des letzten Jahrhunderts v. Chr. dagegen hat bis jetzt noch nirgends eine eingehendere Würdigung in ihrem ganzen Zusammenhange gefunden, wenn auch zallreiche Einzeluntersuchungen vorliegen. ${ }^{1}$ ) Die Weiterverfolgung dieses Gesichtspunktes und die Verknüpfung mit ähnlichen Erscheinungen längs des suebischen Wander»ugs nach Süden muss ich indessen für eine andere Gelegenheit aufsparen.

Ich bin am Schlusse meiner Darlegungen angelangt. War es auch im Rahmen dieser: Zeitschrift nicht möglich, die behandelten Denkmälergruppen in ihrer ganzen Entwicklung und in allen Einzelheiten vorzuführeu, so hoffe ich doch überzeugend nachgewiesen zu haben, von welch hoher Bedeutungsie für das schwierige Problem der Scheidung gallischer und germanischer Kulturhinterlassenschaft und für die historische Darstellung dieser Epoche sind.

Diese wichtigien Bodenurkunden germanischer Frülıgeschichte zu sammeln und in einem grösseren Werke (ähnlich etwa dem von C. Schuchhardt herausgegebenen „Die Urnenfriedhöfe in Niedersachsen“) geordnet und gedeutet vorzulegen, wäre eine würdig'e Aufgabe der deutschen Wissenschaft nach dem grossen Kriege, der das dentsche Volk wieder anf sich selbst und den Wert seiner Kultur besiunen lehrte.

1) Ausser der oben angegebenen Literatur vgl. z. B. die Arbeiten Kossinnas, Korr.-Bl. f. Anthr. 1907 S. 58, wo er die Gräber vom Nauheimer Typus durch Thüringen, Sachsen bis in die Dresdener Gegend verfolgt, auch Ztschr. f. Ethn. 1905 S. 388, Mannusbibl. Nr. 6 (1911) S. 20, Nr. 9 2. Aufl. S. 170 f., wo namentlich der Unterschied zwischen west- und ostgermanischer Mäanderkeramik dargelegt ist. R. Beltz, Die vorgesch. Alt. d. Grossh. Mecklenburg-Schwerin 1910 S. $294 \mathrm{f}$. P. Kupka, Die frühe Eisenzeit in der Altmarli, Jahresschr. f. d. V.org. d. säçhs.-thür. Länder X (1911) S. 47 f. 